\title{
DOE/NE Program in Robotics for Advanced Reactors
}

Contract No. DE-FG02-86NE37967

A Remote Telepresence Robotic System for Inspection and Maintenance of a Nuclear Power Plant

\section{ANNUAL RESEARCH STATUS REFORT UNIVERSITY OF FLORIDA}

February 1, 1993

Principal Investigators

Carl D. Crane III James S. Tulenko

University of Florida Gainesville, FL 32611

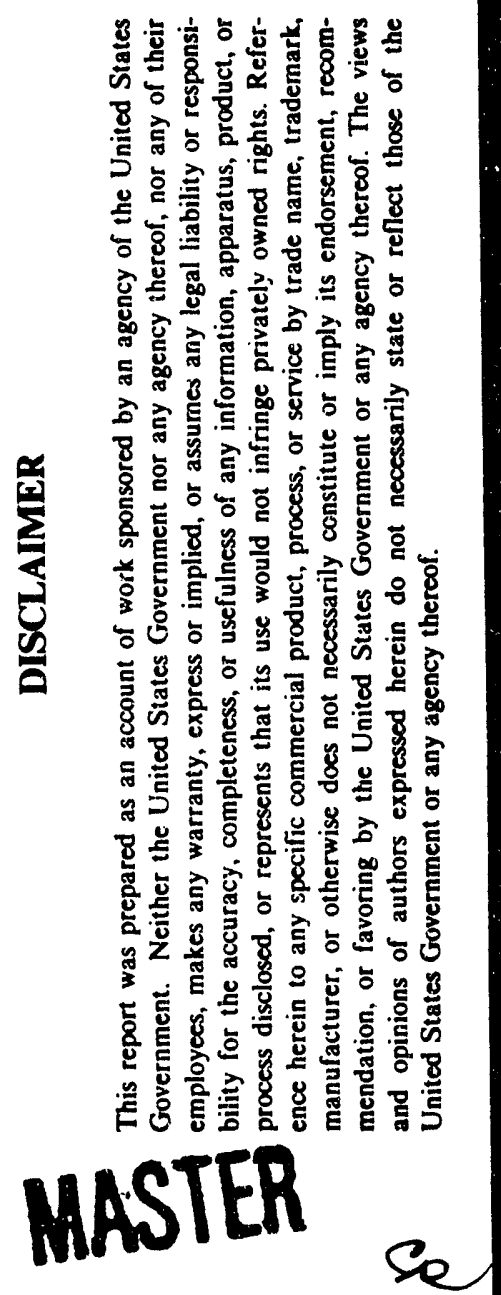


TABLE OF CONTENTS

LIST OF FIGURES $\ldots \ldots \ldots \ldots \ldots \ldots \ldots \ldots \ldots \ldots \ldots \ldots$

LIST OF TABLES $\ldots \ldots \ldots \ldots \ldots \ldots \ldots \ldots \ldots \ldots \ldots \ldots \ldots$

1992 RESEARCH TEAM MEMBERS $\ldots \ldots \ldots \ldots \ldots$. . . . . . . . . . . .

1992 PUBLICATIONS AND PRESENTATIONS BY UNIVERSITY

OF FLORIDA TEAM MEMBERS $\ldots \ldots \ldots \ldots \ldots \ldots \ldots$ ix

1992 CONFERENCES AND OTHER TRAINING ACTIVITIES $\ldots \ldots \ldots \ldots$ xi

1.0 ENVIRONMENTAL HARDENING $\ldots \ldots \ldots \ldots \ldots \ldots \ldots$

1.1 ANNEAL TECHNIQUE DEVELOPMENT $\ldots \ldots \ldots \ldots \ldots$

1.2 HARDNESS OF CURRENT GENERATION ROBOTIC SYSTEMS . . . 4

1.3 RADIATION TESTING OF CMOS DEVICES AND

INTEGRATED CIRCUITS $\ldots \ldots \ldots \ldots \ldots \ldots$

1.3.1 EXPERIMENTAL SETUP $\ldots \ldots \ldots \ldots \ldots \ldots$

1.3.2 FULLY AUTOMATED DATA ACQUISITION SYSTEM . . . 11

2.0 DATABASE/WORLD MODELING $\ldots \ldots \ldots \ldots \ldots \ldots$

2.1 ADVANCED LIQUID METAL REACTOR $\ldots \ldots \ldots \ldots \ldots$

2.1.1 MODELING OF SEISMIC ISOLATORS $\ldots \ldots \ldots \ldots$

2.1.2 CENTER OF GRAVITY MODELING ......... 13

2.1.3 MOVEMENT OF HEAT EXCHANGER $\ldots \ldots \ldots \ldots$

2.1.4 ROBOTIC SYSTEM MODELING $\ldots \ldots \ldots \ldots \ldots$

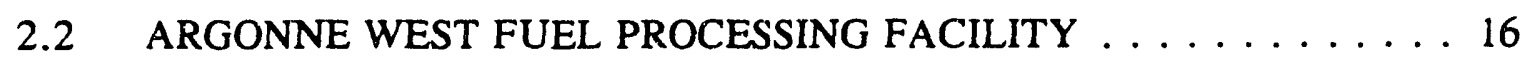

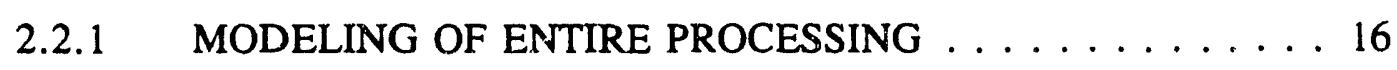

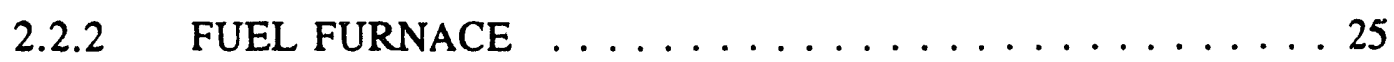

3.0 MAN-MACHINE INTERFACE $\ldots \ldots \ldots \ldots \ldots \ldots \ldots \ldots \ldots \ldots \ldots \ldots$ 
3.1 DEVELOPMENT OF NEW THREE DIMENSIONAL GRAPHICS

VISUALIZATION TECHNIQUES $\ldots \ldots \ldots \ldots \ldots \ldots \ldots \ldots$

3.1 .1 OBJECTIVE $\ldots \ldots \ldots \ldots \ldots \ldots \ldots \ldots \ldots \ldots \ldots \ldots$

3.1 .2 INTRODUCTION $\ldots \ldots \ldots \ldots \ldots \ldots \ldots \ldots \ldots$

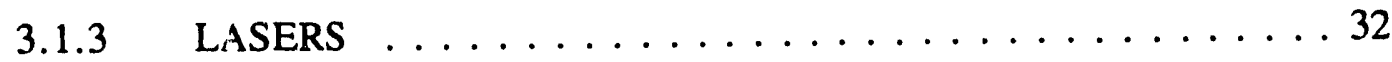

3.1.4 PLEXIGLASS VOXELS $\ldots \ldots \ldots \ldots \ldots \ldots \ldots \ldots$

3.1.5 DISPLAY USING CONCAVE MIRRORS $\ldots \ldots \ldots \ldots . \ldots 34$

3.2 TELEPROPRIOCEPTION SENSE DEVELOPMENT . . . . . . . . 34

4.0 DEVELOPMENT OF THE ADVANCED LIQUID METAL REACTOR

(ALMR) MAINTENANCE INSPECTION ROBOT DESIGN . . . . . . 36

4.1 INTRODUCTION $\ldots \ldots \ldots \ldots \ldots \ldots \ldots \ldots \ldots \ldots \ldots \ldots$

4.2 STACK INSPECTION ROBOT $\ldots \ldots \ldots \ldots \ldots \ldots$

4.2.1 BACKGROUND $\ldots \ldots \ldots \ldots \ldots \ldots \ldots \ldots \ldots \ldots \ldots$

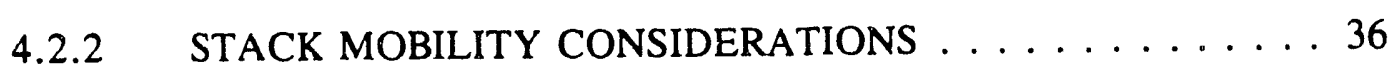

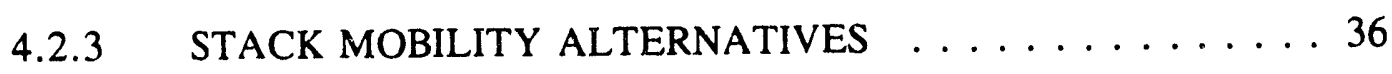

4.2.4 RECOMMENDED STACK MOBILITY DESIGN . . . . . . 38

4.2.5 STACK SYSTEM DESCRIPTION $\ldots \ldots \ldots \ldots$

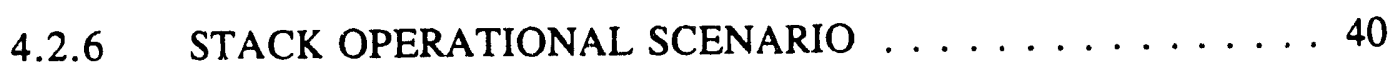

4.2.6.1 COLD STACK INSPECTION . . . . . . . 40

4.2.6.2 HOT STACK INSPECTION . . . . . . . 40

4.2 .7 STACK PLANT IMPACT $\ldots \ldots \ldots \ldots \ldots \ldots \ldots \ldots$

4.3 PLENA AND VERTICAL ANNULI INSPECTION . . . . . . 41

4.3.1 PLENA BACKGROUND $\ldots \ldots \ldots \ldots \ldots \ldots \ldots \ldots$

4.3.2 PLENA MOBILITY CONSIDERATIONS . . . . . . 41

4.3.3 RECOMMENDED PLENA MOBILITY DESIGN . . . . . 41 
4.3.4 PLEN

4.3.4.1 PRIMARY ROBOT $\ldots \ldots \ldots \ldots \ldots \ldots 42$

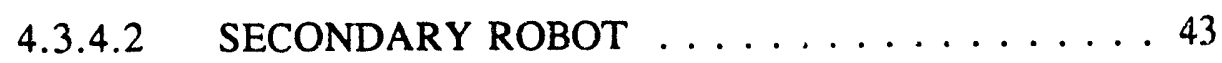

4.3 .4 .3 TETHER MANAGEMENT $\ldots \ldots \ldots \ldots \ldots 44$

4.3.5 PLENA ROBOT OPERATIONAL SCENARIO . . . . . . 47

4.3.6 PLENA PLANT IMPACT $\ldots \ldots \ldots \ldots \ldots \ldots$

4.4 REACTOR VESSEL INSPECTION ROBOT $\ldots \ldots \ldots \ldots \ldots$

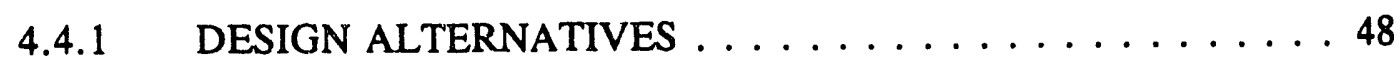

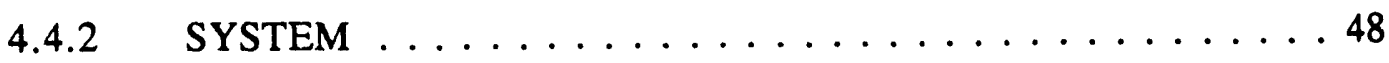

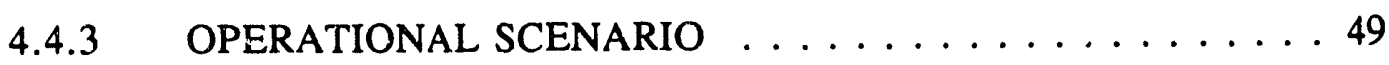

$4.4 .4 \quad$ PLANT IMPACT $\ldots \ldots \ldots \ldots \ldots \ldots \ldots$

5.0 ARTICULATED TRANSPORTER/MANIPULATOR SYSTEM (ATMS)

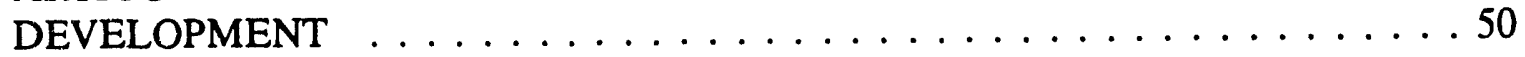

5.1 EVALUATION OF PROTOTYPE HARDWARE $\ldots \ldots \ldots \ldots$

5.2 DESIGN IMPROVEMENTS $\ldots \ldots \ldots \ldots \ldots \ldots \ldots \ldots \ldots$

5.31992 SEGMENT DESIGN $\ldots \ldots \ldots \ldots \ldots \ldots \ldots \ldots \ldots$

5.4 EXPECTED PERFORMANCE $\ldots \ldots \ldots \ldots \ldots \ldots \ldots$

5.5 COMPUTER SOFTWARE AND HARDWARE FOR THE SYSTEM . . . 56

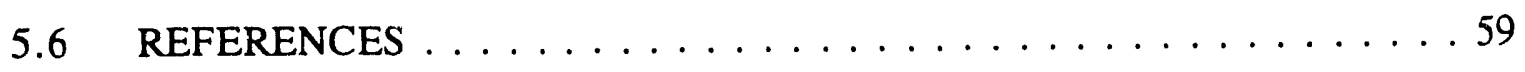




\section{LIST OF FIGURES}

FIGURE 1.1 THERMAL ANNEALING OF INTERFACE TRAPS:

VOLTAGE SHIFT vs. TOTAL DOSE $\ldots \ldots \ldots \ldots \ldots$

FIGURE 1.2 THERMAL ANNEALING OF OXIDE TRAPS:

VOLTAGE SHIFT vs. TOTAL DOSE $\ldots \ldots \ldots \ldots \ldots \ldots$

FIGURE 1.3 AC ANNEALING OF OXIDE TRAPS:

VOLTAGE SHIFT vs. TOTAL DOSE $\ldots \ldots \ldots \ldots \ldots$

FIGURE 1.4 AC ANNEALING OF INTERFACE TRAPS:

VOLTAGE SHIFT vs. TOTAL DOSE $\ldots \ldots \ldots \ldots \ldots \ldots$

FIGURE 1.5 EXPERIMENTAL SETUP FOR TESTING CMOS DEVICES

AND INTEGRATED CIRCUITS $\ldots \ldots \ldots \ldots \ldots \ldots \ldots$

FIGURE 1.6 AUTOMATED DATA ACQUISITION SYSTEM FOR

TESTING CMOS DEVICES AND INTEGRATED CIRCUITS $\ldots . .12$

FIGURE 2.1: VIEW SHOWING SEISMIC ISOLATORS

LOCATIONS ON FLOOR . . . . . . . . . . . . . 14

FIGURE 2.2: VIEW SHOWING INDIVIDUAL SEISMIC ISOLATOR AND JACKS $\ldots \ldots \ldots \ldots \ldots \ldots$

FIGURE 2.3: SECOND VIEW SHOWING INDIVIDUAL SEISMIC . . . . . . 15

FIGURE 2.4: VIEW SHOWING REMOVAL OF BOLTS AND ISOLATOR PADS $\ldots \ldots \ldots \ldots \ldots \ldots$

FIGURE 2.5: BASIC 3D MODELING OBJECTS $\ldots \ldots \ldots \ldots \ldots$

FIGURE 2.6: EXTERIOR OF INTERMEDIATE HEAT EXCHANGER . . . . . 17

FIGURE 2.7: WIRE FRAME REPRESENTATION OF THE HEAT EXCHANGER $\ldots \ldots \ldots \ldots \ldots \ldots \ldots$

FIGURE 2.8: FRONT VIEW SHOWING CENTER OF GRAVITY $\ldots \ldots \ldots \ldots 18$

FIGURE 2.9: TOP VIEW SHOWING CENTER OF GRAVITY . . . . . . . . 19 
FIGURE 2.10: COLLISION DETECTION, WHILE MOVING HEAT

EXCHANGER . . . . . . . . . . . . . . . . 19

FIGURE 2.11: VIEW OF SIDE OF PLENUM ROBOT $\ldots \ldots \ldots \ldots \ldots$

FIGURE 2.12: FRONT VIEW SHOWING PLENUM ROBOT AND

DAUGHTER ROBOT PACKAGE $\ldots \ldots \ldots \ldots \ldots \ldots$

FIGURE 2.13: REAR VIEW SHOWING PLENUM ROBOT SENSOR PACKAGE . 21

FIGURE 2.14: VIEW OF STACK ROBOT DELIVERY SYSTEM . . . . . . . 21

FIGURE 2.15: REAR VIEW OF STACK ROBOT DELIVERY SYSTEM . . . . . 22

FIGURE 2.16: FRONT VIEW OF REACTOR VESSEL INSPECTION

ROBOT AND INSERTION DEVICE (BELOW ROBOT) $\ldots \ldots \ldots 23$

FIGURE 2.17: SIDE VIEW OF RV INSPECTION ROBOT AND

INSERTION DEVICE $\ldots \ldots \ldots \ldots \ldots \ldots \ldots \ldots$

FIGURE 2.18: REAR VIEW OF RV INSPECTION ROBOT AND

INSERTION DEVICE $\ldots \ldots \ldots \ldots \ldots \ldots \ldots \ldots \ldots$

FIGURE 2.19: OVERALL VIEW OF FURNACE ASSEMBLY . . . . . . . 26

FIGURE 2.20: VIEW OF FURNACE FROM DIFFERENTT VIEWPOINT . . . . . 27

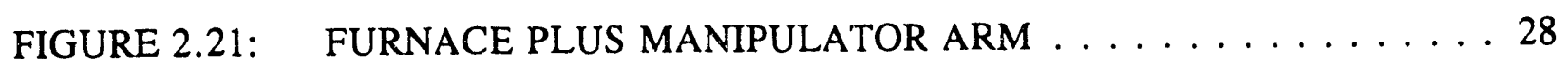

FIGURE 2.22: CLOSEUP SHOWING WIREFRAME DETAILS OF

VALVE ASSEMBLY . . . . . . . . . . . . . . . 29

FIGURE 2.23: CLOSEUP SHOWING VALVE ASSEMBLY AND

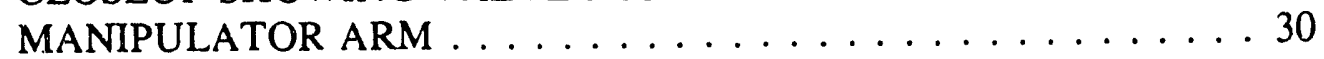

FIGURE 3.1: STEREO ANIMATION $\ldots \ldots \ldots \ldots \ldots \ldots \ldots \ldots \ldots$

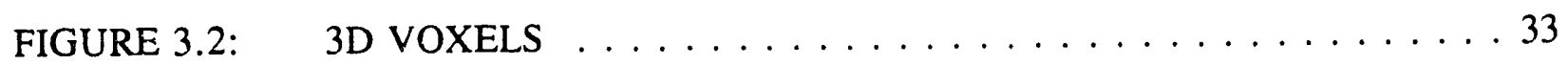

FIGURE 3.3: $\quad$ GRID OF $12 \times 12$ UNIT CUBES $\ldots \ldots \ldots \ldots \ldots$

FIGURE 3.4: PLEXIGLASS SPHERE $\ldots \ldots \ldots \ldots \ldots$

FIGURE 3.5: $\quad$ UNIT CUBE $\ldots \ldots \ldots \ldots \ldots \ldots \ldots \ldots \ldots \ldots \ldots \ldots \ldots$ 
FIGURE 3.6: $\quad$ SCHEMATIC DIAGRAM $\ldots \ldots \ldots \ldots \ldots \ldots \ldots$

FIGURE 3.7: $\quad$ OBJECT IN MID-AIR $\ldots \ldots \ldots \ldots \ldots \ldots \ldots \ldots \ldots \ldots$

FIGURE 3.8: REFLECTIONS OF TWO OBJECTS $\ldots \ldots \ldots \ldots$

FIGURE 4.1: ADVANCED LIQUID METAL REACTOR $\ldots \ldots \ldots \ldots$

FIGURE 4.2: $\quad$ STACK INSPECTION ROBOT $\ldots \ldots \ldots \ldots \ldots \ldots$

FIGURE 4.3: STACK ROBOT DEPLOYMENT INTO COLD STACK $\ldots \ldots \ldots 39$

FIGURE 4.4: $\quad$ STACK ROBOT DEPLOYED INTO HOT STACK $\ldots \ldots \ldots \ldots . .40$

FIGURE 4.5: $\quad$ PLENA INSPECTION ROBOT $\ldots \ldots \ldots \ldots \ldots \ldots \ldots \ldots$

FIGURE 4.6: DOCKING MECHANISM $\ldots \ldots \ldots \ldots \ldots \ldots$

FIGURE 4.7: $\quad$ SECONDARY ROBOT $\ldots \ldots \ldots \ldots \ldots \ldots \ldots \ldots$

FIGURE 4.8: $\quad$ BULLET OF TETHER MECHANISM $\ldots \ldots \ldots \ldots \ldots$

FIGURE 4.9: TETHER BEARING COLLARS $\ldots \ldots \ldots \ldots \ldots$

FIGURE $4.10: \quad$ PLENA ROBOT DEPLOYMENT $\ldots \ldots \ldots \ldots \ldots$

FIGURE 5.1: SEGMENT CROSS SECTION $\ldots \ldots \ldots \ldots \ldots$

FIGURE 5.2: $\quad$ EXO BODY FOR 1992 Ai ${ }_{i}$ MS $\ldots \ldots \ldots \ldots \ldots$

FIGURE 5.3: $\quad$ SLIDE STRUCTURE $\ldots \ldots \ldots \ldots \ldots \ldots \ldots$

FIGURE 5.4: $\quad$ RING/CROSS $\ldots \ldots \ldots \ldots \ldots \ldots \ldots \ldots \ldots$

FIGURE 5.5: COMPUTER HARDWARE CONFIGURATION $\ldots \ldots \ldots \ldots 7$

FIGURE 5.6: OPERATING ENVIRONMENT $\ldots \ldots \ldots \ldots \ldots \ldots$ 


\section{LIST OF TABLES}

TABLE 1.1 RADIATION DOSE LIMITS FOR COMMON INSULATING MATERIALS AND FLASTOMERS $\ldots \ldots \ldots \ldots$

TABLE 1.2 RADIATION DOSE LIMITS OF COMPONENT PARTS $\ldots \ldots \ldots .7$

TABLE 1.3 RADIATION DAMAGE TO PARTS OF MOTOR, SELSYNS, RELAYS, AND SWITCHES $\ldots \ldots \ldots \ldots \ldots \ldots$

TABLE 1.4 TYPICAL ROBOTIC CONTROL SYSTEM ELECTRONICS . . . . 9

TABLE $5.1 \quad 1991$ TEST SEGMENT WEIGHT $\ldots \ldots \ldots \ldots$

TABLE $5.2 \quad 1992$ TEST SEGMENT WEIGHT $\ldots \ldots \ldots \ldots 6$ 
1. PRINCIPALS

Dr. Carl D. Crane

Prof. James S. Tulenko
2. ASSOCIATED

FACULTY

Dr. R. Dalton

Dr. J. Duffy

Dr. R. Harrell

Dr. F. Fox

Dr. R. Singh

Dr. F. Sias
3. POST-DOCTORAL ASSOCIATES

P. Adsit

S. Toshkov

\section{PROGRAM SUPPORTED STUDENTS}

S. Chiang: Ph.D. Student - Autonomous Path Planning; Graduated Spring 1992

H. Dai:

Ph.D. student

- ALMR Modeling Man-machine Interface

R. Jurcyzk:

Ph.D. student

- 3-D Visualization

D. Miko:

Ph.D. student

- Radiation Effects; Environmental Hardening

D. Rocheleau

Ph.D. student

- Man-Machine Interface; Graduated Spring 1992

S. Chaudhry: Masters student

- Radiation Effects; Environmental Hardening

P. Cherukuri: Masters student

- Radiation Effects; Environmental Hardening

S. Clifford: Masters student

- Software and Computer Interfaces Between the Sun, Silicon Graphics, and VAX Computers and the Cybermotion Robot

S. Gluckman: Masters student

- $\quad$ ALMR Review and ATMS Design and Fabrication

D. Haddox: Masters student

ALMR and Argonne Fuel Cycle Facility Modeling

D. Ioannou: Masters student

Navigation; Visual Data Reconciliation

Y. Jang:

Masters student

ATMS Control

S. Mandal: Masters studen

- Radiation Effects Annealing

S. Ridgeway: Masters student

ATMS Design and Fabrication

R. Ross:

$$
\text { Masters student }
$$

ALMR Review

M. Vasu:

Masters student

Man-machine Interface

X. Wang: Masters student

- PDMS Modeling of Argonne Fuel Cycle Facility

E. Swilley: Bachelors student - Hardware and Software Integration 


\section{PUBLICATIONS AND PRESENTATIONS \\ BY UNIVERSITY OF FLORIDA TEAM MEMBERS}

Chaudhry, S. Radiation Hardening of Electronic Components. Presented at the DOE/NE Robotics for Advanced Reactors Program Student Conference, Oak Ridge, TN (1992).

Chianig, S. Autonomous Path Planning for an Articulated Transporter/Manipulator System. Presented at the DOE/NE Robotics for Advanced Reactors Program Student Conference, Oak Ridge, TN (1992).

Chiang, S., Crane, C., and Duffy, J. Hierarchical Path Planning for an Articulated Transporter/Manipulator System in a Three Dimensional Environment, in Proceedings of the 5th Annual Conference on Recent Advances in Robotics. Boca Raton, FL: Florida Atlantic University, pp. 236-248 (1992).

Chiang, S. C., Crane, C., and Duffy, J. Path Planning for an Articulated Transporter/Manipulator System, in Proceedings of the ASME Mechanisms Conference. Phoenix, AZ (1992).

Crane, C. A Computer Graphics Based Approach to Range Sensor Simulation, in Proceedings of the Society of Phoio-Optical Instrumentation Engineers (SPIE) Conference on Applications of Artificia! Intelligence X: Machine Vision and Robotics. Orlando, FL (1992).

Crane, C. Research Issues in Robot Locomotion. Presented at the DOE/NE Robotics for Advanced Reactors Program Student Conference, Oak Ridge, TN (1992).

Dai, H. ALMR Modeling: Intelligent Navigation System. Presented at the DOE/NE Rubotics for Advanced Reactors Program Student Conference, Oak Ridge, TN (1992).

Dai, H., Dalton, R., and Tulenko, J. Fuzzy Reasoning for an Integrated Mobile Robotic System, in Proceedings of the 5th Annual Conference on Recent Advances in Robotics. Boca Raton, FL: Florida Atlantic University, pp. 555-559 (1992).

Dai, H. Q., Dalton, G. R., and Tulenko, J. S. Fuzzy Control System for a Mobile Robot. Transactions of the American Nuclear Society, 65, 464-465 (1992).

Dai, H. Q., Dalton, G. R., Tulenko, J. S., and Crane III, C. D. Development of An Advanced Intelligent Robot Navigation System. Transactions of the American Nuclear Society, $\underline{65}$, 463-464 (1992).

Haddox, D. Modeling of the IFR Vacuum Furnace. Presented at the 1992 Robotics for Advanced Reactors Student Conference, January 1992, Oak Ridge, TN. 
Haddox, D. Engineering Design Visualization and Simulation Using 3-Dimensional Graphics. Presented at the DOE/NE Robotics for Advanced Reactors Program Student Conference, Oak Ridge, TN (1992).

Haddox, D., Dalton, R., Tulenko, J., and Clifford, S. Visualization in Remote Robotic Control Using 4-D Graphics, in Proceedings of the 5th Annual Conference on Recent Advances in Robotics. Boca Raton, FL: Florida Atlantic University, pp. 101-109 (1992).

Ridgeway, S., Adsit, P., and Stivender, S. Articulated Transporter Manipulator System: Design, Fabrication, and Testing of a Parallel Joint Actuation Scheme. Presented at the DOE/NE Robotics for Advanced Reactors Program Student Conference, Oak Ridge, TN (1992).

Ridgeway, S., Crane, C., Adsit, P., and Harreil, R. The Design of an Articulated Manipulator Transporter System, in Proceedings of the 5th Annual Conference on Recent Advances in Robotics. Boca Raton, FL: Florida Atlantic University, pp. 142-156 (1992).

Ridgeway, S., Crane, C., Adsit, P., and Harrell, R. The Mechanical Design of a Parallel Actuated Joint for an Articulated Mobile Robot, in Proceedings of the ASME Mechanisms Conference. Phoenix, AZ (1572).

Rocheleau, D. Assembly Modeling of Spatial Mechanisms Using Geometric Constraints. Ph.D. Thesis, University of Florida (1992).

Rocheleau, D. and Crane, C. Development of a Graphical Interface for Robotic Operation in a Hazardous Environment. Presented at the DOE/NE Robotics for Advanced Reactors Program Student Conference, Oak Ridge, TN (1992). 


\section{CONFERENCES AND OTHER TRAINING ACTIVITIES}

1992 DOE Robotics for Advanced Reactors Student Conference, Oak Ridge, TN, January 1992, attended by P. Adsit, S. Chaudhry, P. Cherukuri, S. Chiang, C. Crane, H. Dai, D. Haddox, D. Ioannou, R. Jurcyzk, S. Ridgeway, D. Rocheleau, F. Sias, E. Swilley, and J. Tulenko.

EPRI Workshop on Robotic Maintenance for Utility Activities, Salt Lake City, UT, February 1992, participation by J. Tulenko.

Radi-Sys Conference, Orlando, FL, February 1992, participation by H. Dai, D. Haddox, D. Ekdahl and G. Dalton.

Cybermotion K2A Robot Users Conference, Atlanta, GA, March 1992, participation by H. Dai, D. Haddox, D. Ioannou, G. Dalton and F. Sias.

SPIE Conference, Orlando, FL, April 1992, attended by C. Crane.

PDMS Users Meeting, Vancouver, B.C., May $19 c^{2}$, attended by G. Dalton.

Fifth Anrual Conference on Recent Advances in Rototics, Boca Raton, FL, June 1992, attended by G. Dalton, E. Swilley, D. Haddox and C. Crane.

ACME Design Review and Presentation, San Jose, CA, June 1992, attended by G. Dalton, C. Crane and S. Gluckman.

ALMR Meeting, Gainesville, FL, July 1992, attended by P. Adsit, C. Crane, H. Dai, G. Dalton, S.Ridgeway, R. Ross, J. Tulenko.

American Nuclear Society Annual Meeting, Boston, MA, June 1992, attended by J. Tulenko and H. Dai.

IGRIP Training Session at Deneb Robotics, June 1992, Auburndale, MI, attended by D. Haddox.

Technical Review, ORNL, September 1992, participation by D. Haddox, H. Dai, D. Ioannou and G. Dalton.

IGRIP Users Group Meeting, Auburndale, MI, September 1992, attended by D. Haddox.

ASME Mechanisms Conference, Phoenix, AZ, September 1992, attended by C. Crane, J. Duffy and S. Ridgeway.

PDMS Training Session, Gainesville, FL, October 1992, attended by H. Dai, D. Haddox, X. Wang and G. Dalton.

American Nuclear Society Winter Meeting, Chicago, IL, November 1992, attended by J. Tulenko. Fuzzy Logic Workshop, IEEE, Houston, TX, December 1992, attended by H. Dai and D. Ekdahl. 


\subsection{Environmental Hardening}

During the reporting period of 1992, the research on environmental hardening of electronic components and niaterials for robotic systems for advanced nuclear facilities focused on three subtasks. First, work continued on the development of methods to anneal out radiation defects, allowing electronic components to work for extended periods in radiation environments. As part of this task an automated data recording system would be developed. Secondly, work continued on reviewing current generation robotic systems for their hardness for application in advanced nuclear facilities. Thirdly, a development program was formulated to write a code to record component failure automatically allowing for long testing periods without the need for personal attendance.

\subsection{Anneal Technique Developınent}

During 1992 results were obtained for the behavior of radiation defects in a simple MOS capacitor structure under normal operation and on-line annealing processes. In contrast with post radiation annealing studies conducted earlier by various researchers, we experimented with new in-situ on-line annealing riethods for lifetime extension. Two separate on line annealing methods were conducted: 1) thermal annealing and, 2) AC bias annealing. The on-line thermal an w experiments were carried out as a function of total dose and dose rate.

The team was able to separate out the change in voltage due to interface traps and oxide traps as a function of radiation dose. Capacitance-Voltage $(C-V)$ measurements were used to extract the voltage shifts due to oxide and interface charges. The change in voltage (radiation effect) due to oxide traps is greater than a factor of ten (order of magnitude) more important than that due to interface traps. At a dose of $100 \mathrm{krads}$, the interface traps account for a voltage change of 0.3 (Figure 1.1) volts versus a change of approximately 7 volts for the oxide traps at 100 krads (Figure 1.2). The effect of an on-line temperature anneal of the interface and oxide traps is also shown in Figures 1.1 and 1.2. Figure 1.1 shows no change in the voltage drop as the temperature of anneal is increased from $25^{\circ} \mathrm{C}$ to $150^{\circ} \mathrm{C}$. Figure 1.2 shows that at a dose of $100 \mathrm{krads}$ changing the temperature of operation from $25^{\circ} \mathrm{C}$ to $150^{\circ} \mathrm{C}$ reduces the voltage drop by approximately 0.5 volts.

High frequency $\mathrm{AC}$ on-line annealing was found to be an attractive method for the reduction of radiation induced oxide charge and interface traps. In these experiments an $\mathrm{AC}$ bias of $50 \mathrm{MHz}$ was superimposed on a DC bias. The magnitude of $\mathrm{AC}$ and $\mathrm{DC}$ bias were different for different sets of experiments. Up to $50 \%$ annealing of radiation induced charges were observed even when the devices were exposed to worst operating conditions. The magnitude of the annealing depends on the frequency and peak to peak voltage of the AC bias and also on the DC bias of iset. We also observed significant annealing in these capacitors even when the voltage did not shift from the accumulation regions. This created a way for applying the AC bias with a DC offset across $n$-channel MOSFETs which are subjected to ionizing radiation. Based on the capacitor results preliminary experiments on the threshold voltage shifts of MOS transistors are being conducted now.

Figure 1.3 shows the effect of on-line AC annealing of the oxide traps. The improvement in voltage drop is considerably more as the voltage change is increased from \pm 3.5 to \pm 5 , bringing the capacitor into a negative voltage state At $\pm 5 \mathrm{~V} \mathrm{AC}$, the voltage drop has 


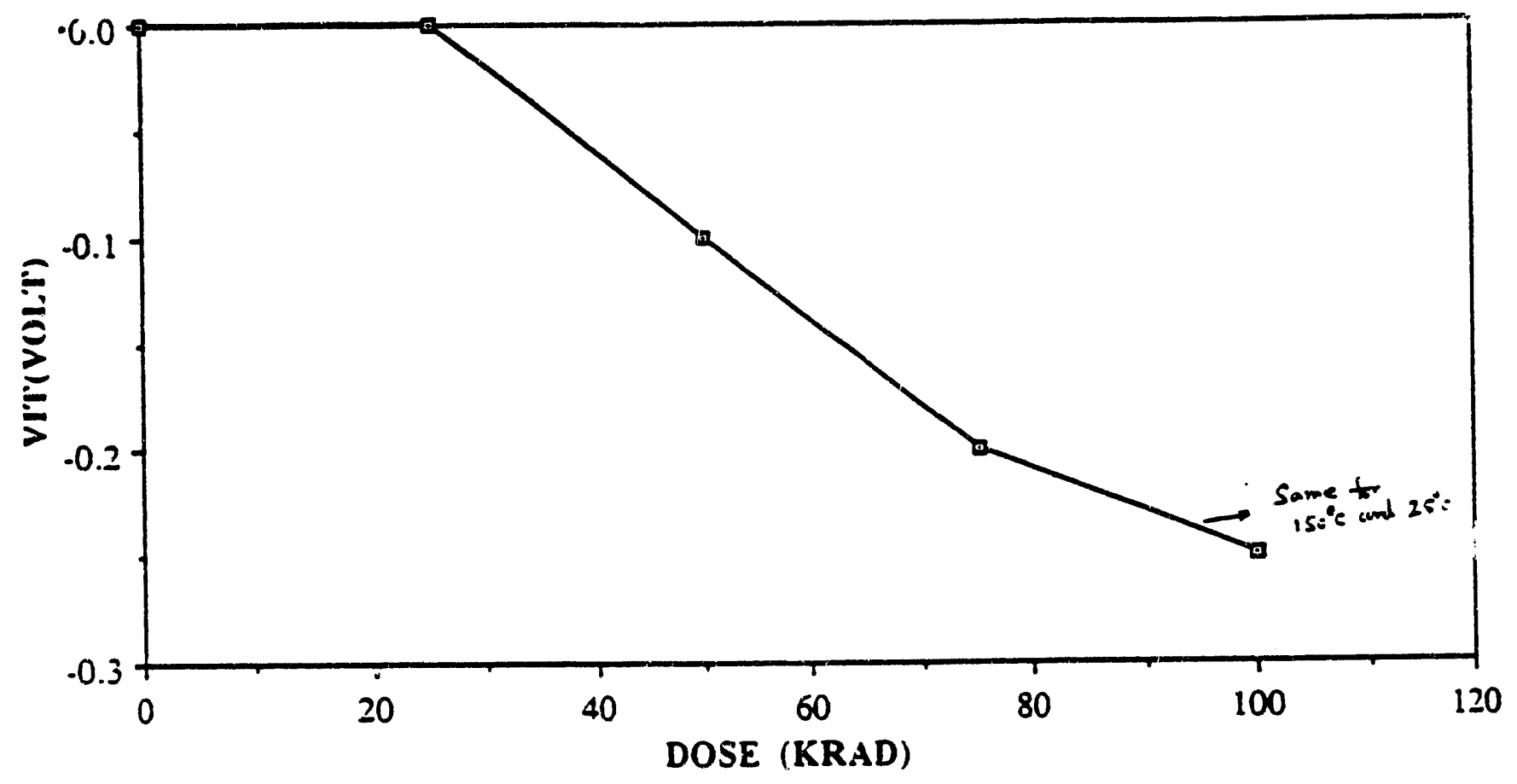

Figure 1.1 Thermal Annealing of Interface Traps:

Voltage Shift vs. Total Dose

\section{ANNEALING AT 150 C}

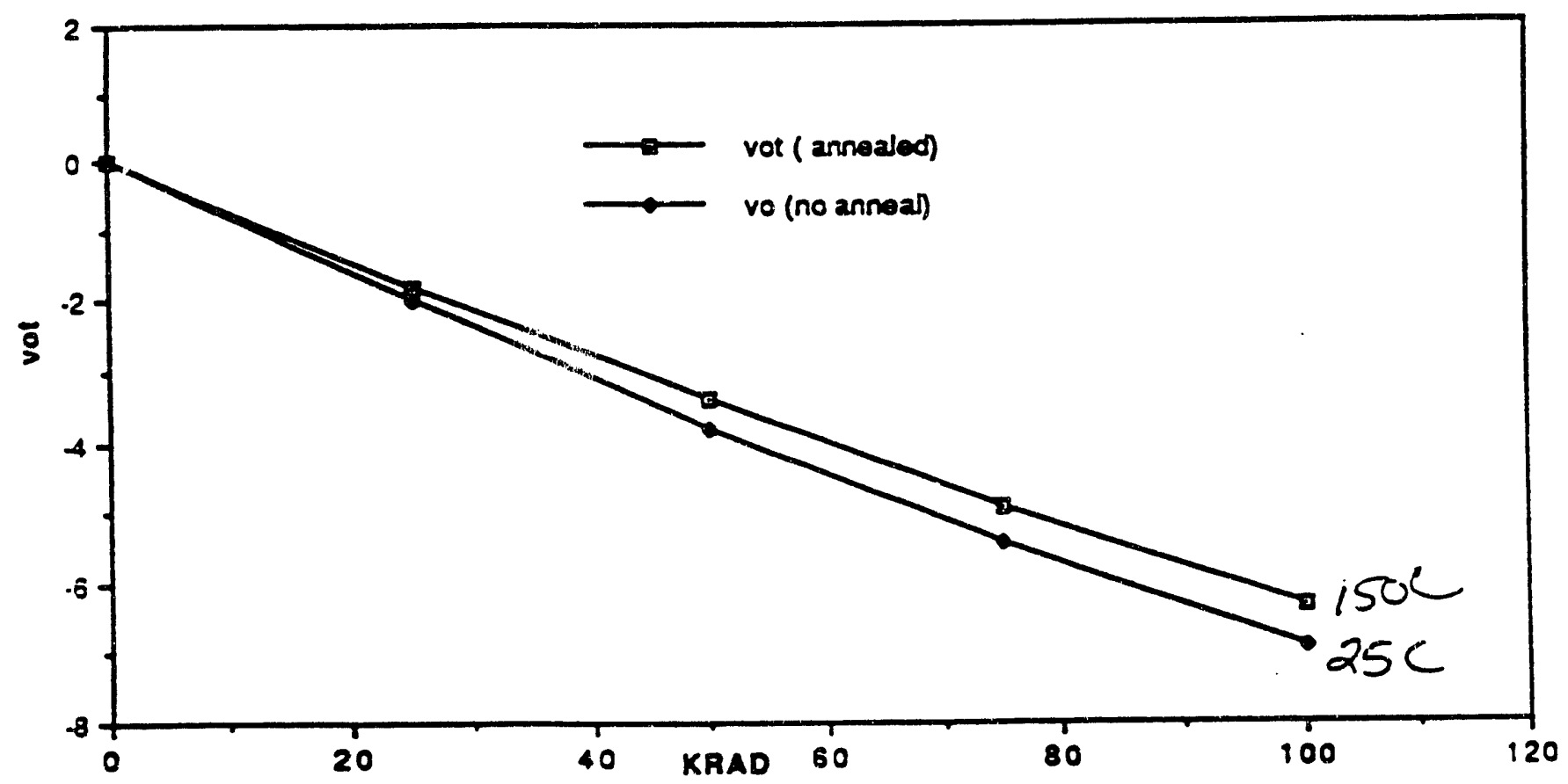

Figure 1.2 Thermal Annealing of Oxide Traps:

Voltage Shift vs. Total Dose 


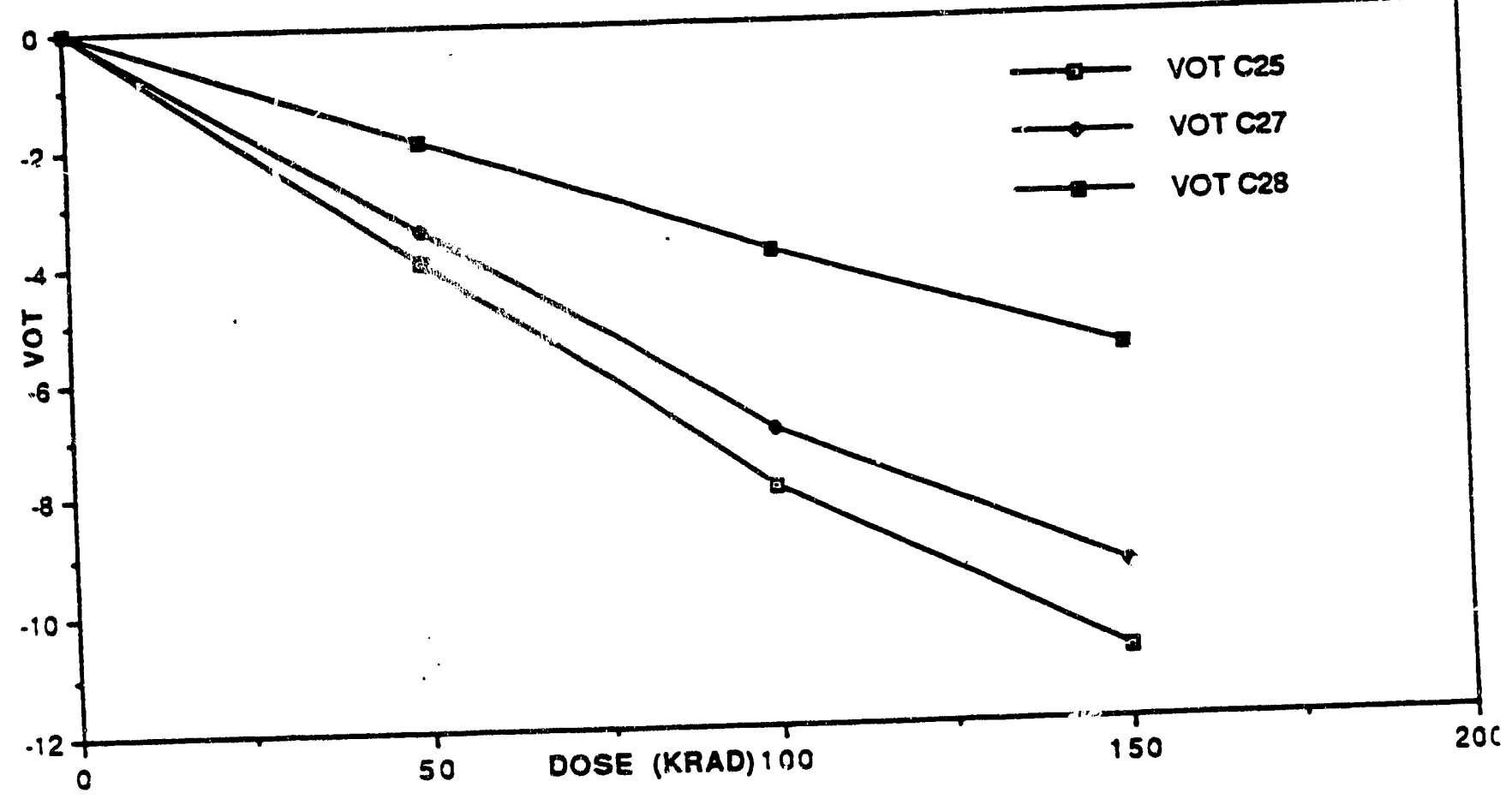

Figure 1.3 AC Annealing of Oxide Traps:

Voltage Shift vs. Total Dose

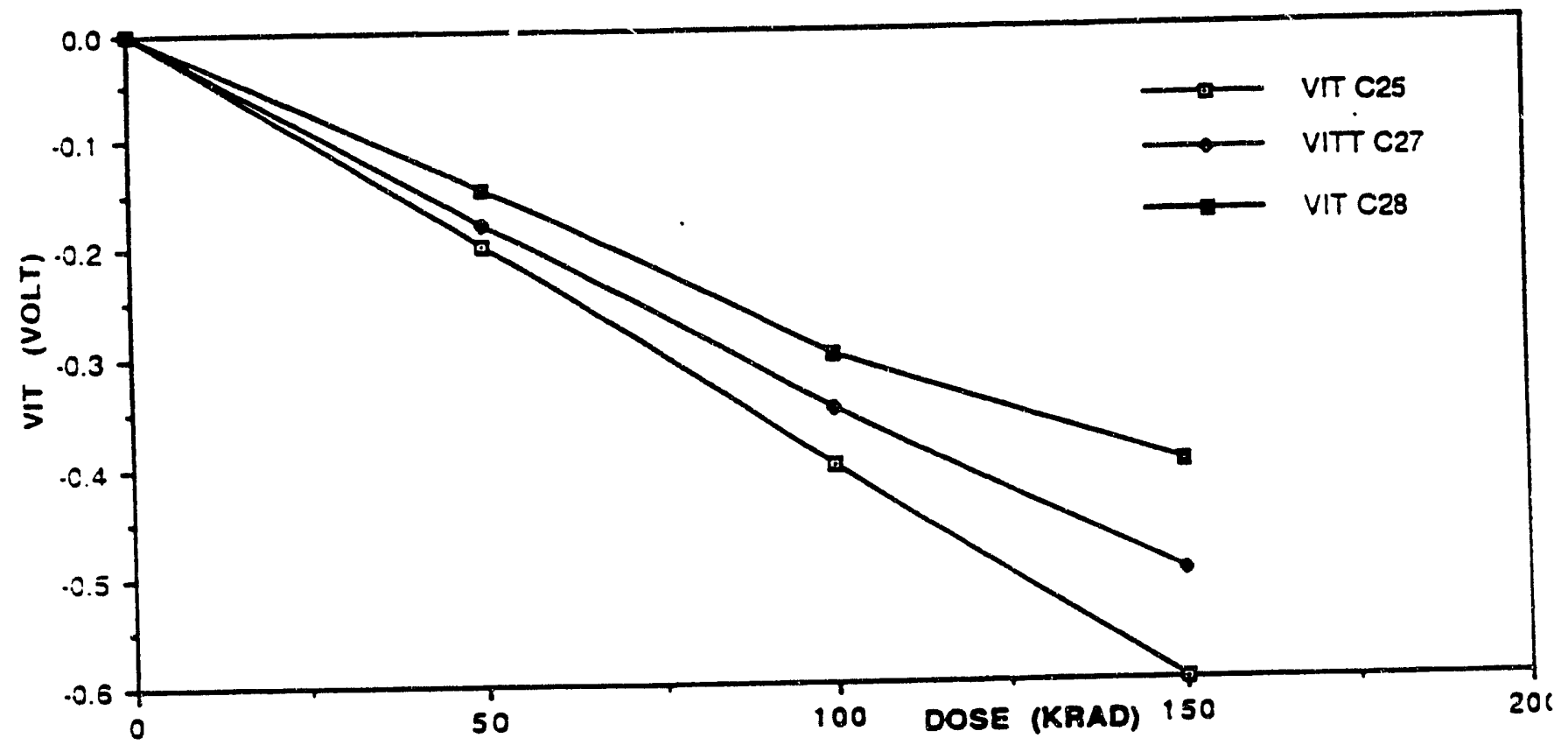

Figure 1.4 AC Annealing of Interface Traps:

Voltage Shift vs. Total Dose 
been changed by 5 volts or approximately $62.5 \%$ of the total increase. Thus, AC annealing appears to be an effective and quick-acting annealing mechanism. From Figure 1.4, it can be seen that $\mathrm{AC}$ anneal is also effective in decreasing the voltage drop due to interface traps by approximately $20 \%$. These results are in sharp contrast to thermal annealing which had no effect on interface traps. In carrying out these experiments the MOS capacitors were fabricated in-house by a CMOS line available in the Electrical Engineering Department at the University of Florida. The high-frequency and low-frequercy capacitance-voltage (CV) curves of MOS capacitors were used to extract parameters like oxide charge and interface-trap density. Keithley 590 high-frequency and Keithley 595 quasi-static CV meters were used. These instruments were further automated using LABVIEW software. A heater assembly was also develcped to conduct annealing experiments.

Preliminary experiments on AC annealing were also conducted on n-channel MOSFETs. In this set of experiments, an $\mathrm{AC}$ bias of peak to peak 4 volt superimposed on $+4 \mathrm{~V} \mathrm{DC}$ was separately applied only to drain, and both to drain and gate of the n-channel MOSFET. In this set of experiments, an AC bias of peak to peak 4 volt superimposed on $+4 \mathrm{~V} \mathrm{DC}$ was separately applied only to drain, and both to drain and gate of the n-channel MOSFET. In both cases it was noticed that the threshold voltage change was much less than the case when no AC high frequency bias was used, thus showing significant annealing in the MOSFETs. Further work. on high frequency annealing of MOSFETs will be carried out in 1993 to determine the optimum combination of AC and DC biases for best annealing of gamma radiation induced defects. Similar experiments will be conducted on p-channel MOSFETs.

\subsection{Hardness of Current Generation Robotic Systems}

The following radiation classification scheme has been utilized as a basis for categorizing compor ents for radiation hardness:

$$
\begin{array}{ll}
\text { Category I } & 0-10,000 \operatorname{rad}(\mathrm{Si}) \text { Total Dose } \\
\text { Category II } & 10,000-100,000 \operatorname{rad}(\mathrm{Si}) \text { Total Dose } \\
\text { Category III } & 100,000-1 \mathrm{M} \operatorname{rad}(\mathrm{Si}) \text { Total Dose } \\
\text { Category IV } & >10^{6} \mathrm{rad}(\mathrm{Si}) \text { Total Dose }
\end{array}
$$

Military Specification test methods MIL-STD-883C Method 1019.3 specifies that Total-Dose radiation tests will be performed using dose rates between 1 and $3 \mathrm{~Gy}(\mathrm{Si} / \mathrm{sec})$ which corresponds to $100-300 \mathrm{rad}(\mathrm{Si}) / \mathrm{sec}$ which, in tum, correspond to dose rates of the order of 360,000 to $1,080,000 \mathrm{R} / \mathrm{hr}$. Roentgens $(\mathrm{R})$ and rads are not precisely equivalent since the absorbed dose depends on the material being irradiated. However, direct conversion of $R / h r$ to $\mathrm{rad}(\mathrm{Si}) / \mathrm{hr}$ will give an answer with 20 percent of the correct value.

Most scenerios in which a mobile robot could be used would be considered low dose rates as far as radiation damage to electronic devices is concerned. For this reason, total-dose radiation evaluations based on MIL-STD-883C Method 1019.3 do not predict electronic device 
failure thresholds for radiation-soft devices in all of the above categories. The classification of electronic devices in this report is usually based on high-dose-rate testing and thus only provides a first approximation of total-dose classification. Tests of radiation-soft electronic components must be performed at the actual application dose rate to obtain a reliable estimate of total-dose hardness when exposed to low dose-rate ionizing radiation or else some special modification of Method 1019 must be used to predict the behavior of the device at iow dose rates.

According to vendors, the total-dose hardness based on MIL-STD-883C Method 1019.3 tends to be a more reliable prediction of the total-dose hardness of radiatior-hardened components when the components are used at low dose rates. This is due to the fact that interface trap effects, which generally cause low-dose-rate failure, are minimized by the manufacturing technologies used during the nanufacture of radiaion-hardened Metal Oxide Semiconductor (MOS) components.

The effect of radiation on materials has been studied extensively and the effect of radiation on semiconductors is still a very active area of research. Developing a radiation-hardened robot will involve four main areas of investigation:

1. Radiation-hardness of structural materials.

2. Radiation-hardness of passive electronic components.

3. Radiation-hardness of active electronic 0.:nonents

which are primarily semiconductor devices.

4. Protection of internal modules and the later decontamination of protective cases or coverings.

The effect of radiation on aluminum, steel or other structural metals will be of little concern. Organic structural materials such as rubbers, plastics, and lubricants are affected by gamma radiation doses that could be encountered. The same materials also are some concern in electrical and electronic systems since many plastics are used in the construction of systems as insulation or "potting" materials. Teflon is a notable example since insulation made of this material may be affected by gamma radiation doses as low as IE4 rads.

Teflon is found as insulation for wire and as sheet insulation in motors and relays, for example. Table 1.1 shows a number of common insulating materials along with the radiation exposure that will cause measureable damage to the material that may result in the failure of the device in or on which the insulation is used.

From this table it can be seen that teflon and epoxy resin have the lowest threshold for radiation damage while there are several insulating materials that have much higher dose limits. 
Table 1.1 Radiation Dose Limits for common insulating materials and elastomers

Material

Silicon-treated mica

Siliconl-varnished glass fiber

Polyethelyne

Mylar

Teflon

Polyurethane glass fiber

Polyvinalchloride (PVC)

Polystyrene

Bakelite

Epoxy resin

Glass-bonded mica

Diallyl Phthalate

Nylon

Natural rubber

Butyl rubber

Neoprene

Viton A

Silicon Rubber

Buna- $N$
Exposure in Rads

1E7

1E7

1E7

1E7

1E\}

$1 E 8$

1E5

$1 \mathrm{E} 8$

1E8

$1 \mathrm{E} 4$

$1 \mathrm{E} 8$

$1 \mathrm{E} 8$

$1 \mathrm{E} 5$

$1 \mathrm{E} 6$

$1 \mathrm{E} 6$

$1 \mathrm{E} 6$

1E7

1E6

IE5

When used in the manufacture of component parts some materials such as epoxy appear to have higher dose limits as shown in Table 1.2. Table 1.3 Shows the effect of radiation on some susceptable components used to manufacture motors, selsyns, relays and switches. One fact that stands out from Tables 1.1, 1.2 and 1.3 is that only one structural or insulating material, teflon, reduces radiation resistance below one mega-rad. Since this material is used so much to manufacture electrical parts, one must be very careful to screen all components for teflon component parts. By the careful selection of materials many electrical devices can be radiation hardened to withstand a total dose of $1 E 7$ or $1 E 8$ rads.

Semiconductor components are, by far, the weak link in the design of radiation-hardened systems. Some semiconductor integrated circuits, that have not been specifically radiation hardened, may fail at a total dose of ionizing radiation as low as a few hundred rads. Modern designs of Very Large Scale Integrated (VLSI) circuits such as Complementary Metal Oxide Semiconductor (CMOS) microprocessors may have an inherent radiation resistance to a total dose of around 10,000 $\mathrm{rad}(\mathrm{Si})$ even without using special radiation-hardening techniques. Some non-hardened bipolar analog circuits and Transistor-transistor Logic (TTL) may be usable to a total dose of IES rads(Si) or higher. With special hardening techniques several manufacturers have produced microprocessors and logic families capable of withstanding a total dose of ionizing radiation of 1 mega-rad(Si) or greater. 
Table 1.2 Radiation Dose Limits of Component Parts

\section{Componenı}

Resistor, carbon composition slug

Resistor, carbon composition film

Resistor, metal film

Resistor, carbon film

Resistor, oxide film

Resistor, wirewound on ceramic

Resistor, wirewound on epoxy

Resistor, film potentiometer

Resistor, wirewound variable

Resistor, film variable

Capacitor, paper

Capacitor, ceramic

Capacitor, glass

Capacitor, mica

Capacitor, Plastic

Capacitor, Tantalum slug, wet

Capacitor, Tantalum slug, dry

Capacitor, Tantalum foil

Transformers, relays

Quartz crystals

Foil-clad ix minates (printer circuit boards)

Connectors, Duroc ceramic

Connectors, Melamine plastic

Silicon varnish insulation

Varistors, silicon

Varistors, selenium and copper
Dose limit (Rads)

$1 \mathrm{E7}$

$1 \mathrm{E} 8$

$1 E 11$

IE9

$1 \mathrm{E6}$

$1 \mathrm{E} 12$

1E9

$1 \mathrm{E7}$

1E9

$1 E 7$

IE7

$1 \mathrm{E} 10$

$1 \mathrm{E} 10$

1E9

1E7

1E7

1E9

1E7

1E9*

1E7

1E7

3E8

3E8

$1.4 \mathrm{E} 9$

1E9

1E5

* Depends on insulating materials used. 
Table 1.3 Radiation damage to parts of motor, selsyns, relays, and switches

Component part

Dose (rads) to produce $25 \%$ change

Brush holder, Linen-filled phenolformald 3E6

Brush holder, Paper-filied phenolformald 8E6

Grease seal, Neoprene 6E6

Grease seal, Buna- $N$ 4E6

Gre use seal, Felt 5E6

Insulating tape, Rubberized Cloth 5E6

Insulating tape, Polyvinyl chloride (PVC) 1.2E8

Insulating tape, Natural rubber $\quad 2.6 \mathrm{E} 7$

Insulating tape, Teflon-coated fiber glass $3 E 4$

Insulating tape, Fiber glass and silicone resin 5E8

Insulating tape, Acetate cloth $1.6 \mathrm{E} 7$

Insulating tape, Buna-N-treated fiber glass 4E6

End punchings, Teflon-coated fiber glass $3 E 4$

Slot insulation, Teflon-coated fiber glass 3E4

Shaft insulation, Fiber glass melamine $\quad 6.4 \mathrm{E} 7$

Shaft insulation, Mylar $\quad 1.2 \mathrm{E} 8$

Shaft insulation, Teflon 3E4

Shaft insulation, Mica with shellac 4E7

Shaft insulation, Mica with mylar 1.2E8

Shaft insulation, Paper-filled phenolformald 8E6

Shaft insulation, Asbestos-filled phenolformald 5.3E8

Shaft insulation, Kel-F $1.7 \mathrm{E7}$

Shaft insulation, Fish Paper 5E7

Shaft insulation, Varnished cambric 5E6

Shaft insulation, Polyvinylchloride 1.2E8

Shaft insulation, Cellulose acetate $\quad 1.6 \mathrm{E} 7$

Wire insulation, Teflon 3E4

Wire insulation, Formvar $\quad 9.7 \mathrm{E} 7$

Wire insulation, Fiber glass and silicone resin $5 E 8$

Wire insulation, Nylon 4E6

Wire insulation, Neoprene 6E6

Wire insulation, Paper 5E6

Relay, switch base, Asbestos-filled phenolformald IE9

Relay, switch base, Unfilled phenolformald $1 E 7$

Gaskets, Buna- $N$ rubber 4E6

Gaskets, Hycar-PA 3E6

Connectors, Polystyrene 6E9

Connectors, Polyethylene 9E7 
A commercially available robotic system (ANDROS) was evaluated to determine relative hardness of components versus information available in data bases. Typical electronic components and their expected radiation failure level are shown in table 1.4. During the coming year these components will be radiated to determine their actual failure levels and the availability for hardening more radiation resistant replacements will be evaluated.

Table 1.4 Typical Robotic Control System Electronics

\begin{tabular}{||l|c|c||}
\hline \multicolumn{1}{|c|}{ FUNCTION } & NAME & $\begin{array}{c}\text { RADIATION FAILURE } \\
\text { LEVEL (krad) }\end{array}$ \\
\hline Interface Chip & MAX231CPD & 70 \\
\hline TTL Chip (4K ROM) & 74F573 & 30 \\
\hline Program Array Logic & $16 \mathrm{~L} 8$ & 30 \\
\hline 2 I/D and Gate & 74LS08 & 100 \\
\hline SRAM 8K x 8 bit & UM6264-10L & 24 \\
\hline EPROM 8K & 2764 & 10 \\
\hline Microprocessor Monitor & MAX694CPA & 20 \\
\hline $\begin{array}{l}\text { 8bit Digital/Analog } \\
\text { Converter }\end{array}$ & AD558JN & 10 \\
\hline Hex Inverter & 74LS04 & 7 \\
\hline
\end{tabular}

\subsection{Radiation Testing of CMOS Devices and Integrated Circuits}

Work during the last year has focused on extending the radiation lifetime of SRAMS and other integrated circuits. During the last two years, temperature and high frequency AC annealing effects on microprocessors were observed in experiments conducted at the University of Florida. The results were presented at the January 1992 meeting in Oak Ridge, Tennessee. Results obtained from these experiments showed a considerable increase in lifetime by annealing. These positive results motivated us to further investigate annealing techniques on SRAMs and other integrated circuits.

\subsubsection{Experimental Setup}

The experimental setup is as shown in Figure 1.5. Some of the instruments used in this setup are:

1) FLUKE-9010A: This is a Micro-system testing system which gives us power and flexibility in testing microprocessor-based boards. The FLUKE, which is interfaced to a Z80 processor, has preprogrammed tests that check the functionality of the RAMs, ROMs, etc. 
The RAM test performed by the FLUKE is a quick way to verify that the SRAM is good. To perform this test, the FLUKE writes data into each SRAM location, reads this data back from each location, and verifies that the data read was the same as the data written. The FLUKE also writes ones and zeroes into all bit positions of each RAM location. This verifies that all the bits are "read/writable". There are some additional tests that verify that each RAM address is properly decoded. This type of test is called address decoding verification. Since this RAM test checks the basic operability of the SRAMs, the SRAM could be said to have failed if it fails this RAM test.

The test specimens are enclosed in a $\mathrm{Pb} / \mathrm{Al}$ container to minimize the dose enhancement effects caused by low energy scattered radiation. A new temperature controller using the OMEGA-CN911 miniature microprocessor controller was built. This controller is well suited for a broad range of applications and is easy to install and operate. The user needs to select the cesired input by using the front push buttons.

One end of a three foot long cable is interfaced to the $\mathrm{Z} 80$ processor connected to the FLUKE and the other end connected to the SRAM being irradiated. This aids in isolating the DUT (device under test) from the rest of the equipment. Bias current changes were observed while the chip was being irradiated. The SRAMs were simultaneously and repeatedly tested for failure by the FLUKE.

During thermal annealing test runs, the temperature of electronic components were individually tested at values from $70^{\circ} \mathrm{F}$ to $400^{\circ} \mathrm{F}$ using the temperature controller. Some of the observations from the results obtained are

1) Under room temperature, the standby current of the devices show little change up till approximately $12-15$ krads. Upon further radiation, the standby current increases rapidly. The chip failure occurs in this region.

2) The absolute value of the standby current increases as the room temperature of the device is raised when the device is not being irradiated. For instance, the standby current is less than $0.4 \mu \mathrm{A}$ at room temperature and increases to $90 \mu \mathrm{A}$ at $300^{\circ} \mathrm{F}$.

3) The total dose tolerance of the SRAMs determined from the experiments was found to increase significantly with increased on-line temperature conditions. Room temperature values for failure were in 10-20 krad range, and significantly jumped to 30-40 krad range with increase in temperature.

4) At room temperature, the slope of the standby current vs. total dose curves increase significanitiy in the vicinity of the memory failure. However, at elevated temperatures, the slope remains approximately constant. Thus, actual memory failure cannot be correctly predicted by monitoring standby current.

5) High frequency AC experiments did not significantly effect the total dose tolerance of the SRAMs. We speculate that this is due to the inability to access all the device components in the chip. Work is continuing on this aspect into 1993. 
6) Low does rate experiments were carried out. The total dose tolerance had increased for lower doses. However, as these experiments run for several hours and the data had to be recorded manually, we decided to automate the whole setup. An automated data acquisition was desigried and developed for this purpose.

\subsubsection{Fully Automated Data Acquisition System}

The data acquisition system is shown in Figure 1.6. Our data acquisition system consists of the following equipment.

1) The Programmable Power Supply Board, DATEL PC-462, is designed for low cost, medium power source applications. The PC-462 is a high precision, programmable power supply and sensing board for the IBM PC/AT, PS 30 EISA and compatible computers. It is ideal for applications where highly accurate, very stable DC voltage and current sources are required, with low ripple and low noise characteristics. This programmable power supply is mounted on the PC-AT bus.

2) RS-232 interface: The FLUKE was sent to the manufacturer for an RS-232 serial port. The FLUKE now communicates with the host computer through this serial port.

3) A $386 \mathrm{PC}-\mathrm{AT}(33 \mathrm{MHz})$ was assembled at the University of Florida to suit our requirements.

The device driver software for the PC-462, the data acquisition module and the interface module for serial communications with the FLUKE was designed and developed in $\mathrm{C}$ programming language on the host $\mathrm{PC}$.

This data acquisition module is not only capable of recording the relevant data but also communicates with the FLUKE to know the status of the SRAM testing. All the user has to do is to give the interval for each recording of the data and the file to which the data should be written. This system will aid us in performing a number of experiments especially at low dose rates which take several hours to run. The software can be easily modified to support testing any type of ICs in future applications.

Work on extending the life of CMOS transistors and integrated circuits will continue in coordination with our baseline testing being carried out with CMOS capacitors and MOSFITs. 


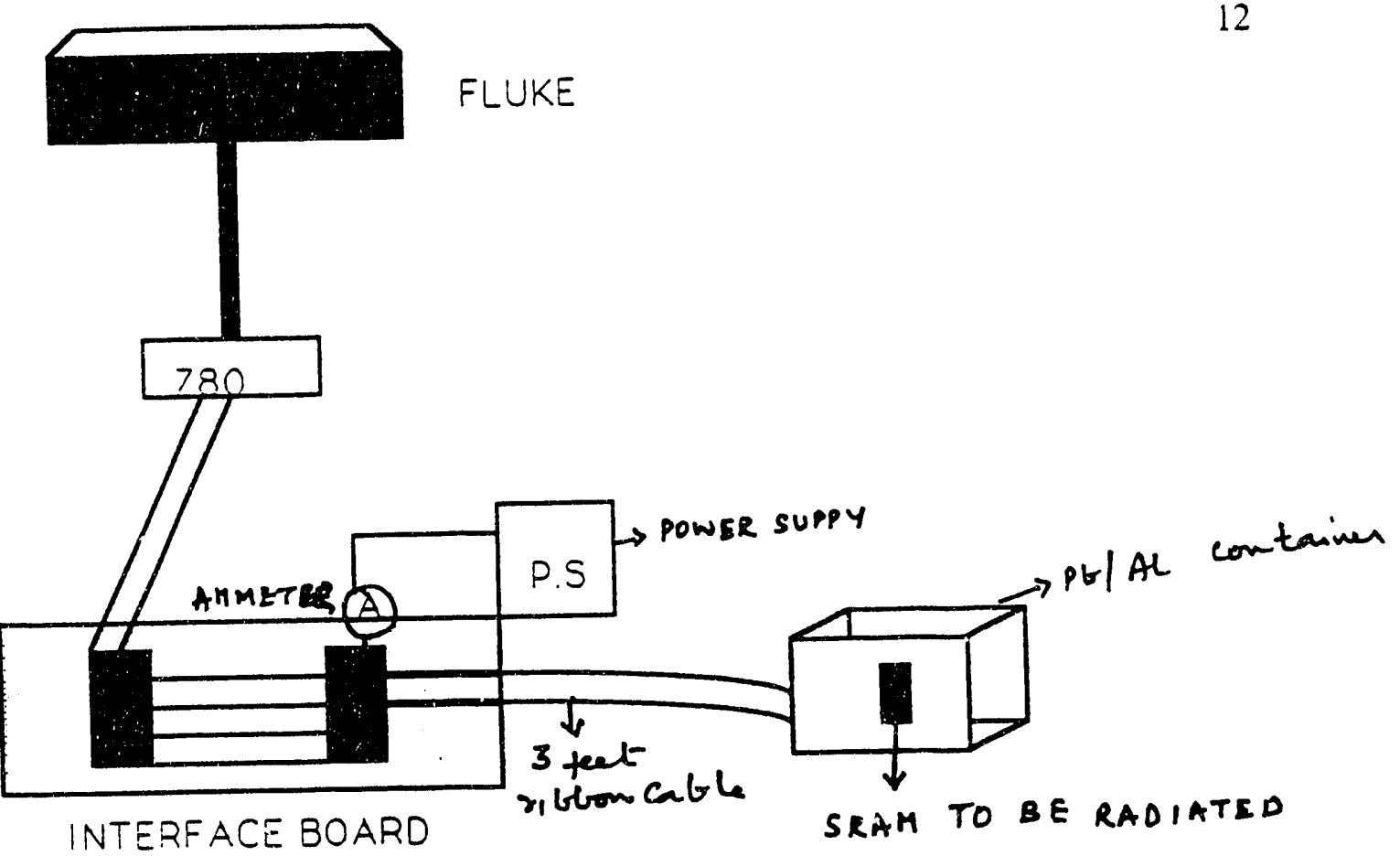

Figure 1.5 Experimental Setup for Testing CMOS Devices and Integrated Circuits

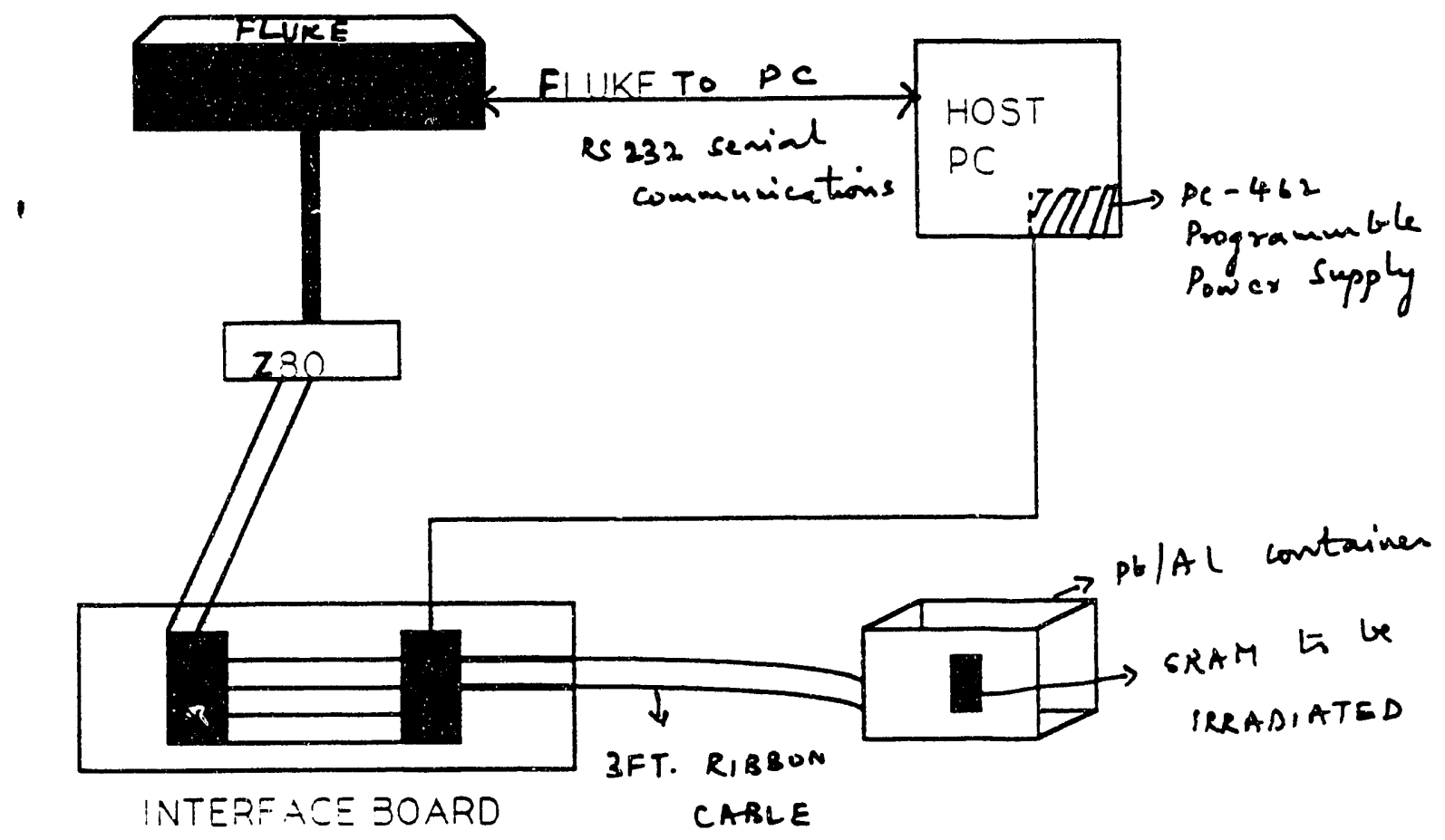

Figure 1.6 Automated Data Acquisition System for Testing CMOS Devices and Integrated Circuits 


\section{0}

Database/World Modeling

The database/world modeling effort has continued to focus on modeling the features of the General Electric Advanced Liquid Metal Reactor (ALMR) and the Argonne West Fuel Processing Facility. The modeling work is progressing using the robotics design tool IGRIP.

In an effort to improve the ALMR modeling, the Plant Design Modeling System (PDMS) code was obtained. PDMS facilitates the modeling of complex features necessary in the design, construction, operation, maintenance, and decommissioning of nuclear facilities. This modeling package was donated to the University of Florida by CadCentre, Inc. of Houston, Texas and Cambridge, England, for use by the Robotics for Advanced Reactors research program. The existing Silicon Graphics workstation has been upgraded and an additional workstation has been acquired to accommodate both the new graphics modeling package and additional users.

In addition to facility modeling, the University of Florida Robotics Team has been working on a preliminary design of robots for surveillance and cleanup in the ALMR during periodic shutdowns for refueling. The related effort in teleproprioception sense development has been delayed due to equipment and personnel limitations, but will proceed with the acquisition of a laser range camera in the next contract year.

\subsection{Advanced Liquid Metal Reactor}

\subsubsection{Modeling of Seismic Isolators}

The modeling of the seismic isolators for the ALMR has been completed. The model includes all available design parts, including the lifting jacks. The parts are individually manipulable, and can be removed and replaced, both as a unit and as individual parts as small as the nuts and bolts that hold the unit together. Attached Figures 2.1 through 2.4 show a single seismic isolator, both assembled and partially disassembled for inspection.

Work on the removal of the disassembled absorber parts using a robot can proceed when design details of the shielded labyrinth are more complete. This task has been part of the revision work currently under review by GE and the Robotics Design Team. When the detailed shielded labyrinth design is available, a more complete animation can be constructed of a large robot picking up the 6 feet diameter $\times 3$ feet high steel and rubber isolator pads and removing them from the plenum area to ground level for replacement. The final report is in preparation and will be delivered before the end of the calendar year.

\subsubsection{Center of Gravity Modeling}

The center of gravity modeling using the center of gravity (CG) function of the IGRIP code package is complete and a final report will be completed by the end of the year. Briefly, 


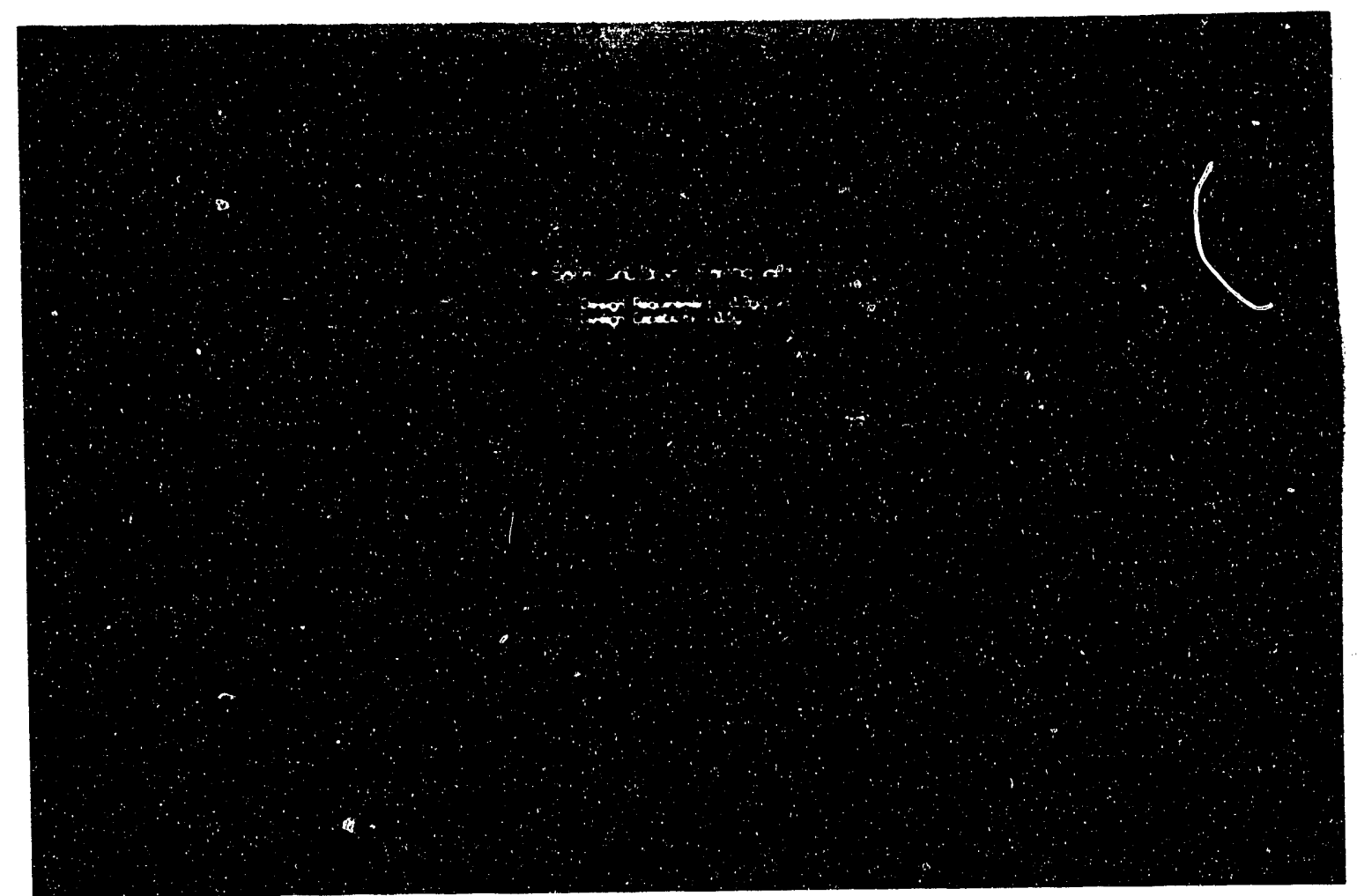

Figure 2.1: View Showing Seismic Isolators Locations On Floor

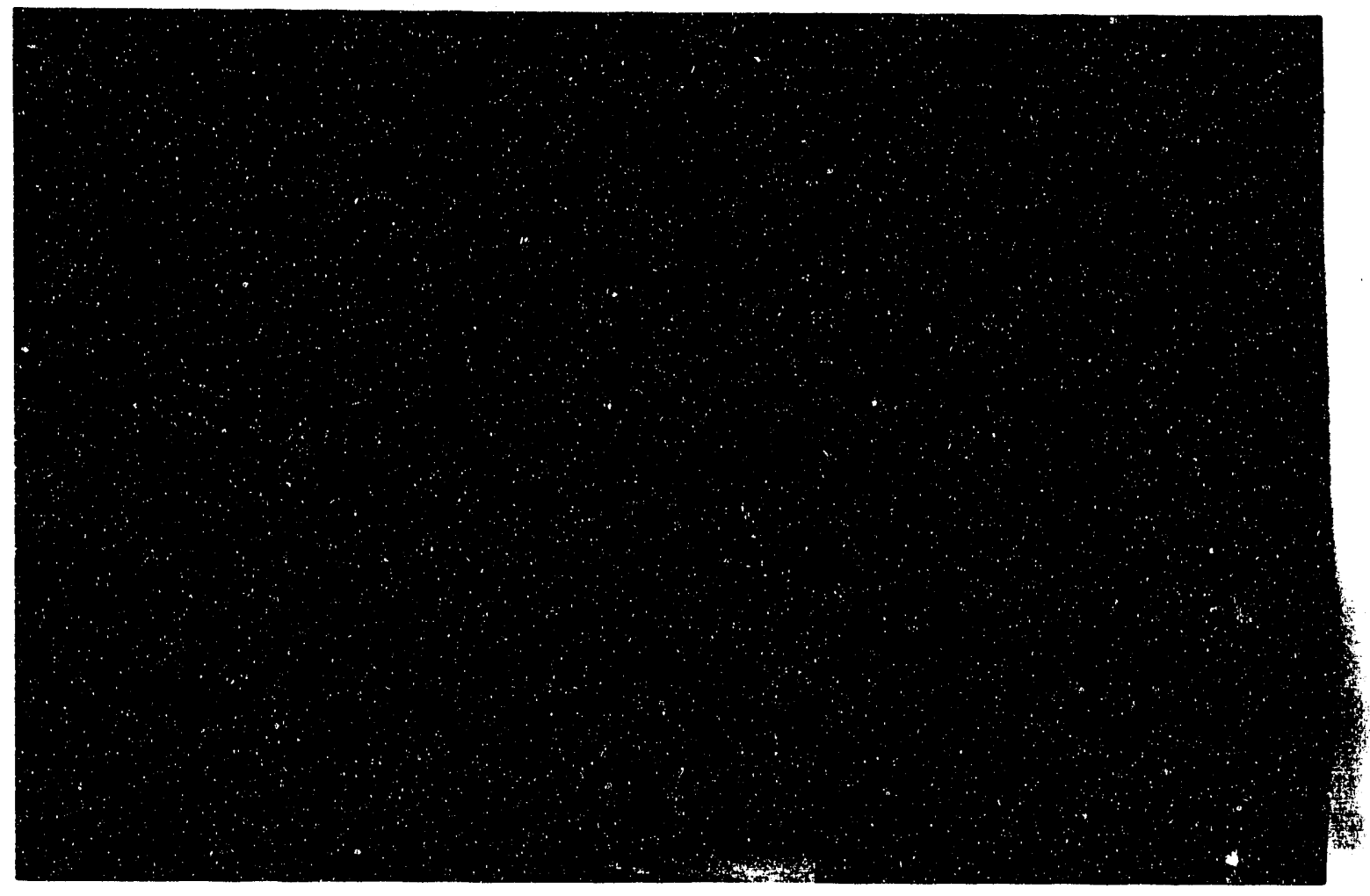

Figure 2.2: View Showing Individual Seismic Isolator and Jacks 


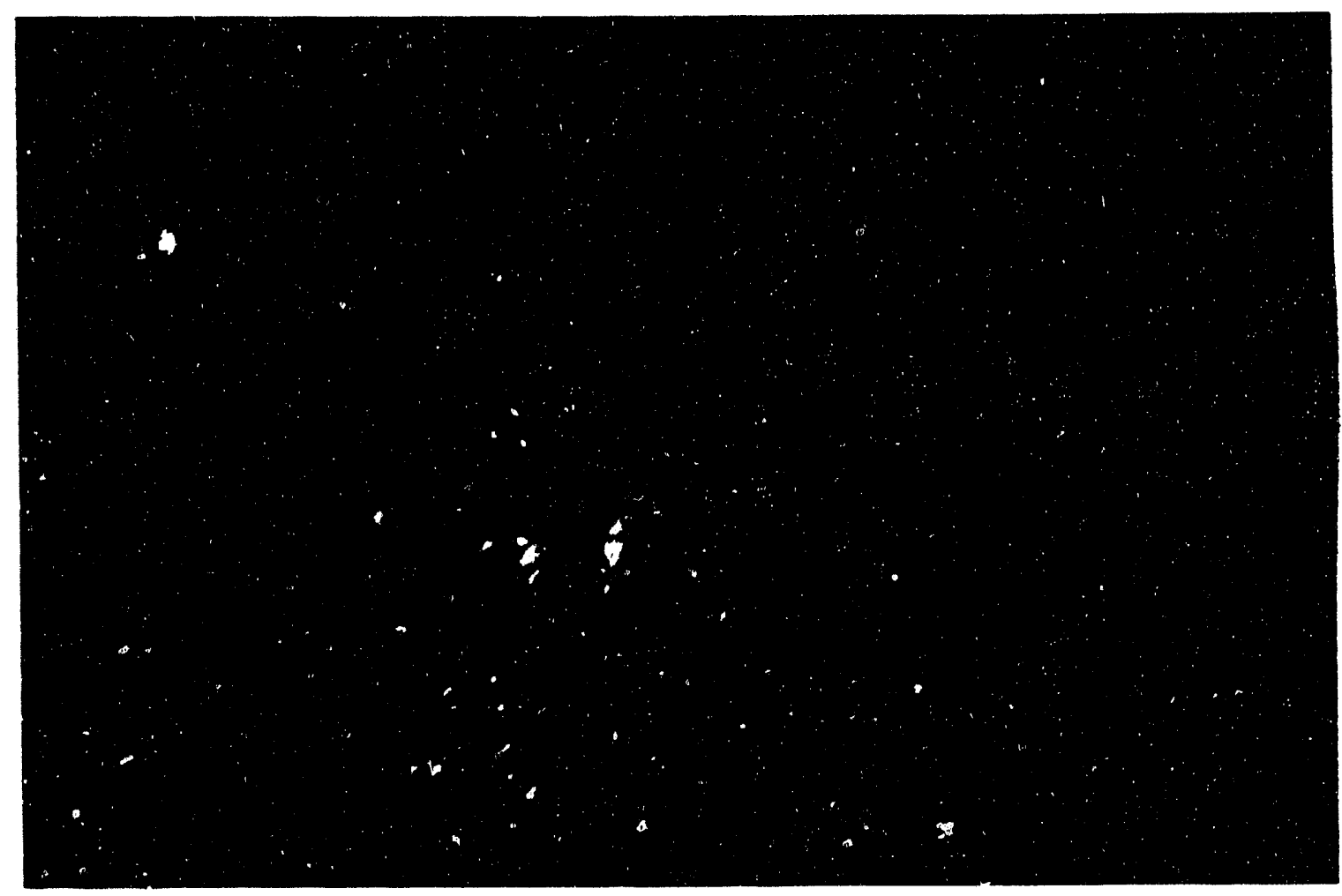

Figure 2.3: Second View Showing Individual Seis:nic Isolator and Jacks

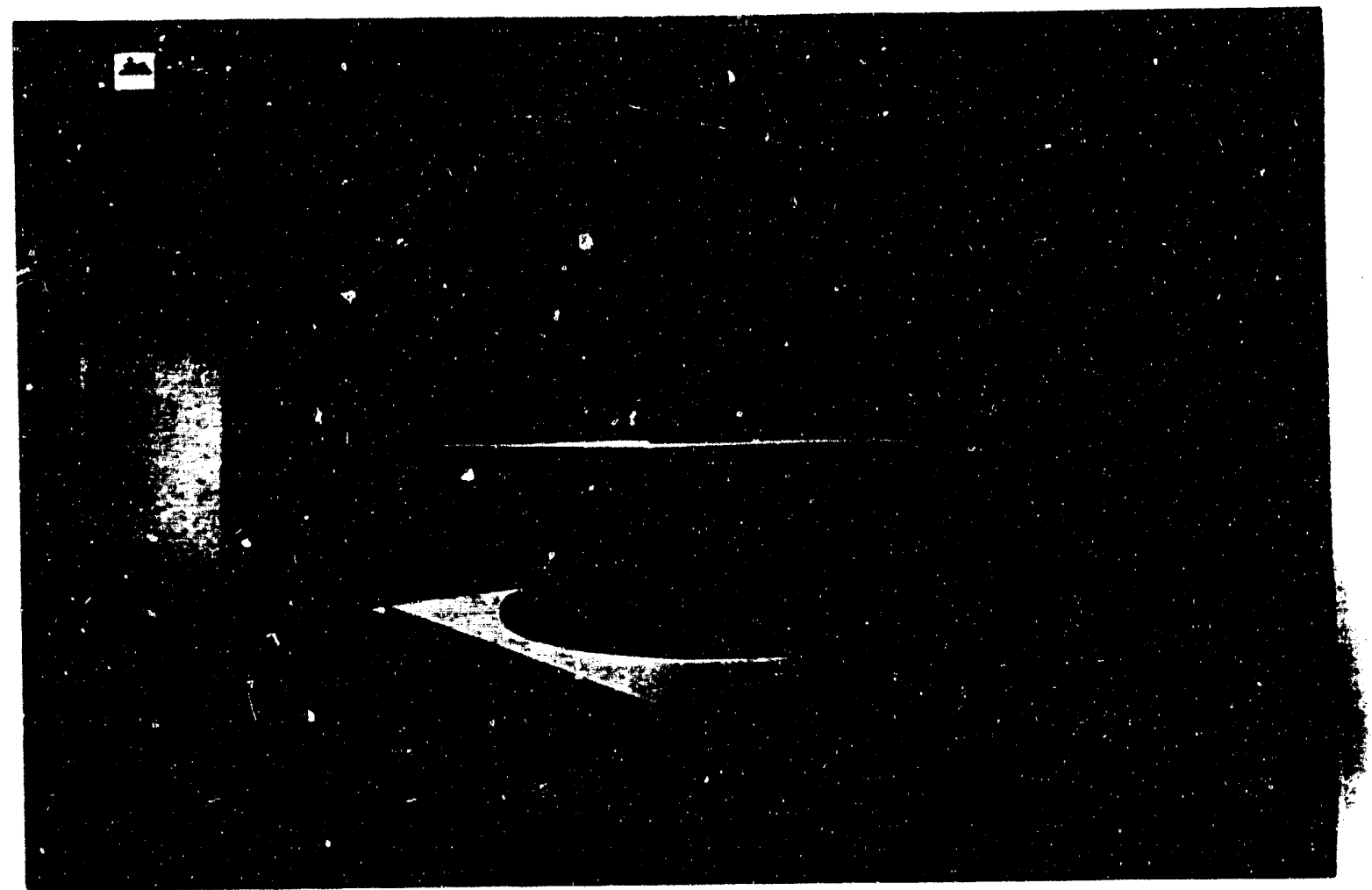

Figure 2.4: View Showing Removal of Bolts and Isolator Pads 
it is found that the CG function works easily and well with simple, 3D closed volumes. The most complicated volume that IGRIP can handle is a truncated cone with a truncated conical hole. Beyond these shapes, one must build the shapes (volumes) using a piece-together method (quilting in 3D) to form the desired volume. The use of the CD function can give unreliable results even though the 3D model has the correct appearance.

The 3D model of the "kidney bean" cross section intermediate heat exchanger is complete. It should be noted that none of the internal details of the heat exchanger are designed at this time. Due to the extensive effort required and the uncertainties of the results obtained, representing the heat exchanger as a series of tube sheets, tubes, shell parts, inlet and outlet piping may not be justified at this time. Figures 2.5 through 2.9 show this center of gravity work.

\subsubsection{Movement of Heat Exchanger}

The modeling of the removal process of an ALMR heat exchanger has been completed. This task was accomplished using IGRIP's abilities to group and move collections of parts and to use collision detection to guide the removal process. Figure 2.10 shows the IGRIP collision detection ability. Two observations can be made from this work: first, only the entities that are near to the object being moved should be included in the database for collision detection; and second, only the external shell of the part being moved should be included. These simplifications cut down on unnecessary parts and speed the movement and checking process. The details of collisions with parts such as the reactor dome and its openings will be completed when a more detailed design of these parts is available. A final report is being completed.

\subsubsection{Robotic System Modeling}

Although not specifically outlined in the 1992 Workscope, work has been completed on 3D IGRIP representations of three surveillance and cleanup robots and their supporting equipment. The designs were done by University of Florida and University of Tennessee team members using AutoCad design representations. These designs have been brought into IGRIP and build into 3D presentations, and are currently being incorporated into the ORNL IGRIP model of the ALMR for a video presentation. Figures 2.11 through 2.18 show these robots.

\subsection{Argonne West Fuel Processing Facility}

\subsubsection{Modeling of Entire Processing}

After reviewing the activities and facilities associated with the Argonne West Fuel Processing Facility, it became clear that modeling of the entire facility was not of high priority. Efforts thus shifted to modeling a small part of the hot cell facility associated with the placement of a vacuum furnace. 
int

$\theta$

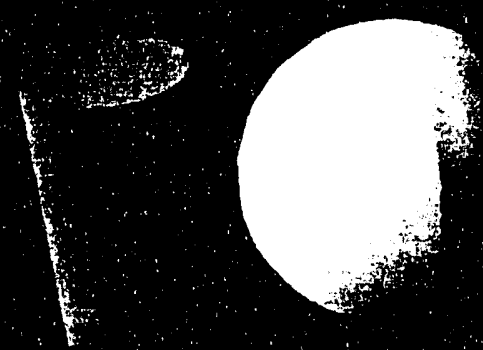

-

H.

).

Figure 2.5: Basic 3D Modeling Objects

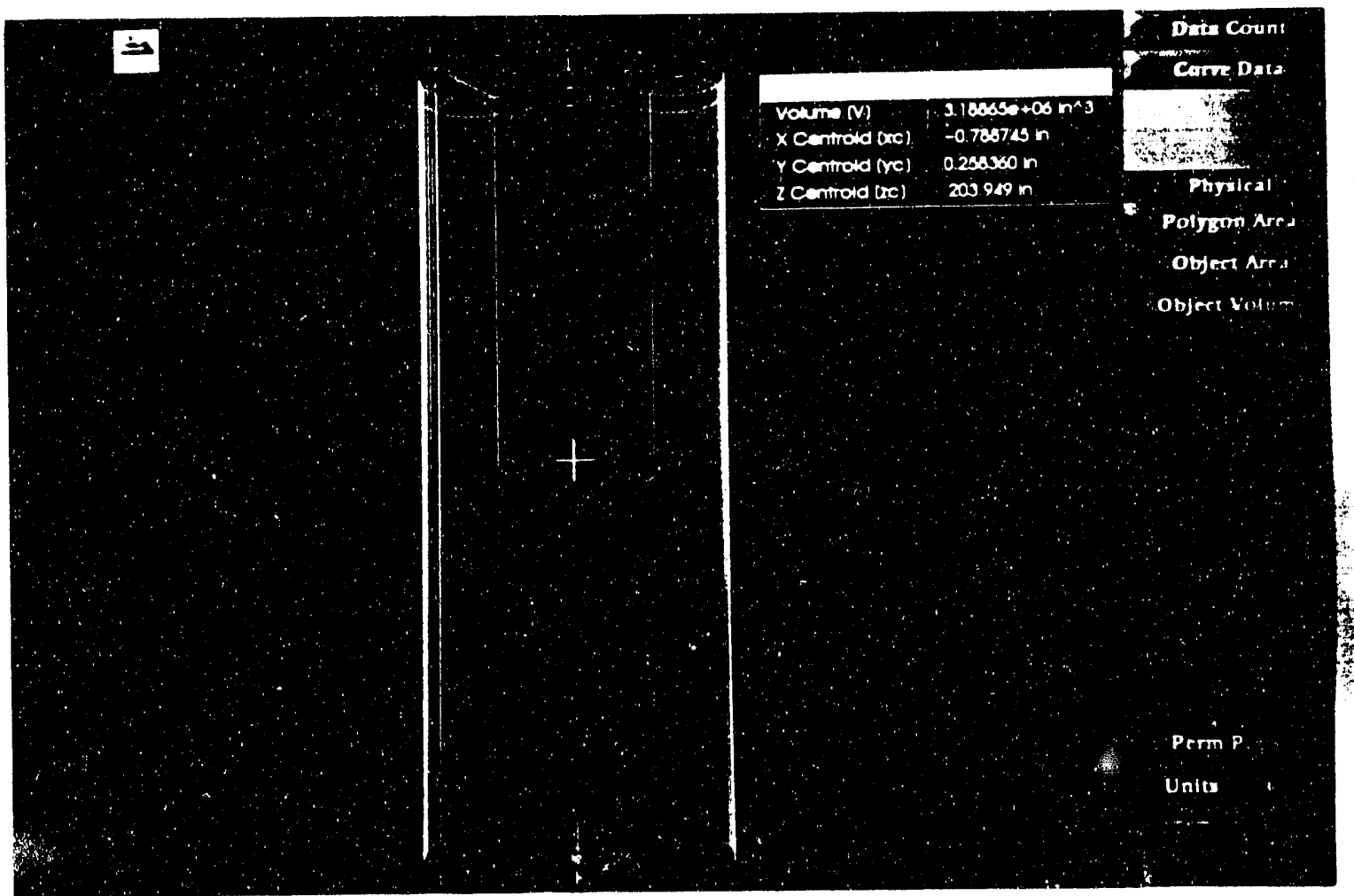

Figure 2.6: Exterior of Intermediate Heat Exchanger 


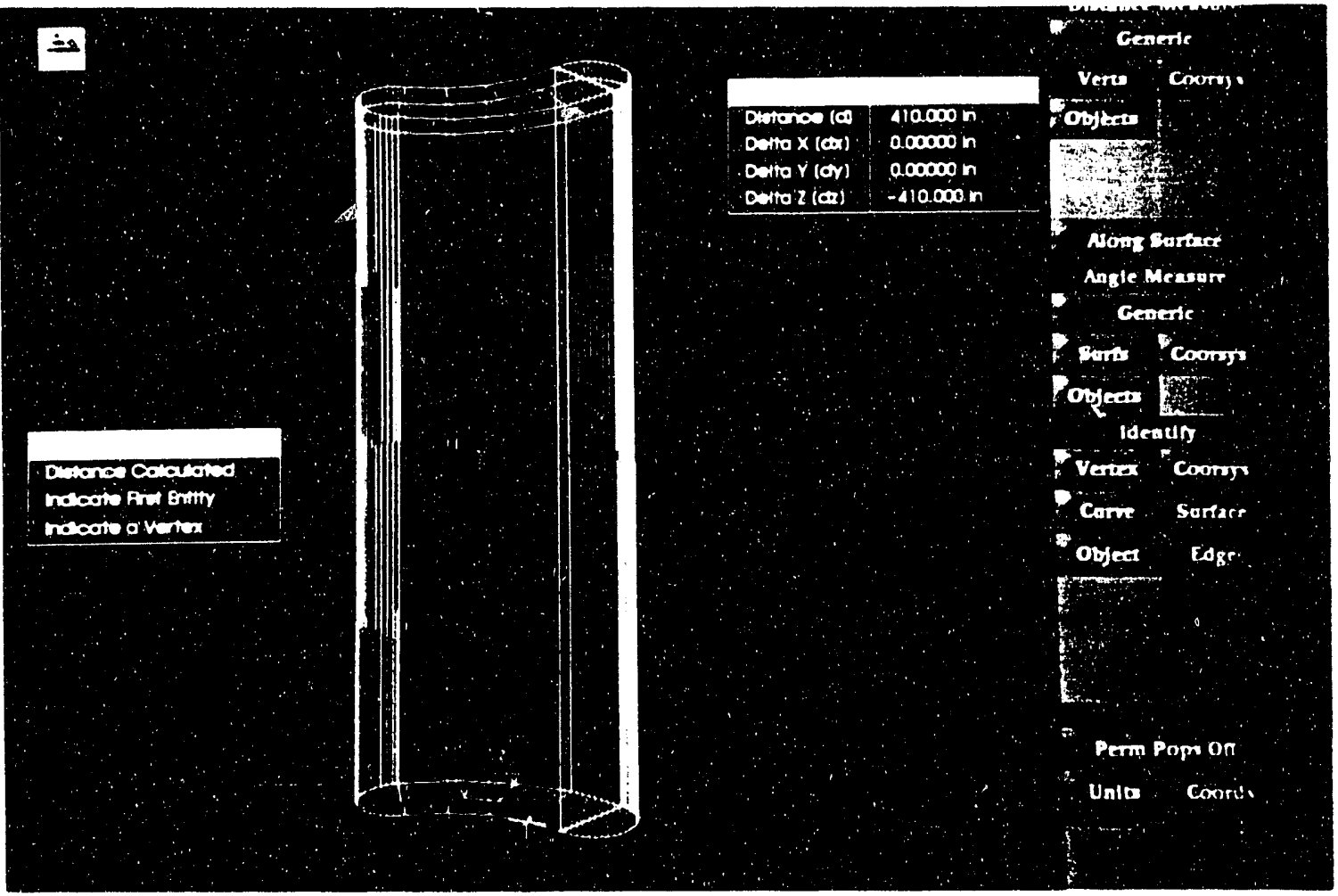

Figure 2.7: Wire Frame Representation of The Heat Exchanger

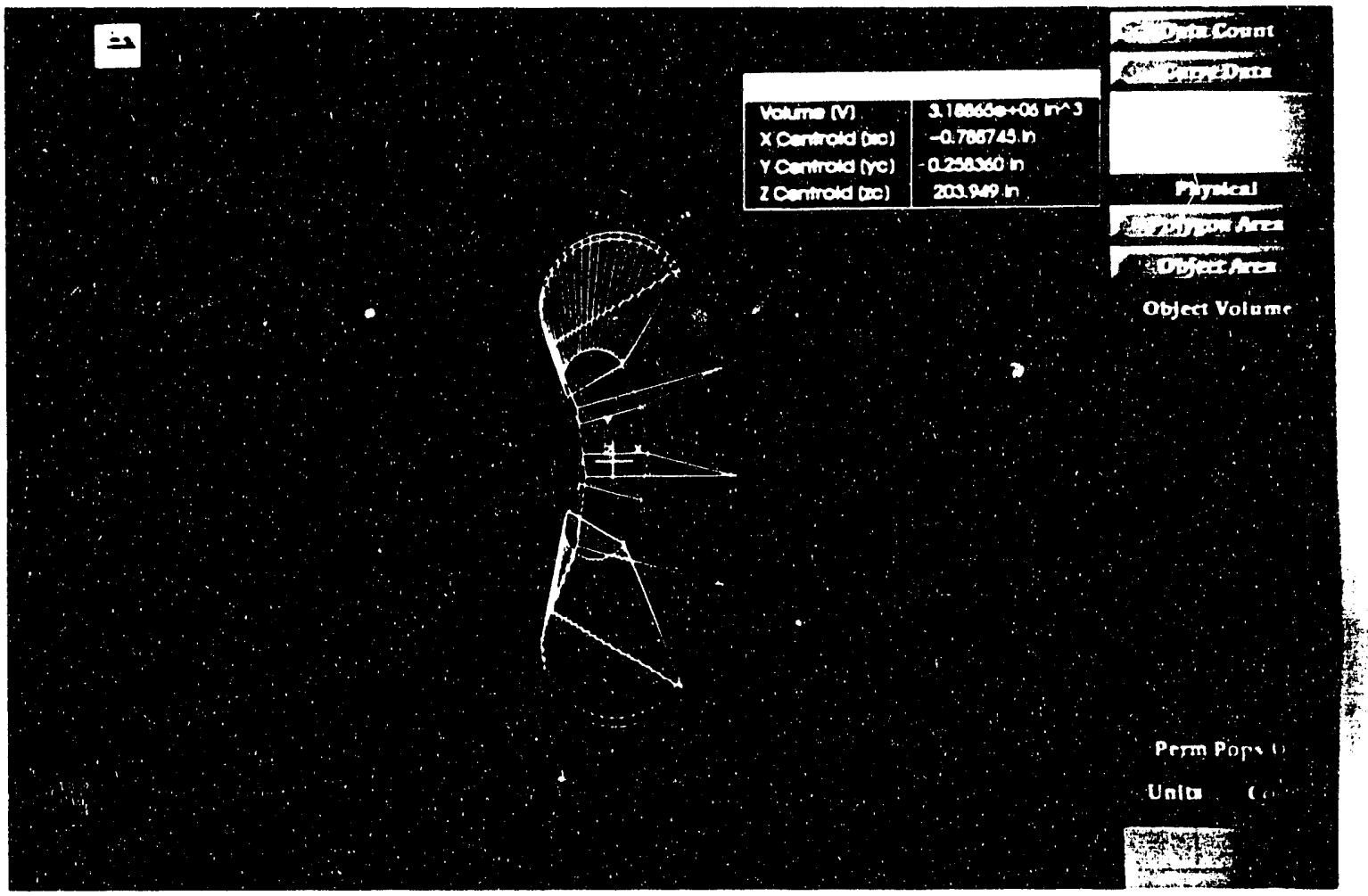

Figure 2.8: Front View Showing Center of Gravity 


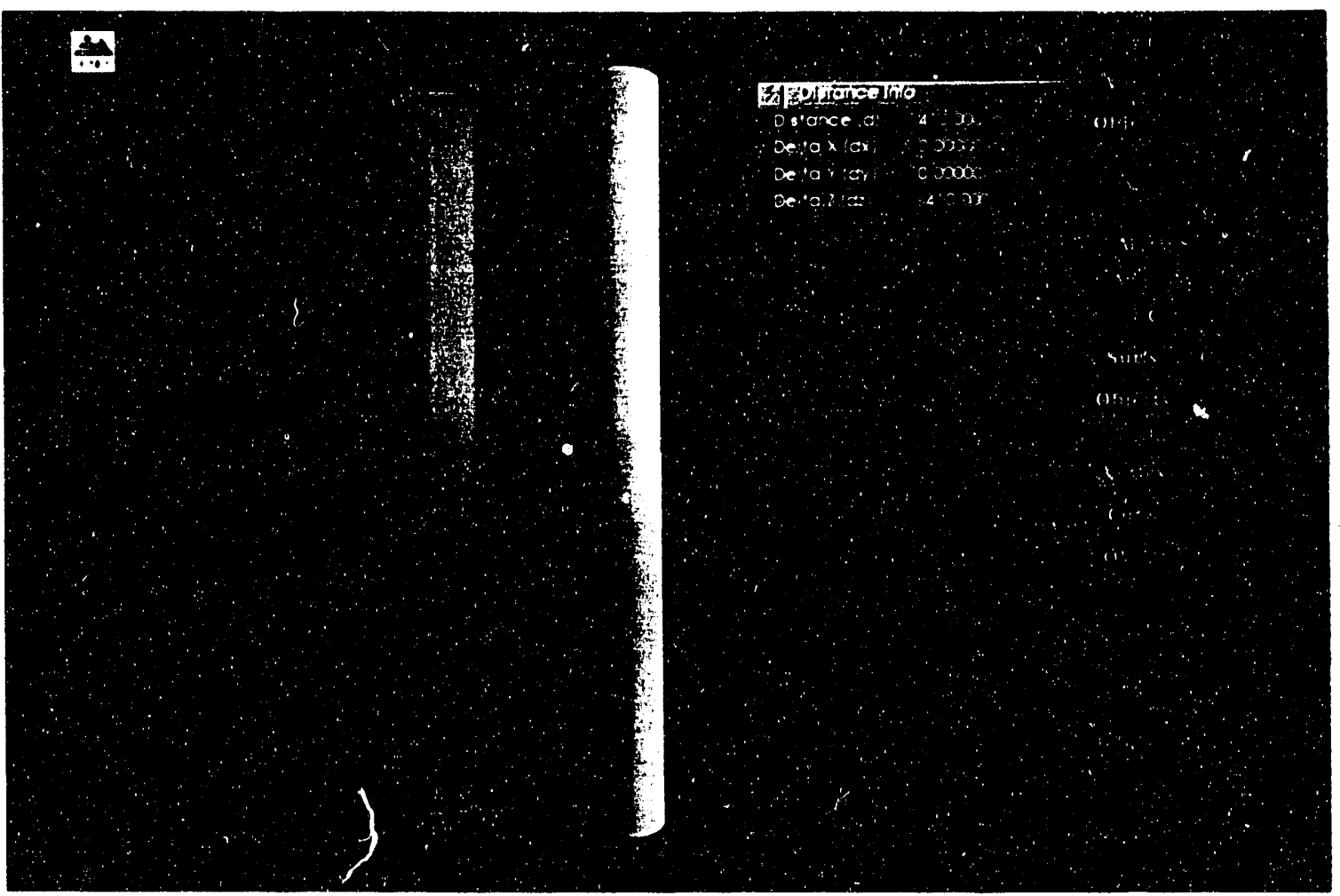

Figure 2.9: Top View Showing Center of Gravity

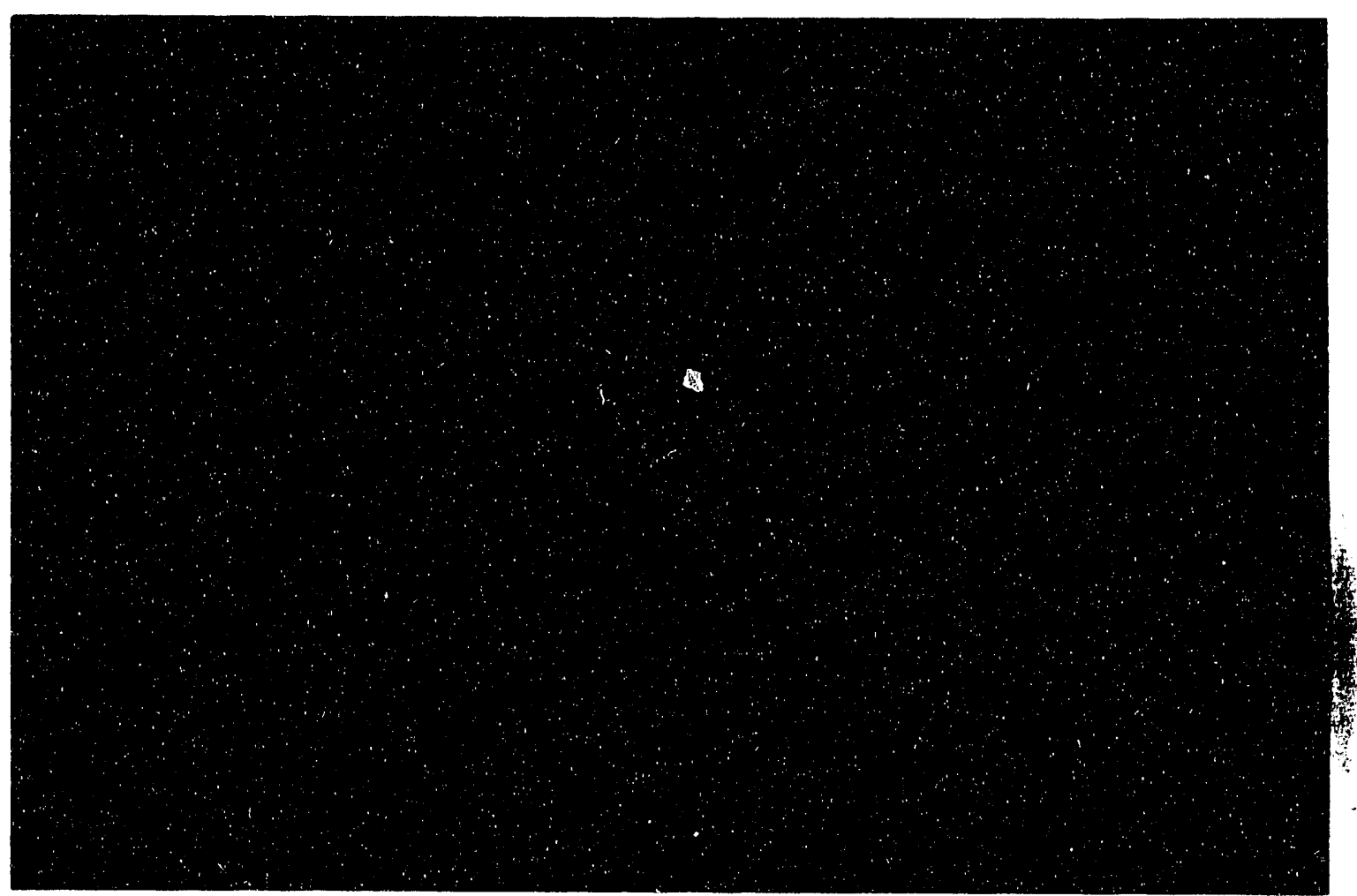

Figure 2.i0: Coilision Detection, while ivioving Heat Exchanger 


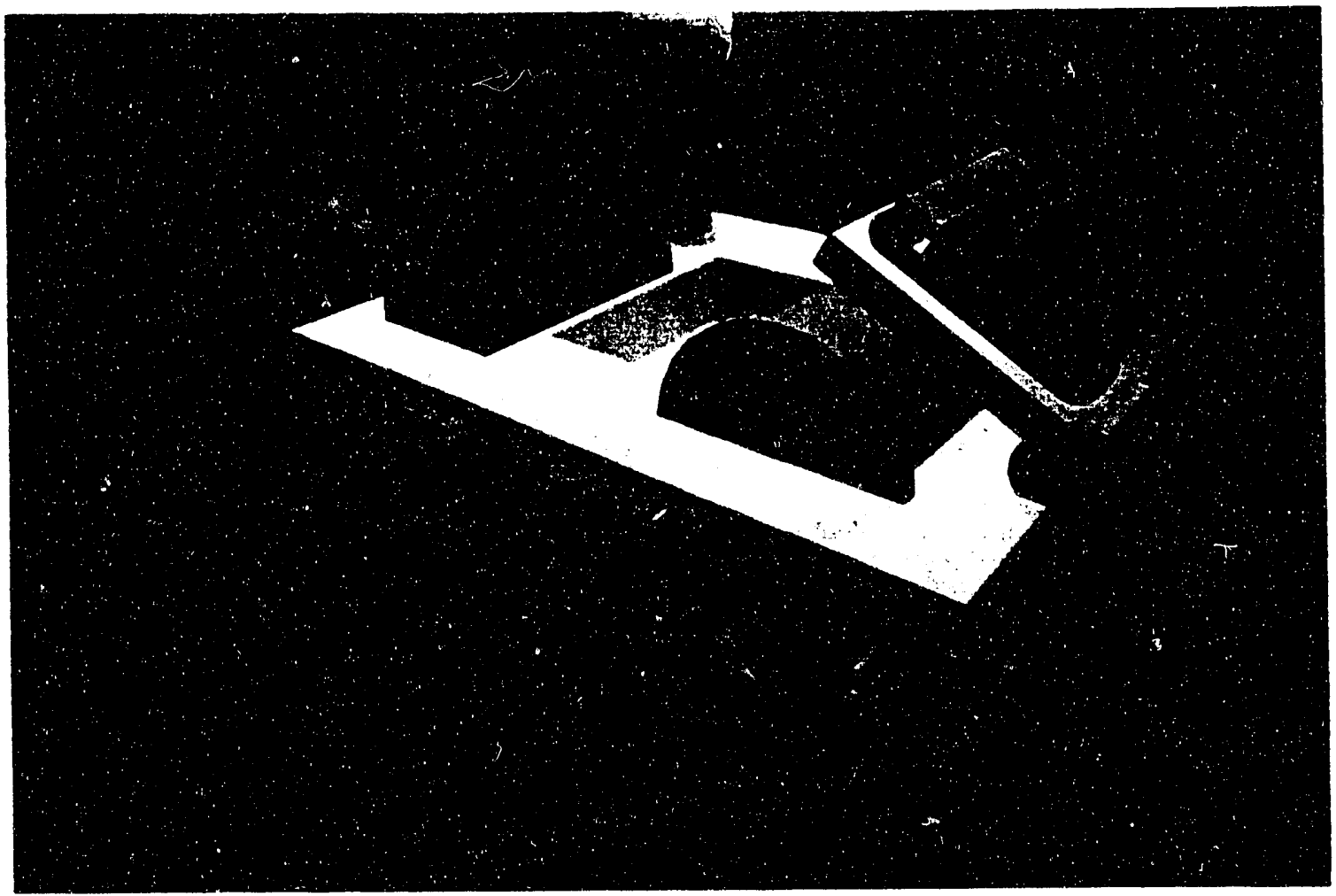

Figure 2.11: View of Side of Plenum Robot

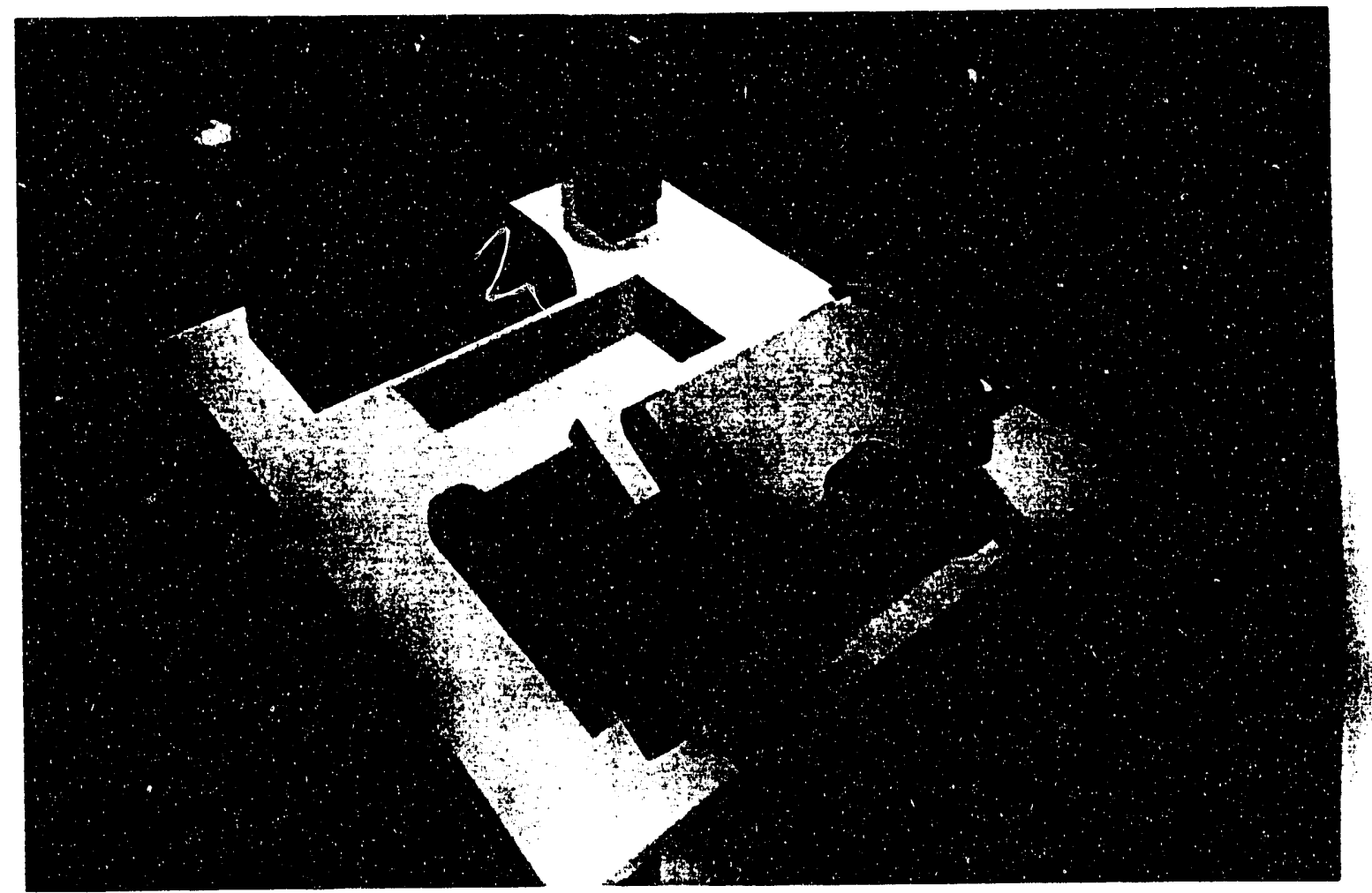

Figure 2.12: Fronit Vicw Showing Plenum Robot and Daughter Robot Package 


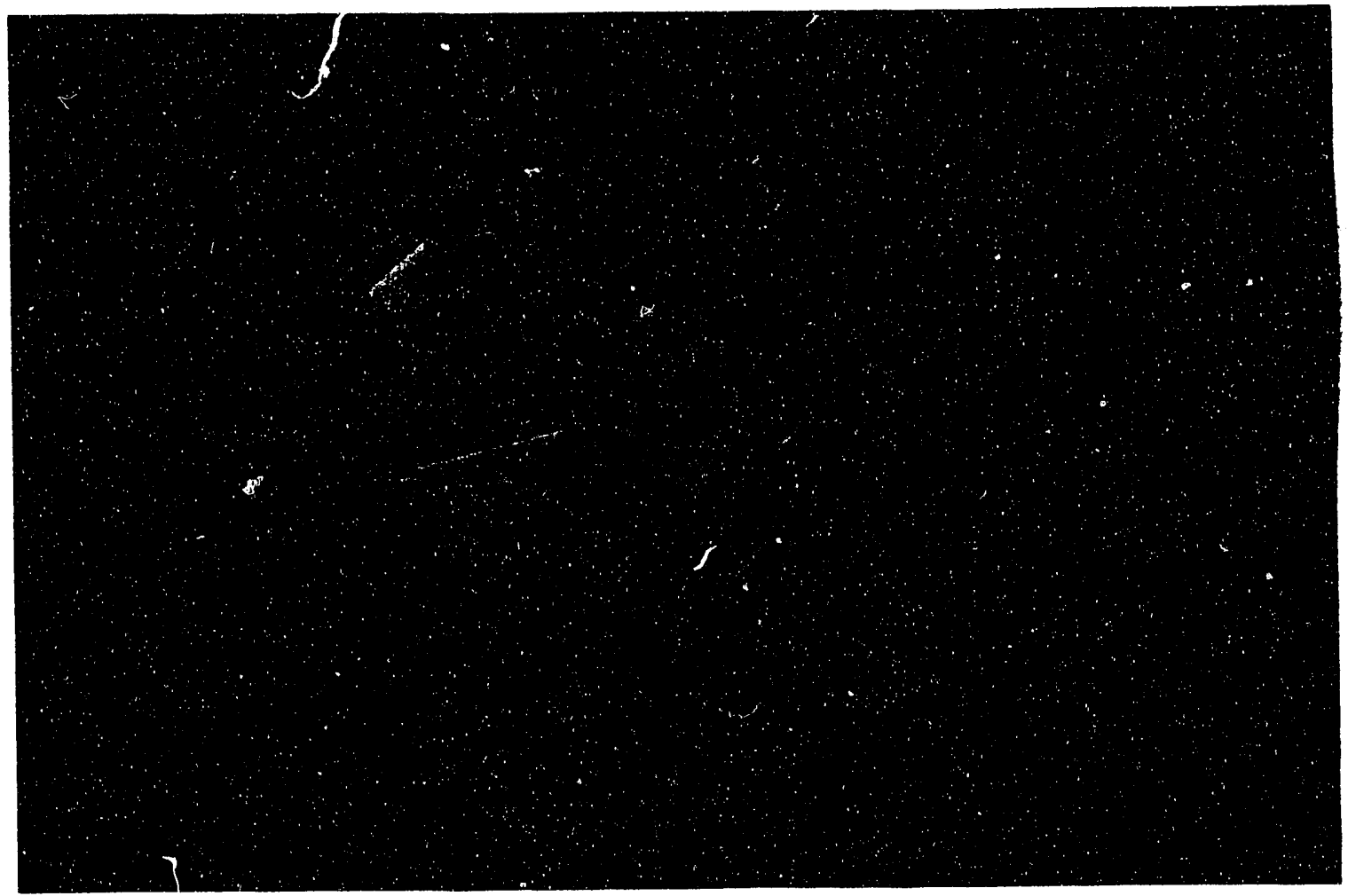

Figure 2.13: Rear View Showing Plenum Robot Sensor Package

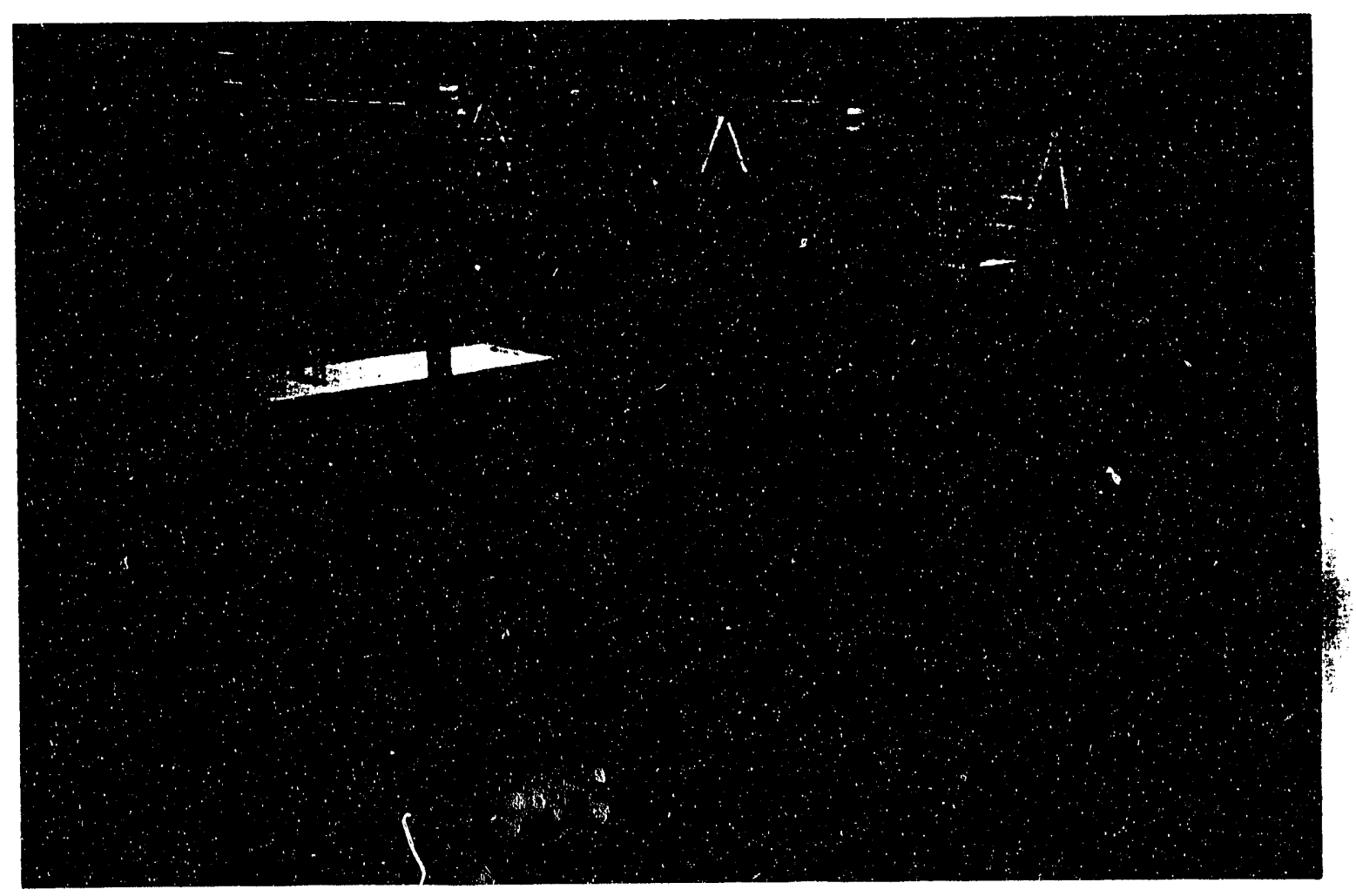

Figure 2.14: View of Stack Robot Delivery System 


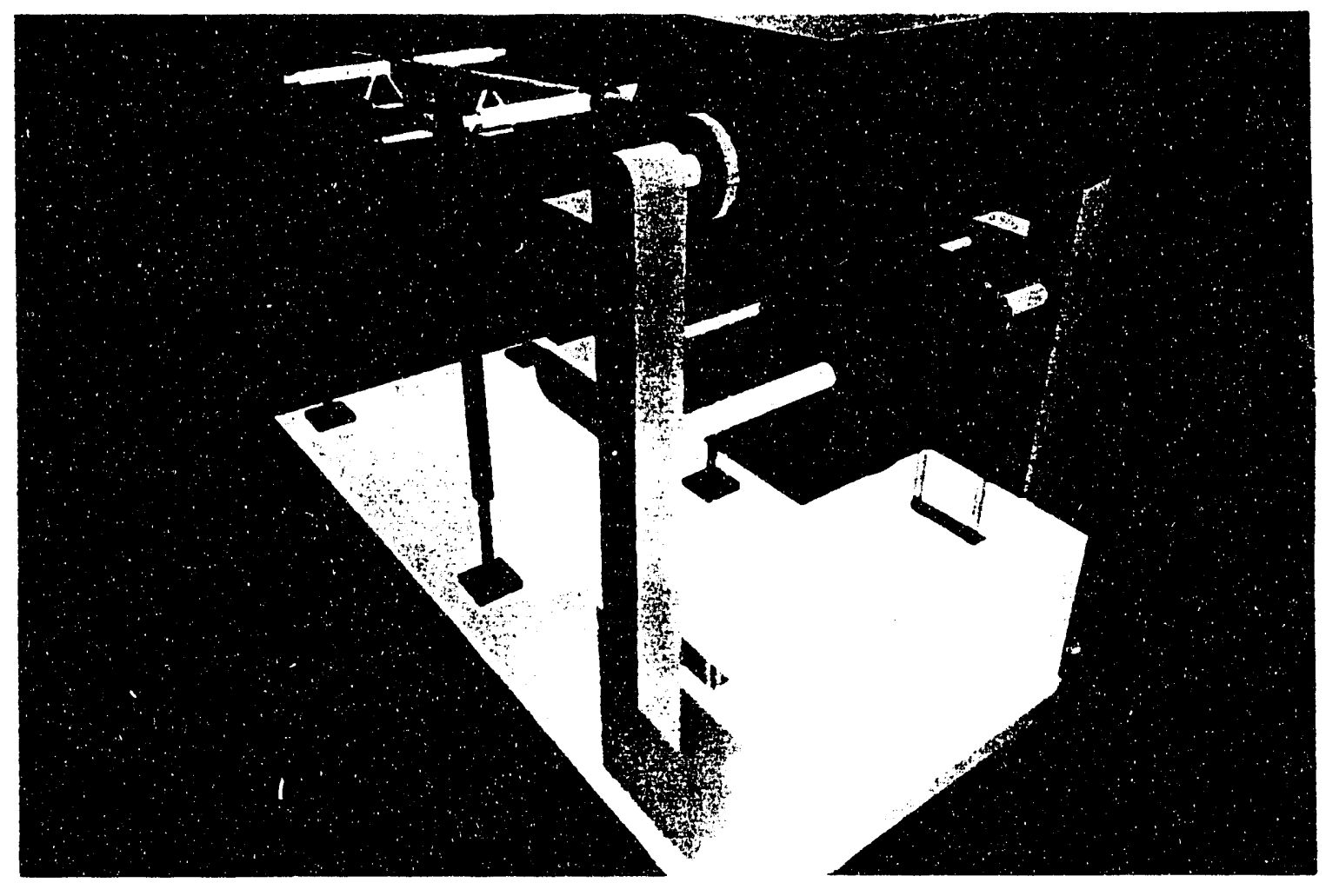

Figure 2.15: Rear View of Stack Robot Delivery System 


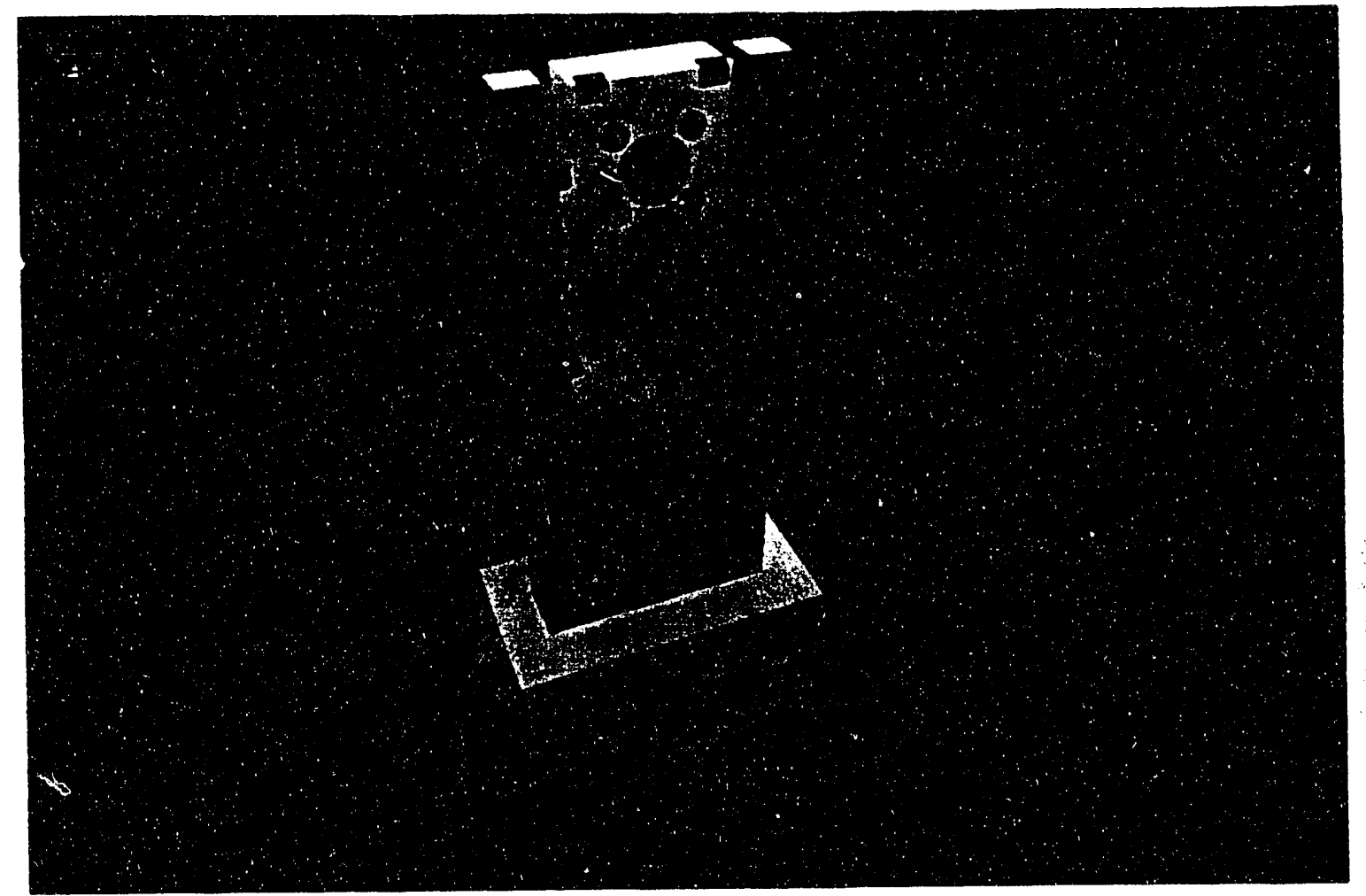

Figure 2.16: Front View of Reactor Vessel Inspection Robot and Insertion Device (Below Robot)

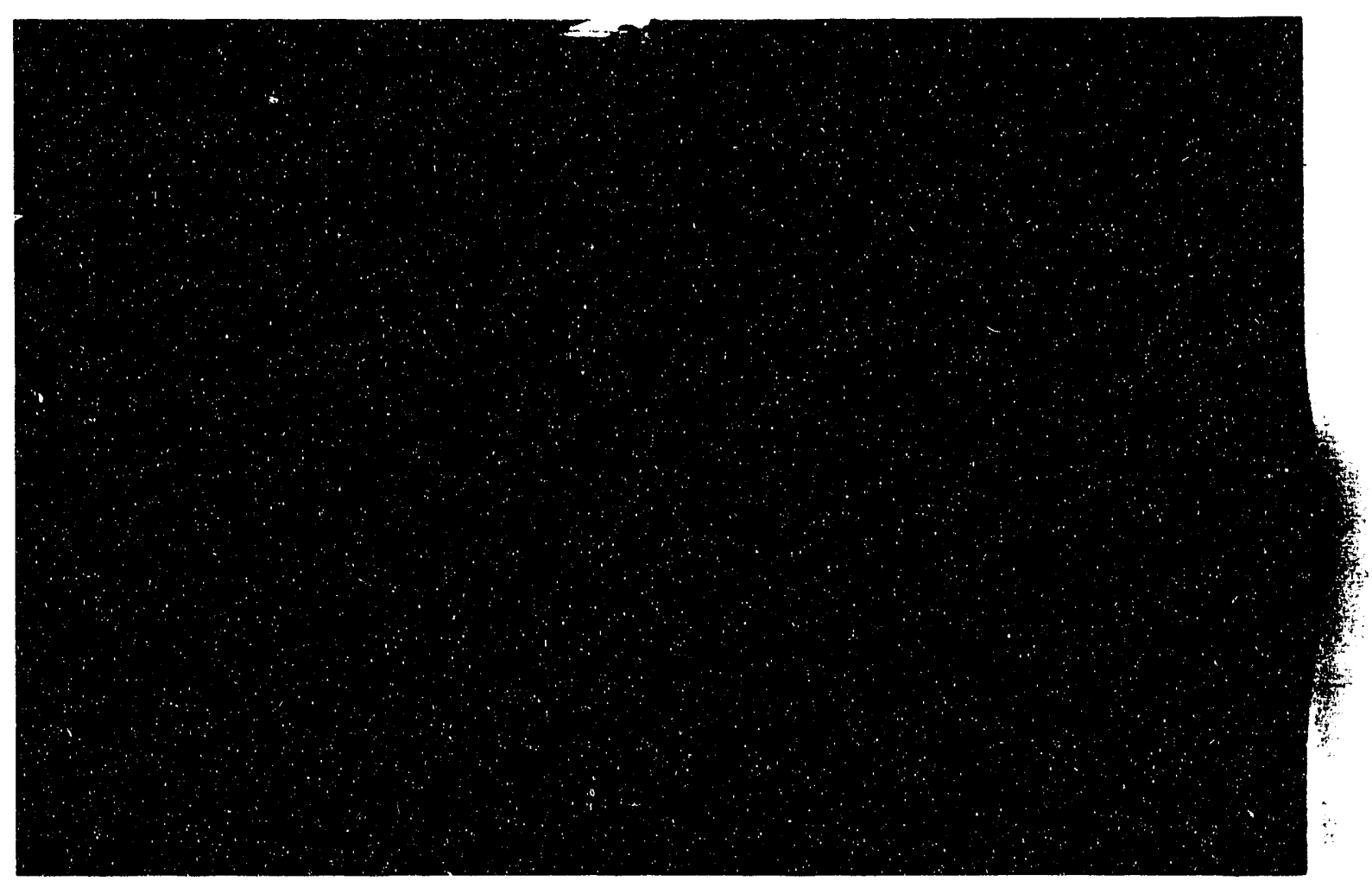

Figure 2.17: Side View of RV Inspection Robot and Insertion Device 



\subsubsection{Fuel Furnace}

The team is in the process of transferring the vacuum furnace model from the IGRIP system into the PDMS design system. This process entails securing additional technical design details available from Argonne West in the form of AutoCad data files. To assist in this data conversion, an additional 486DX personal computer with the AutoCad version 12 has been obtained. Figures 2.19 through 2.23 show the IGRIP representations of the fuel furnace. 


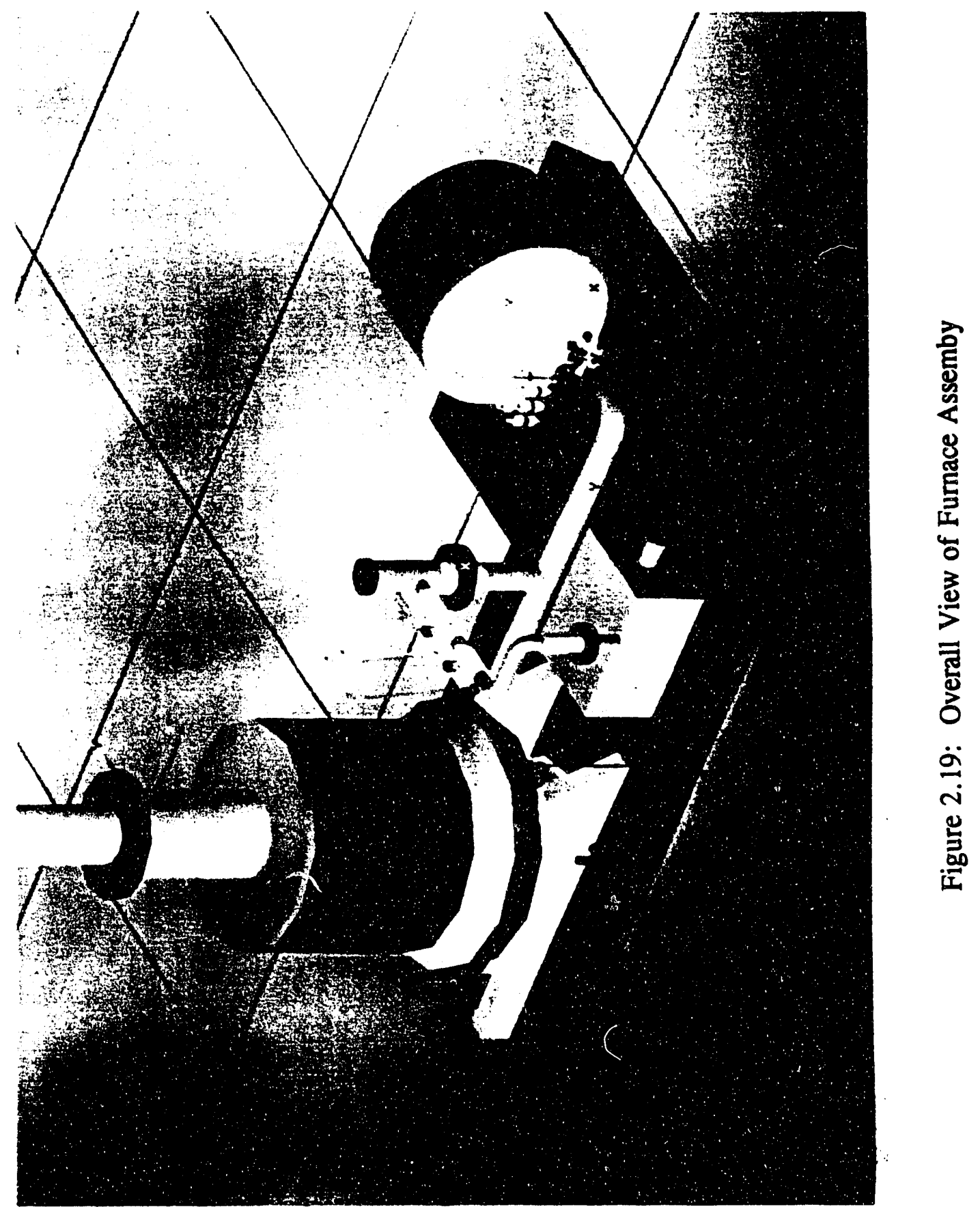




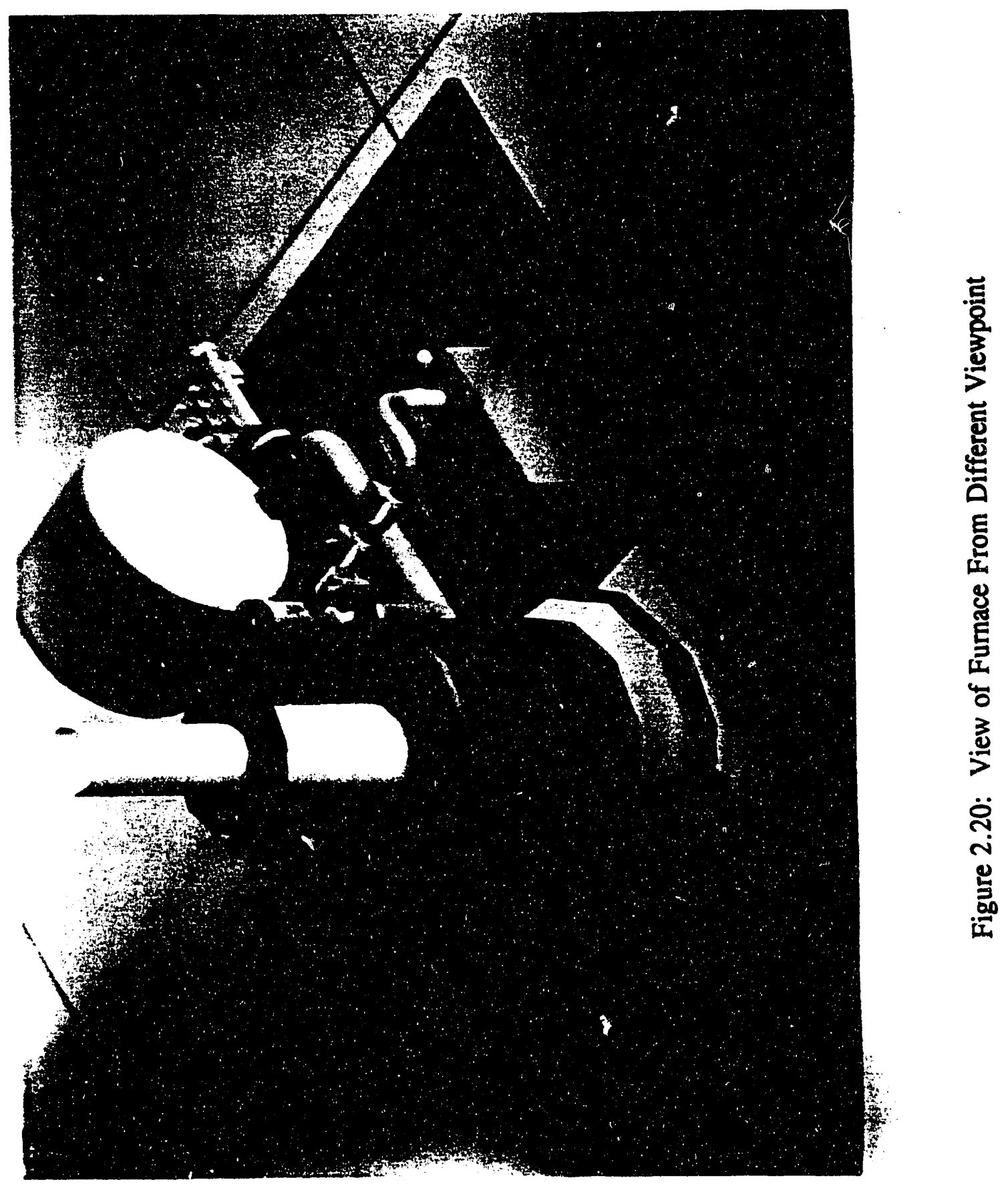




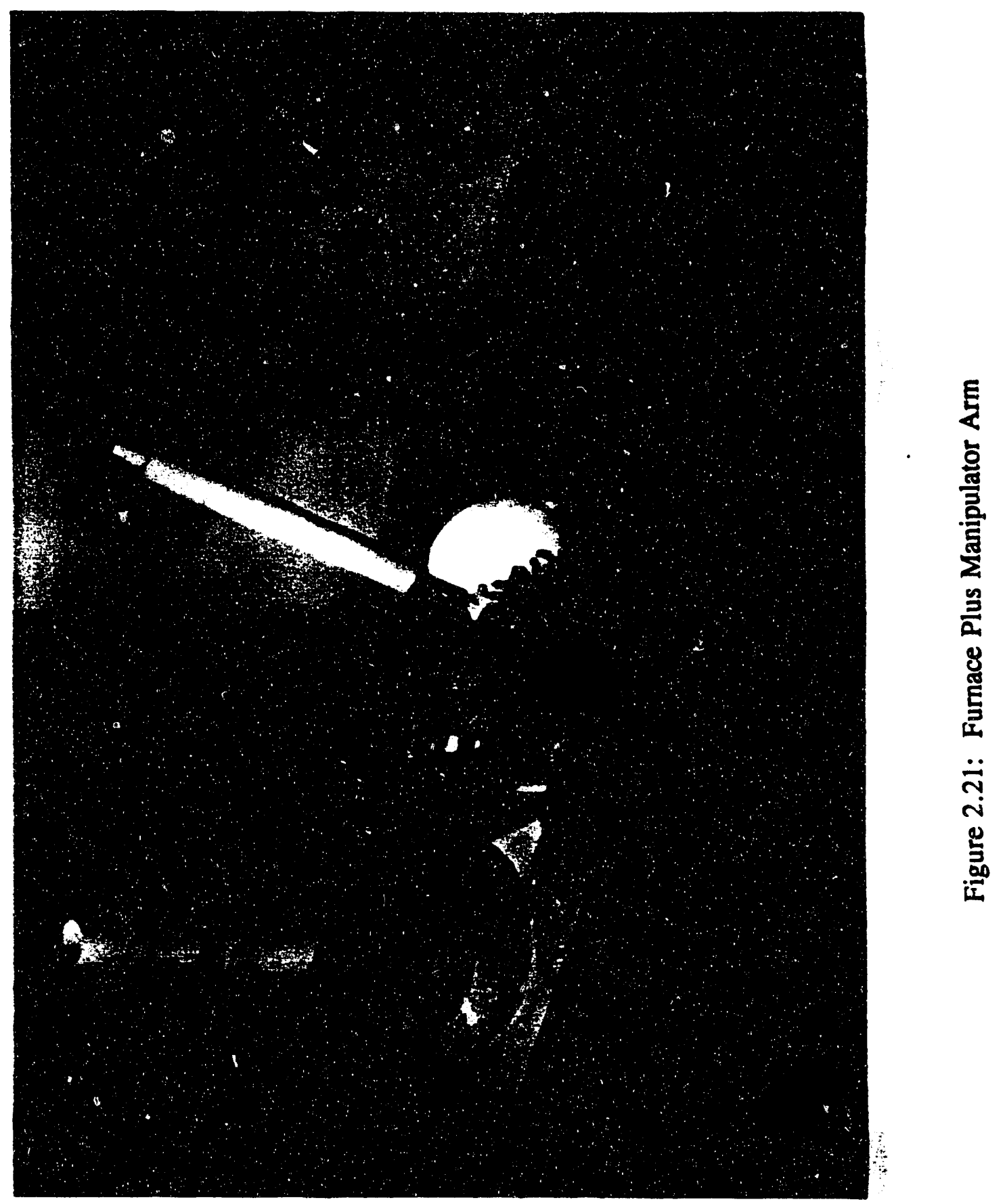




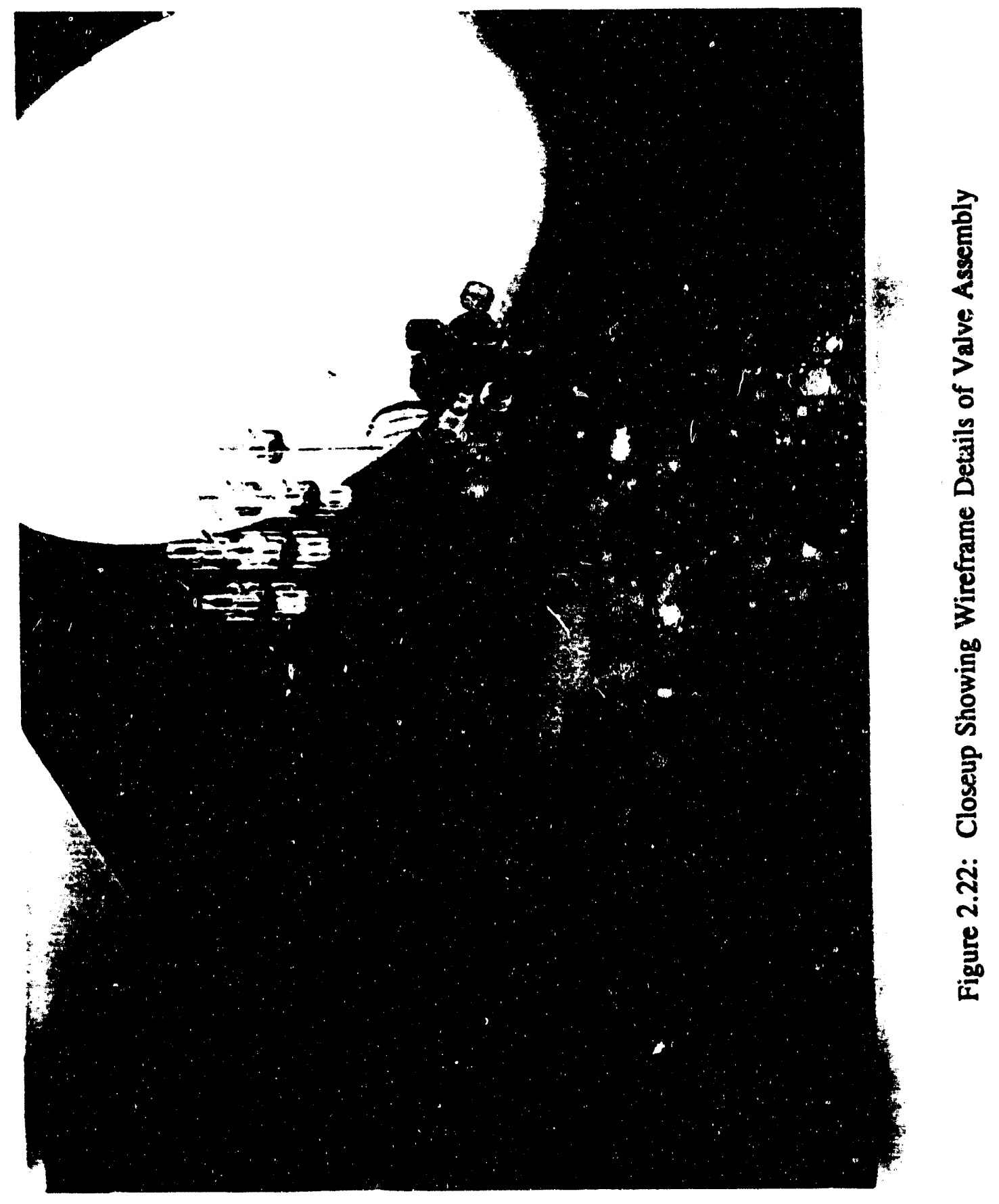




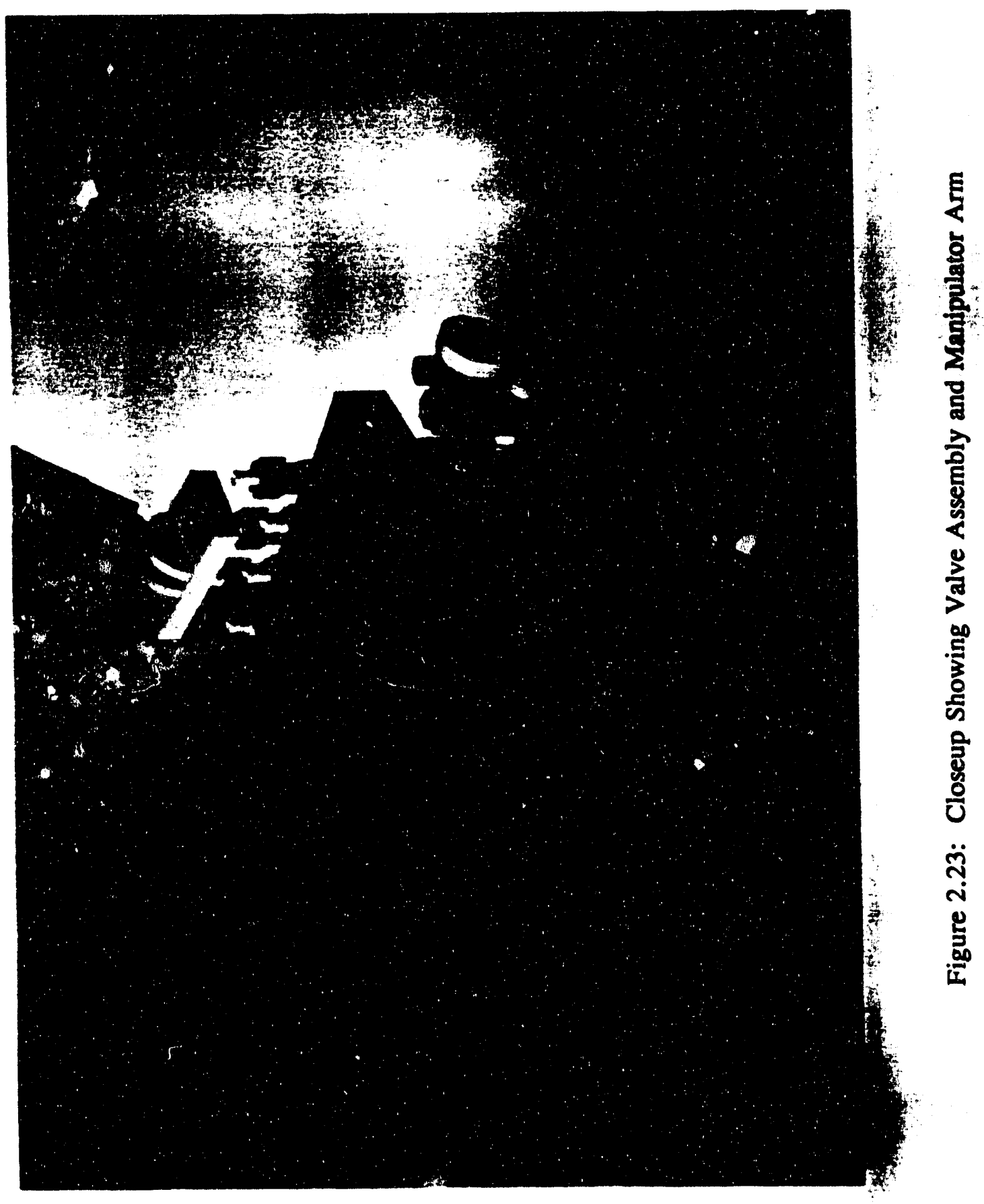

$4+40+4$ $\because-3$

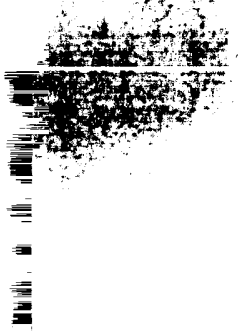




\subsection{Man-Machine Interface}

\subsection{Development of New Three Dimensional Graphics Visualization Techniques}

\subsubsection{Objective}

The overall objective of this effort is to enable the user to see a "real" three dimensional object, apparently suspended in mid-air. Multiple viewing angles are permitted to view the object from any direction by simply moving around the virtual object.

This three dimensional display unit would be very useful as a visualization tool for enhanced man-machine interface, specifically for applications such as path planning or reaching for objects in space.

\subsubsection{Introduction}

The term three-dimensional computer graphics often refers to the images that are created based on a 3D coordinate system and then displayed as a parallel or perspective projection onto a flat CRT screen.

Research has shown that users perform better at reaching for and identifying items in space when they look at a three dimensional scene. Three dimensional scenes can be generated in a multitude of ways. The approach used most often relies on the fact that we see two slightly different pictures with each eye, that are fused in the brain to one three-dimensional picture.

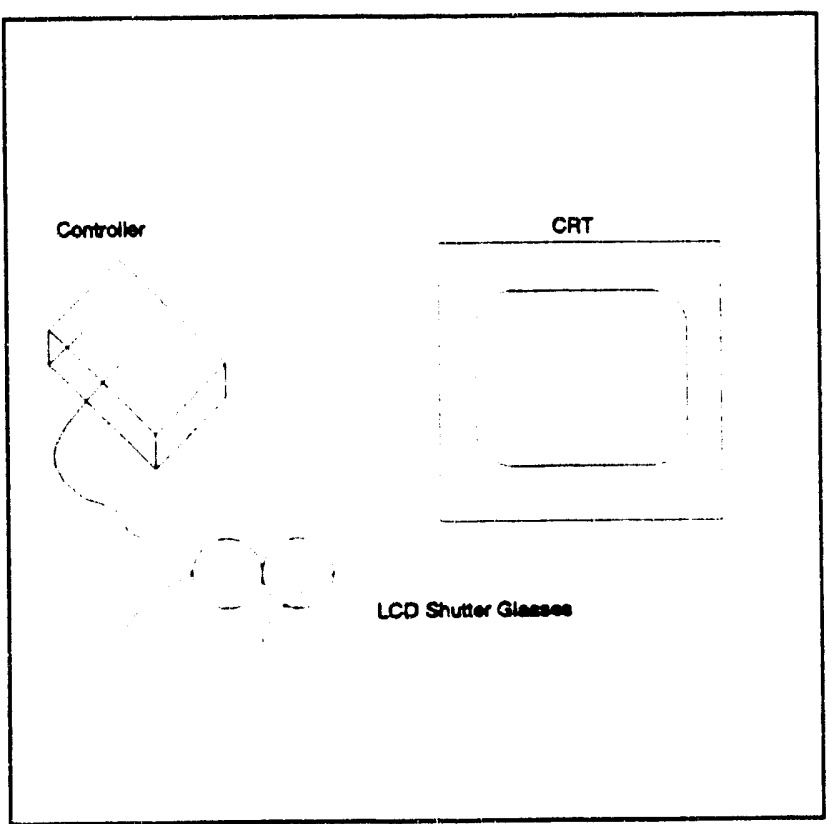

Figure 3.1: Stereo Animation

When an observer looks at 3D scenes, the horizontal separation of the eyes means the image formed at the back of each eye for any particular point in the scene differ in their horizontal position. This effect is referred to as binocular disparity or binocular parallax. Stereopsis involves the brain's merging of these two slightly different 2D images into a single $3 \mathrm{D}$ image.

In a stereoscopic display system we generate two views of a scene and display them so that only the left eye sees the lefteye-view and only the right eye sees the right-eye-view. This is often accomplished by displaying two separate images on a CRT terminal, alternating one (left) after the other (right), while at the same time opening and closing the appropriate shutter in a set of LCD shutter glasses (see Fig. 3.1). As a result, the observer sees an image that appears truly 3D. The disadvantage to this method is that the viewer is unable to 'move around' the scene, 
and that multiple viewers all see the same image, irrespectable of their true position relative to the object being displayed.

Several ways were investigated as to how to create an actual three dimensional image, not just an illusion. Ray tracing was used extensively to test these ideas.

\subsubsection{Lasers}

Initially, the feasibility of a three dimensional 'pixel' was investigated. For this, it was necessary to illuminate a certain area in space. The first technique for accomplishing this involved several lasers and mirrors. Here an image would have to be drawn in space, similar to what can often be: seen at laser light shows. The biggest problem encountered was that the beams from these iasers would somehow have to illuminate only one unique position in space. This seemed close to impossible to accomplish, since the light from these lasers will generally travel nearly infinitely.

\subsubsection{Plexiglass Voxels}

The second method involved creating a three dimensional array of points, i.e. a mesh of $100 \times 100 \times 100$ points. After some deliberation, the idea to use a fiber optic mesh was discarded.

Instead, the use of an array of plexiglass volume elements ("voxels") was investigated. The idea for this case was that we somehow need to illuminate a certain area in space. If we could take a small volume in space and illuminate it in a certain color and intensity, then take many of these 'small' voxels and stack them in a larger grid, i.e. in a display-cube of $100 \times 100$ $x 100$ of these smaller voxels, we would be able to display any image inside of this display-cube (see Fig. 3.2). If these unit voxels were small enough, the image inside the display cube would become somewhat continuous, similar to the effect of using large blocks or small pixels to draw a curved line on a video display terminal; when using larger blocks, the curve looks like a series of steps, whereas using smaller pixels the curve becomes continuous.

For illumination purposes it was planned to use a specially designed lighted LCD display, where one voxel would be either on or off, depending on the underlying LCD crystal.

After running numerous simulations (see figures 3.3 to 3.5 ) with different material properties and various shapes of the plexiglass voxels, this idea was abandoned as extremely difficult to implement using today's technology. 


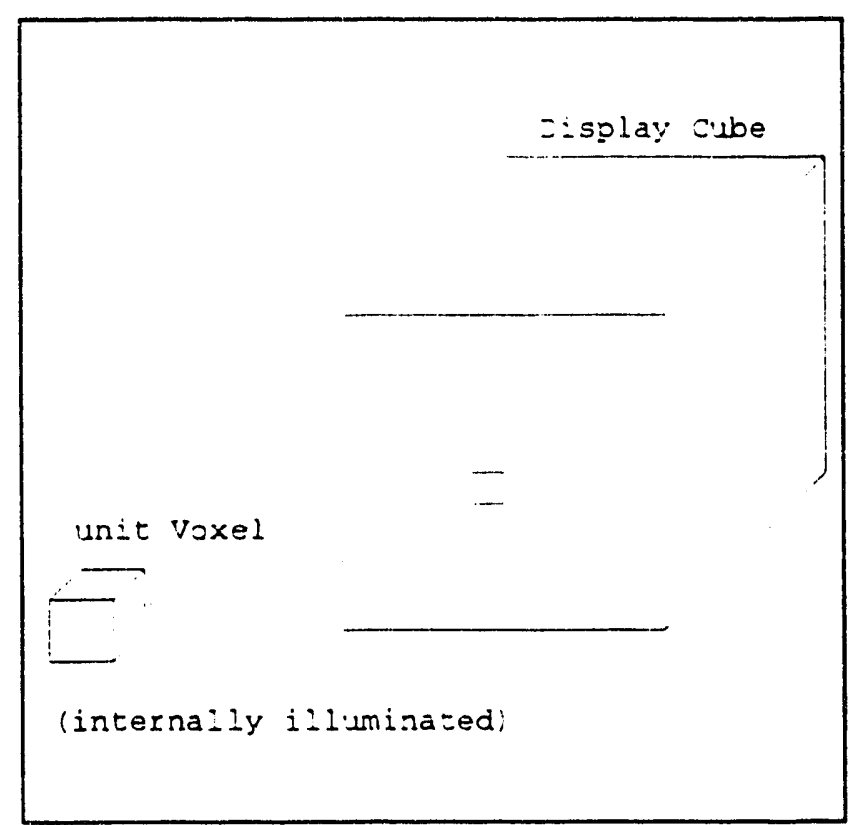

Figure 3.2: 3D Voxels

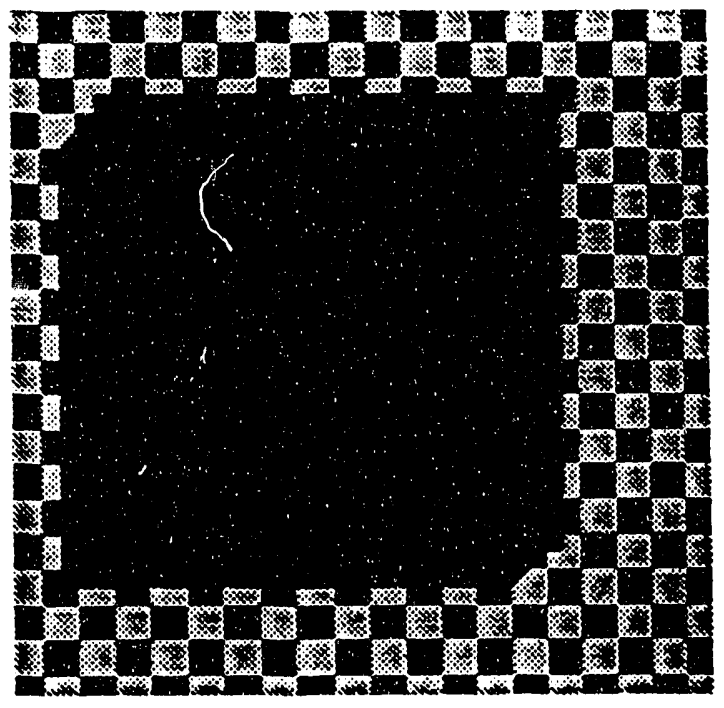

Figure 3.3: Grid of $12 \times 12$ Unit Cubes

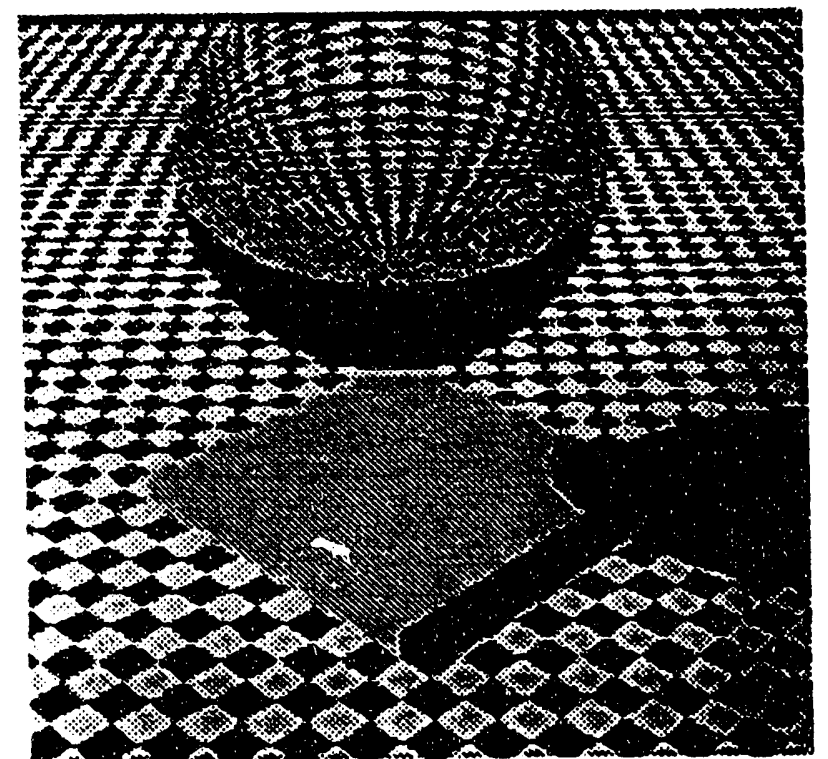

Figure 3.4: Plexiglass Sphere

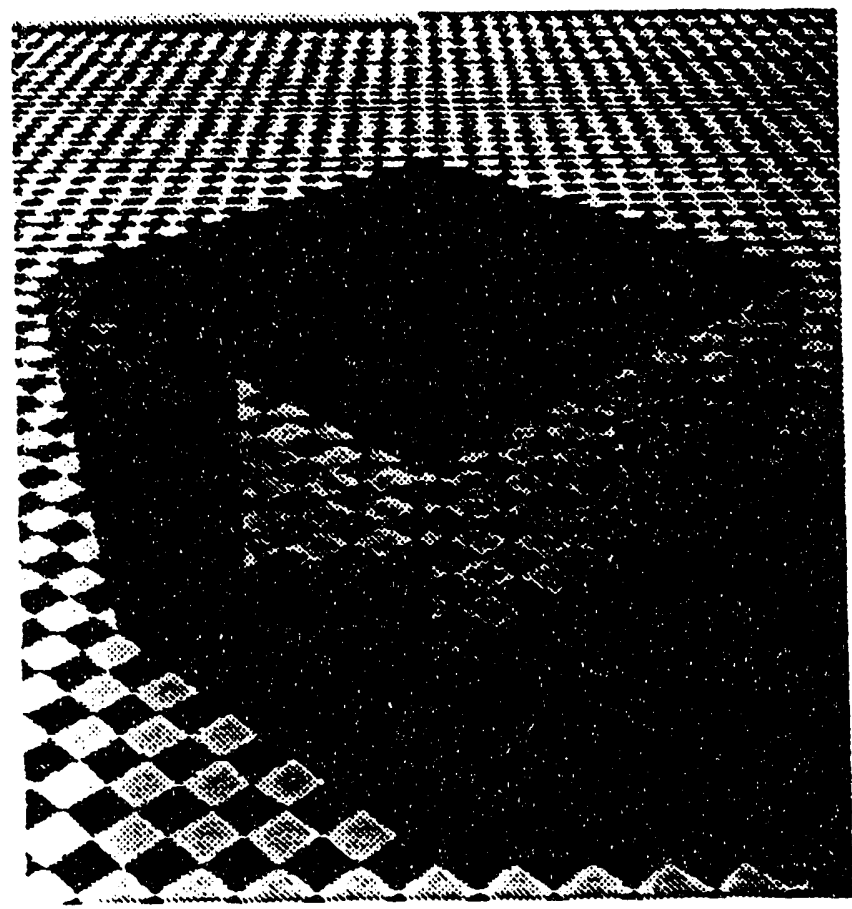

Figure 3.5: L nit Cube 


\subsubsection{Display using Concave Mirrors}

The concept currently under investigation is very different from the concepts mentioned above. This idea relies very heavily on optics. In this case a real ${ }^{1}$ object is displayed above a pair of two facing parabolic mirrors of the same focal length (see Fig. 3.6). The object is displayed through a small hole in the top mirror.

A three dimensional image is generated by the computer. Instead of being displayed on the monitor as usual, the image is further enhanced for the subsequent steps. Once this enhanced image has been created, it is projected from a video projector through a set of focussing lenses, onto the upper concave mirror. From there it is mirrored onto a facing (lower) concave mirror with the same focal length as the first. Then this image is projected out through an opening in the first (upper) mirror. The image that is displayed will be a real image and look three dimensional, and the viewer will be under the impression that the image is 'floating' in the air above the mirrors.

Many simulations have been run to determine the optimum shape of the mirrors for this effect. Figures 3.7 and 3.8 show a computer simulation, and how the real image seems to be floating above the opening in the upper mirror. Since this has been successfully accomplished, it is now important to determine what lenses are necessary to achieve the desired effect. Once the lenses and the display system are chosen, computer software has to be written that takes the computer's internal representation of the 'world' and translates it into a form that is useful for this particular optical system.

The big advantage of this system over the use of the stereoscopic display (described above) is that this system does not require the user to wear any special equipment (i.e. glasses, etc.). This system allows multiple viewers to view a scene in three dimensions, from different angles, depending on their position relative to the projection system, all at the same time. This would also allow any viewer to walk around the object being displayed and inspect the scene from several different angles.

\subsection{Teleproprioception Sense Development}

The implementation, testing and use of a laser camera, and the reconciliation of the range and reflectance data with the real world database has been delayed due to difficulties in obtaining the necessary equipment. In addition, due to personnel limitations, a conflict developed between the proposed work on the laser camera data and the construction of the Argonne West vacuum furnace model. Since there are numerous other DOE personnel involved in the ongoing facility modeling project, it was deemed more important that the vacuum furnace remain on schedule.

${ }^{1}$ The word real signifies that light rays actually converge at the location to form an image. If a screen were placed there (without interfering with the passage of the rays), an image would appear on the screen. A virtual image is the opposite of a real image. Here the light rays do not actually reach the image location, and if a screen were placed there, no image would appear on the screen. 
A laser range camera will be obtained to allow progress on this task during the next contract year, and additional progress in this area will occur with the activation of the robotic control and navigation system being developed for the Cybermotion $\mathrm{K} 2 \mathrm{~A}$ robot. A report on the current state of the work including $C$ language codes, data files, and photos is in preparation.

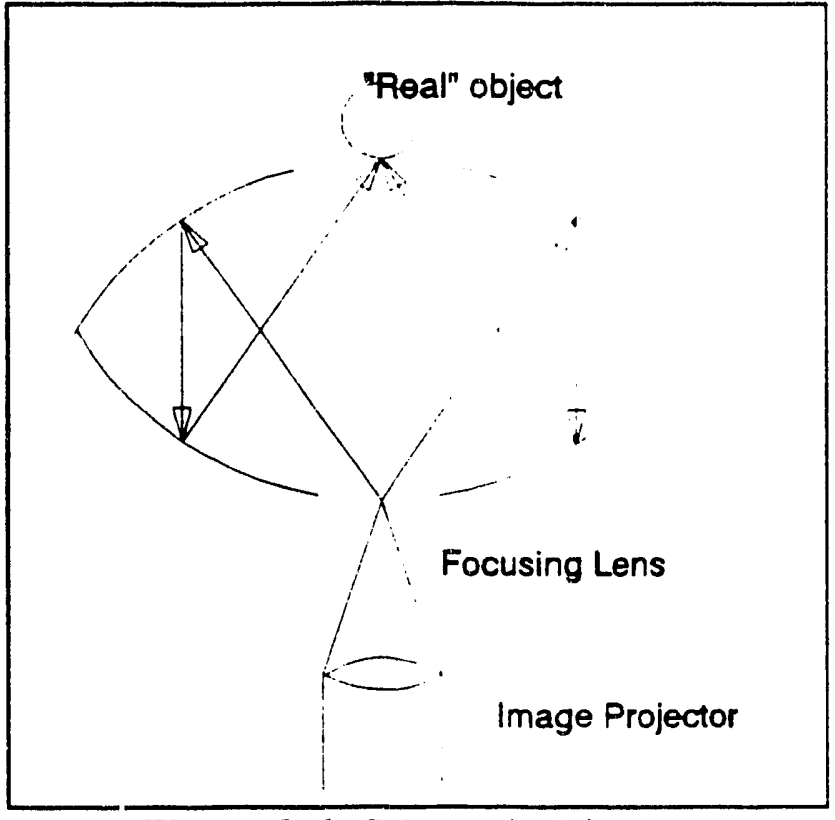

Figure 3.6: Schematic Diagram

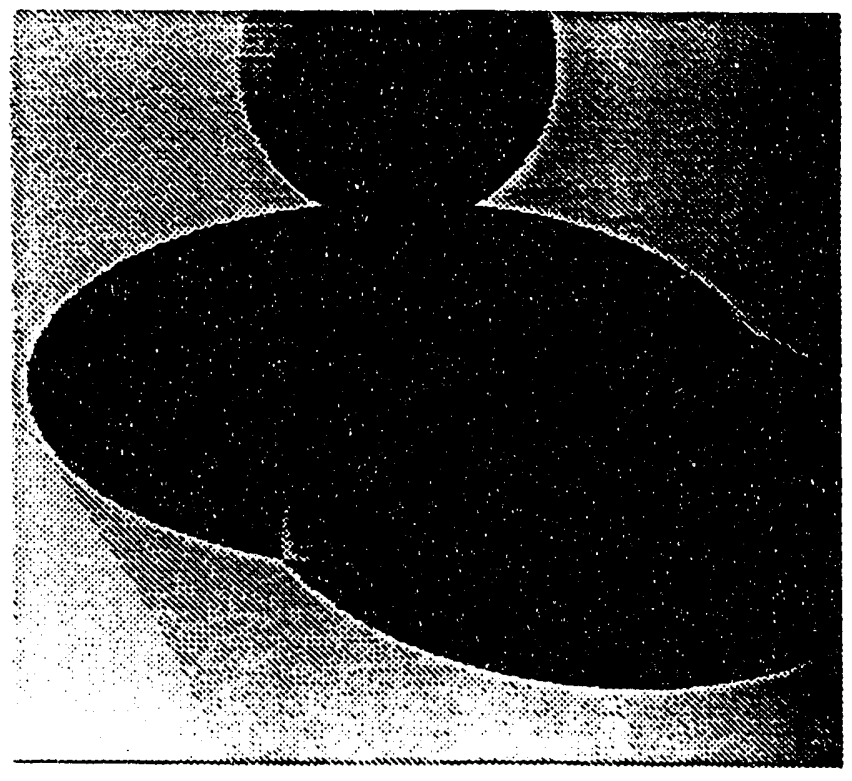

Figure 3.7: Object in Mid-Air

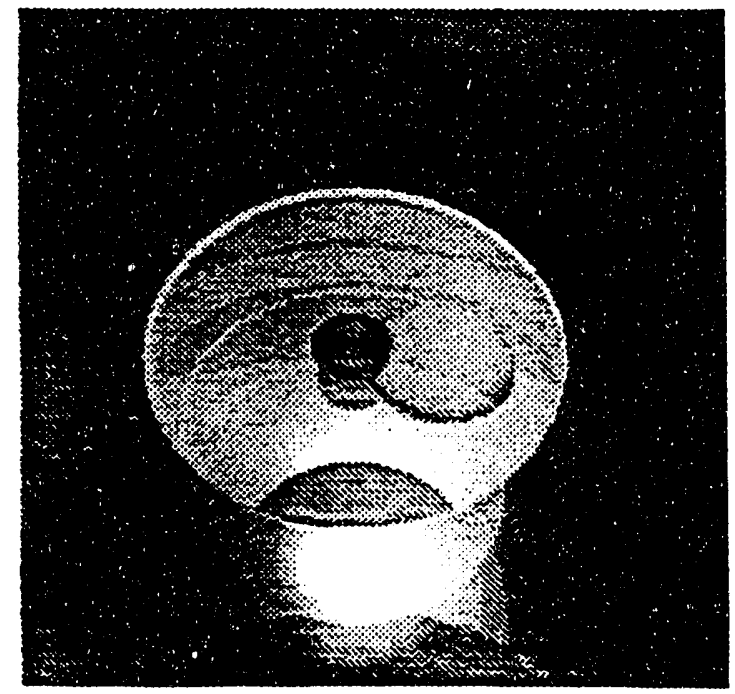

Figure 3.8: Reflections of two Objects 
4.0 Development of the Advanced Liquid Metal Reactor (ALMR) Maintenance Inspection $\underline{\text { Robot Design }}$

\subsection{Introduction}

Figure 4.1 shows the four areas that were to be robotically inspected in the ALMR. Three of the regions (the stack, plena, and vertical annuli) are associated with the RVACS cooling subsystem. The fourth area is located between the reactor vessel and the containment vessel. A brief description of the designed robotic inspection systems will follow. It should be noted that this description will focus on the ability for the robotic systems to move throughout the environment to perform their tasks. The Universities of Michigan, Tennessee, and Texas contributed significantly to the design of other aspects of the system.

\subsection{Stack Inspection Robot}

\subsubsection{Background}

The stack system consists of four groups of two stacks each, the cold air downcomer and the hot air riser, yielding a total of eight stacks for each reactor. The robotic system must inspect the stacks for debris and short circuits of the airflow (holes in the stack wall) as well as take various radiation measurements (smear samples).

\subsubsection{Stack Mobility Considerations}

The inspection system would be operating in a vertical environment. The most important issue of its mobility is its ability to support itself in this vertical environment.

The shape of the stack system itself limits the mobility of the inspection system. Each of the stacks has a different cross sectional geometry. The hot air riser has a rectangular cross sectional area. In the cold air downcomer the work space is limited by the hot air riser stack which is positioned in the middle of the cold air downcomer creating a rectangular annulus cross section.

The stacks are entered through small access ports located at the top of each stack.

\subsubsection{Stack Mobility Alternatives}

Crawler- This alternative collectively refers to any remote inspection system that generates its own vertical support. The support could come from a variety of methods, legs or magnets for example. Since it generates the vertical support on its own this type of inspection system tends to be very complicated in design. In addition, navigation becomes a three dimensional problem and the corners of the stack cross-section could lead to maneuverability diffic lties.

Rail System- The inspection system would move along a rail that would navigate the entire stack system. This alternative would give the inspection system constant support in the vertical direction. It would also reduce the navigation task to one-dimension (distance along the rail) and provide guidance for motion through the complicated geometries of the stack cross-section. 


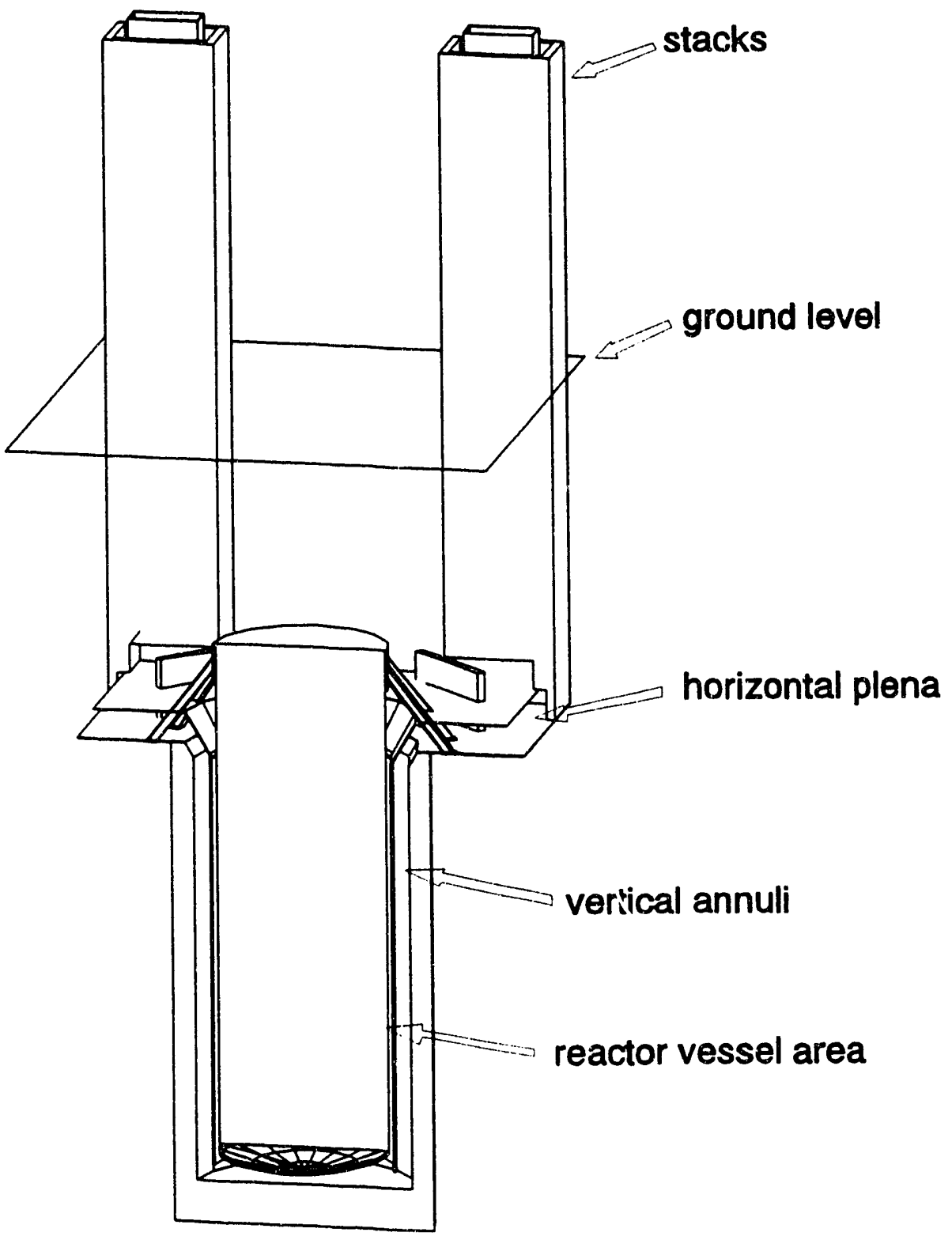

Figure 4.1: Advanced Liquid Metal Reactor 
However, the inspection system would be restricted to move only where the rail could take it. In addition, extensive plant modifications would be required to accommodate the rail system and the rail itself could impede airflow reducing the overall efficiency of the RVACS.

Lower From Top- The inspection unit would be lowered from a support unit located at the top of the stack. The support unit would move along a small rail mounted on the top of the stack. This alternative would allow inspection of the entire stack system by lowering the inspection unit and moving the support unit along the rail.

\subsubsection{Recommender׳ Stack Mobility Design}

The recommended approach for stack inspection is the two- $r$ art system consisting of the inspection unit and the support unit both supported by a rail at the top of the stacks (see Figure 4.2).

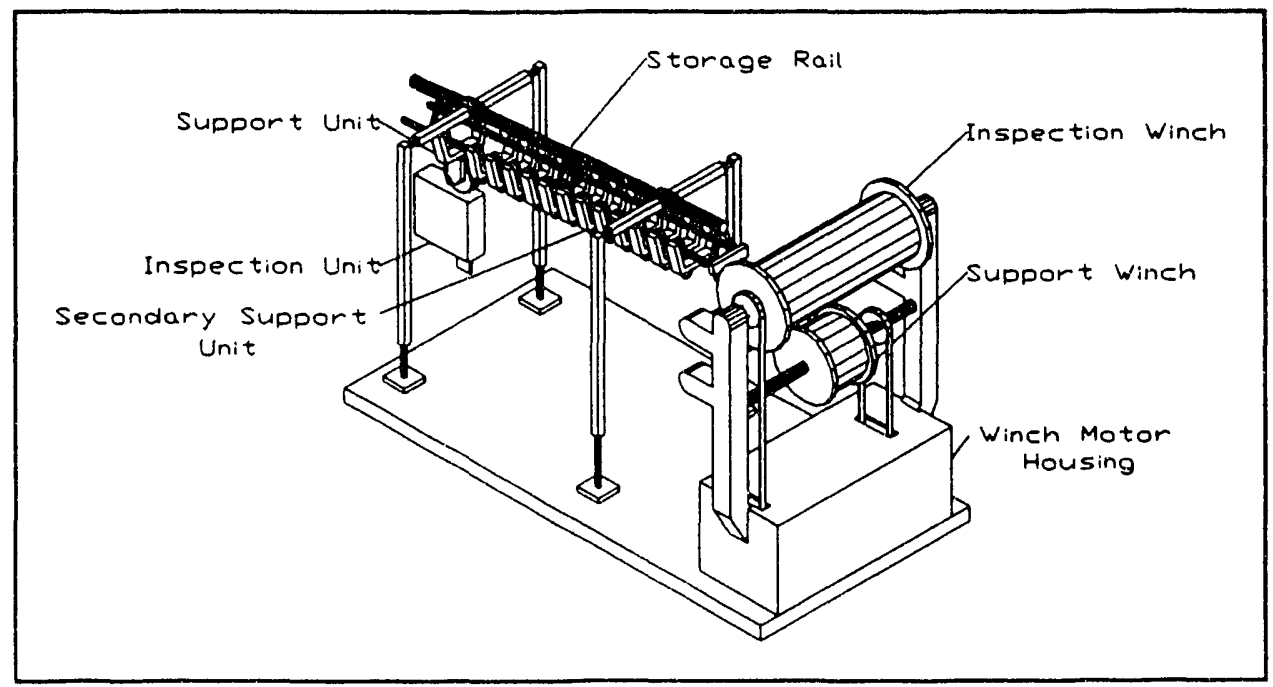

Figure 4.2: Stack Inspection Robot

\subsubsection{Stack System Description}

The inspection system would be deployed and controlled using a storage rail and winch system that would be located outside the stack during inspection. The storage rail would mate with the stack rail and allow the inspection system to deploy itself using gravity. The movement of the inspection system would be controlled by two separate winch units. One would control the distance of the support unit along the rail while the other would control the vertical distance of the inspection unit down the stack.

The support unit, which is controlled by its winch and cable, moves along the rail and provides support to the inspection cable through a pulley. As the support unit changes position along the rail the inspection unit follows it.

The inspection unit is controlled by a separate winch and cable. In addition to following the support unit along the rail, it is capable of moving up and down within the stack, thereby controlling the position of the sensory equipment. To further refine the sensory equipment's 
position, the sensor package is attached to the end of a rotating arm that is capable of 180 degrees of rotation. This arm gives the sensor package greater freedom during the stack inspection. The inspection unit is also equipped with a stabilization device to prevent any swinging motion that may be induced by movement of the support unit or by air flow through the stack. The stabilization device consists of two inflatable air bladders, one on each side of the inspection unit. These bladders can be inflated very rapidly to provide compliant support to the inspection device.

Secondary support units are also provided to prevent the various cables from contacting the stack wall or becoming entangled as the inspection system follows the rail around the stack circumference. There are a total of twelve secondary support units. They are tied together so they evenly distribute themselves as the main support unit moves along the rail.

While the support and inspection units are the same for both the cold air downcomer and the hot air riser, the rail system is different in each case. The cold rail is actually divided into two pieces. Each follows a path half way around the circumference of the stack to reduce the distance the inspection units need to travel in one pass (see Figure 4.3). Thus, inspection of the cold air downcomer would consist of two passes, each inspecting half of the stack. This rail would be installed above the RVACS intake port to reduce its involvement with the air flow.

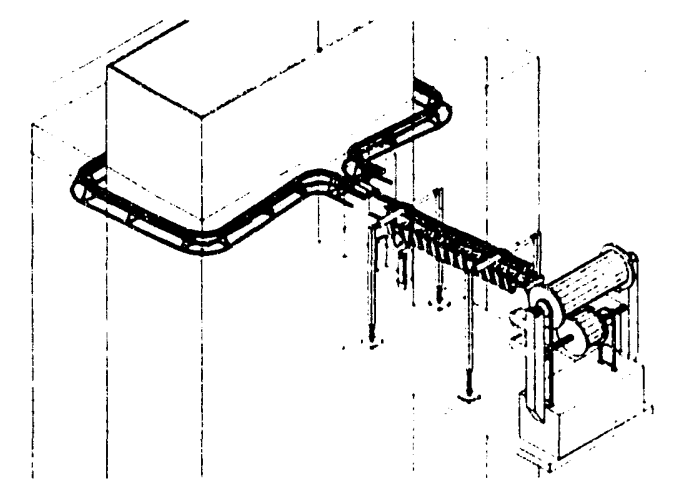

Figure 4.3: Stack Robot Deployment into Cold Stack

Since the hot air riser rail cannot be placed above the RVACS outlet port, it will be removed when the stack system is not being inspected. This is accomplished by opening a second access hatch on the opposite side of the stack. Now a short piece of rail is attached to the end of the deployment rail. This extra rail can be inserted from the platform into the stack itself to accommodate the inspection (see Figure 4.4). This rail would only extend half the stack length to lessen the load on the deployment platform. The second access hatch is required to perform the second half of the inspection. Therefore a total of two inspection passes are needed to inspect each hot air riser.

In both cases, the rail itself consists of one two inch pipe and two one inch pipes configured in a triangular shape. They would be installed with a five degree incline to allow gravity to pull the inspection system along the rail. 


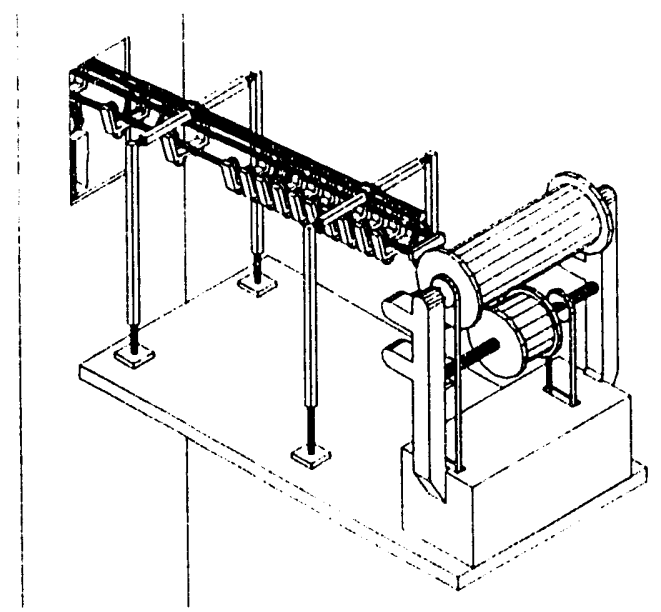

Figure 4.4: Stack Robot Deployed into

\subsubsection{Stack Operational Scenario} Hot Stack

\subsubsection{Cold Stack Inspection}

The storage platform would be positioned near the access hatch the cold air downcomer. The access hatch would be removed by personnel located on the slorage platform. The storage rail would be placed in position to mate with one of the permanent support rails. Personnel would insure that a proper connection has been established and both winches would be released. At the first inspection point the support winch is stopped. Since the inspection winch is still free, the inspection unit is lowered into the stack and inspection begins. Upon completion of the first vertical inspection, the inspection unit is raised and both winches are released to again position the inspection unit along the support rail. The support winch is stopped and the inspection winch is released. The inspection unit is now lowered at the new rail position. This continues until half of the stack has been inspected.

Once the move-lower-raise-move scenario is completed for the inspection for the first rail system, the unit is withdrawn onto the storage rail and the process is repeated for the second support rail.

\subsubsection{Hot Stack Inspection}

The inspection procedure is similar to the cold air downcomer. The difference is how the inspection system is deployed. The storage platform would be positioned near one of the hot air riser access hatches. The hatch would be removed and the extension rail would be mounted on the end of the storage rail. The extension rail would be inserted into the hot air 
riser and the inspection system would be released to inspect half of the stack. This process is repeated from the second access hatch to complete the hot air riser inspection.

\subsubsection{Stack Plant Impact}

The stack inspection system was designed to minimize modifications to the existing plant design. As a result, only three modifications are required:

1) The support rail system must be installed in the cold air downcomer.

2) A second access hatch must be installed on the hot air riser.

3) The access hatch on the cold air stack must be enlarged to 24 inches by 30 inches and the access hatch on the hot air stack must be enlarged to 15 inches by 30 inches.

\subsection{Plena and Vertical Annuli Inspection Robot}

\subsubsection{Plena Background}

This system is designed for inspection and cleaning of (1) the cold and hot plena regions and (2) the two vertical annuli regions between the containment vessel and the reactor silo. The inspection will include visual imaging as well as sample collection (smear samples). Small debris can be expected in this region and its collection and disposal should be accomplished by this robotic system.

\subsubsection{Plena Mobility Considerations}

Perhaps the most important consideration is the tall vertical region that exists between the reactor silo and the collection cylinder in the cold plena, and between the collection cylinder and the containment vessel in the hot plena. The width of these vertical regions limit the overall thickness of an inspection device to seven inches.

The floor of the horizontal plena regions will likely contain many permanent obstacles such as pipe or conduit. The robotic system should be capable of overcoming these obstacles.

The outer walls of the collection cylinder and the containment vessel are coated with a highly emissive coating that must remain unblemished. Therefore the inspection system should not contact these surfaces as it descends through this region.

\subsubsection{Recommended Plena Mobility Design}

The design for the plena inspection device consists of three distinct systems. The first, the primary robot, is a mobile platform driven by two tracks and is designed to navigate the horizontal plena region. The primary robot also serves as a deployment platform for a second robot. This secondary robot is a much smaller platform that is driven by wheels and is designed to navigate the vertical regions next to the collection cylinder. During horizontal plena inspection the secondary robot is located on the primary robot. Each time the secondary robot 
is deployed it descends through the vertical region to the bottom where it travels straight across the horizontal region below the containment vessel. It is then completely withdrawn and the process is repeated at eighteen points along the circumference of the vertical region.

The third system is tether management. This system is responsible for ensuring that the entire robot is recoverable in case of malfunction. It is also responsible for managing the multiple power and control cables so that they do not become an obstacle to navigation.

\subsubsection{Plena System Description}

\subsubsection{Primary Robot}

The primary robot was designed to inspect the horizontal plena regions and to deploy the secondary robot into the vertical annuli regions (see Figure 4.5). It can be best described as a mobile platform driven by two tracks. The tracks were selected for their ability to overcome smail obstacles (pipes, conduit, etc.) without hindering the mobility of the robot. They will be powered by air motors because there will already be a need for compressed air (this is described later in this section).

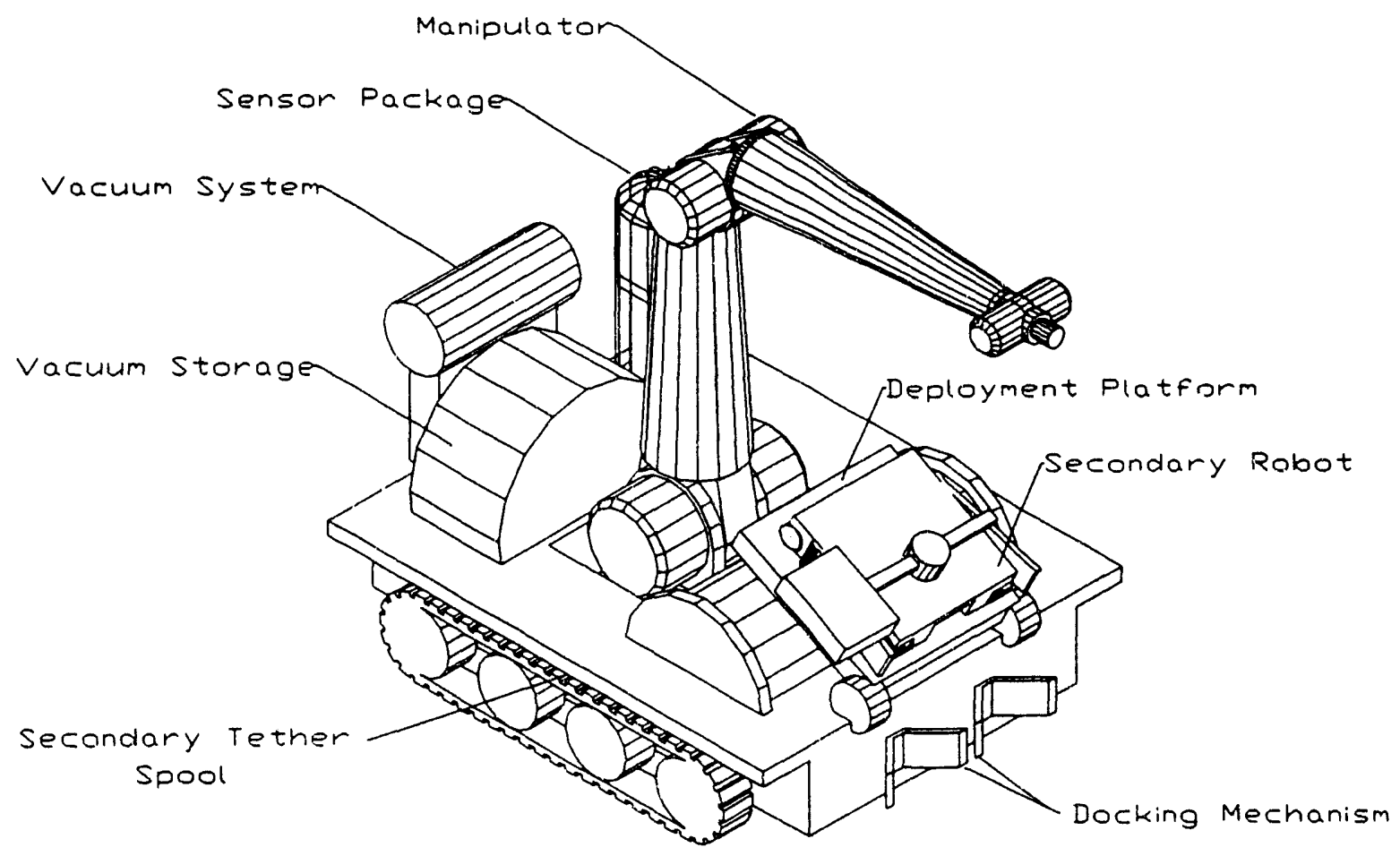

Figure 4.5: Plena Inspection Robot 
The primary robot is deployed using a platform that carries the robot down through the plena access shaft to the access hatch. The robot then drives itself off the platform and into the horizontal plena.

Located on the primary robot are a high strength vacuum, the deployment mechanism for the secondary robot, and various sensors and a serial manipulator that will both be described in later sections.

The vacuum system is a heavy duty, industrial air vacuum such as that manufactured by Hako. Unlike many conventional vacuum systems, the Hako system uses compressed air and the venturi principle to create exceptionally high air flow and static lift. As the compressed air expands through a venturi throat it is accelerated to a very high velocity and generates a strong vacuum. With compressed air as its only input, the syste 1 is simple to operate and requires very little maintenance. A storage container is located on the primary robot to store debris collected during plena inspection.

The secondary robot deployment mechanism is a plate that rotates about one of its edges. The secondary robot rests on the plate until deployment when the plate rotates 180 degrees thereby releasing the robot. Also located on the primary robot is the spool that contains the tether for the secondary robot.

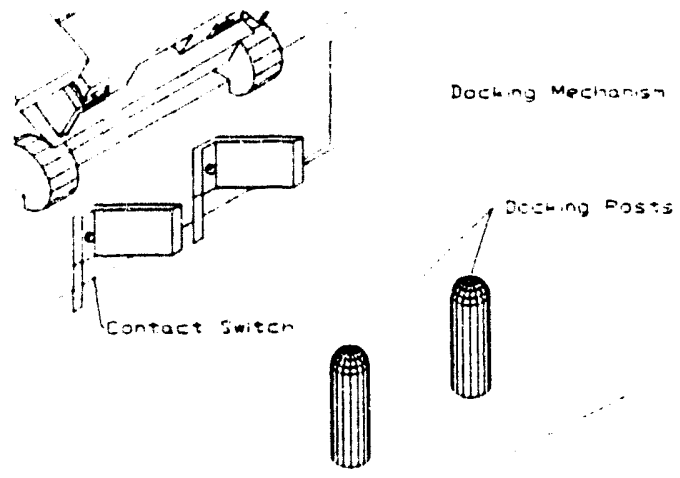

Figure 4.6: Docking Mechanism

To facilitate its positioning for deployment of the secondary robot, the primary robot is equipped with a docking mechanism (see Figure 4.6). The mechanism prevents the robot from moving into the vertical annuli region and also reports when it is in deployment position through the use of two contact switches. The mechanism docks with two small posts mounted into the floor of the horizontal plena. These posts are removable by the primary robot if a situation requires their removal.

\subsubsection{Secondary Robot}

The secondary robot is essentially a small platform on four wheels (see Figure 4.7). The robot is driven by two air motors that power the four wheels. Air motors were chosen because of the readily available compressed air needed for the vacuum system. The wheels are propelled so that the platform can move along the bottom, perform inspections, and remove debris from the reactor silo. The robot itself has no steering capabilities. It is designed to move on a straight path once it is deployed. 
As stated previously, the thickness of the secondary robot is severely limited by the width of the vertical plena regions. In addition, it may not contact the inner wall of either region because of the emissive coating that is present. To insure no contact, a vacuum intake is positioned on the bottom of the robot. This intake serves two purposes. First, when the robot inspects the horizontal region below the containment vessel the vacuum will remove any debris that is passes

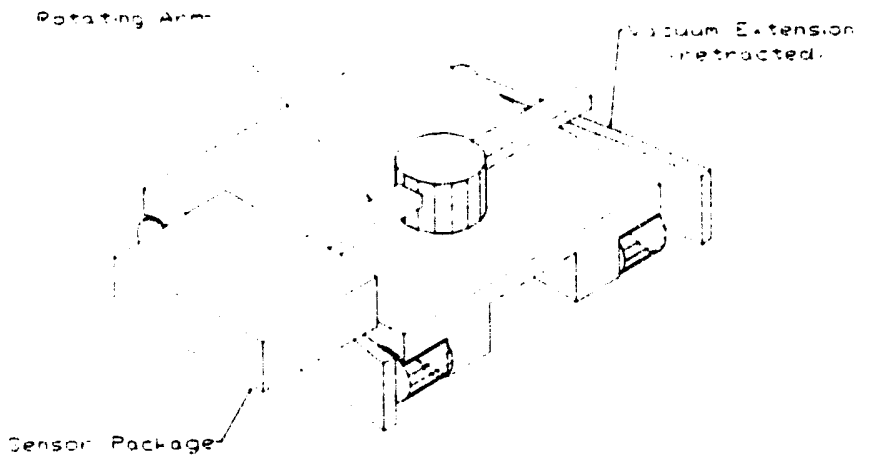

Figure 4.7: Secondary Robot over. Second, the vacuum will hold the robot against the outer wall of the vertical regions during decent preventing contact with the emissive coating.

To extend its workspace the platform is equipped with a three degree of freedom arm. The arm positions the sensory equipment of the robot and allows the robot to inspect more area during each deployment pass. The robot is also equipped with two mechanisms designed to increase vacuum area during its horizontal inspection. The bottoms of these vacuum extensions are lined with vacuum intakes. On the primary robot and during decent the extensions are not needed so they remain closed to save space and reduce the chance of accidental entanglement. During the horizontal inspection the extensions open so that more debris may be removed in one pass.

\subsubsection{Tether Management}

The tether system furnishes the primary and secondary robots with needed power and control signals, as well as the required compressed air. Since it is necessary for correct operation of the inspection system the importance of its management and control cannot be overlooked. In addition to providing the inspection system with its functional requirements, the tether system must also provide a simple means to withdrawal the robot in case of system failure.

To merely pull the tether could have unfortunate results if either the primary or secondary robotic systems became entangled in the reactor support structures. For this reason, an effective tether management system was designed to guide the robot in the event of manual retrieval.

\section{(a) Tether Considerations}

In order to successfully retrieve the robotic system the tether must actively guide it through the plena region. Therefore the tether itself must follow a path through the plena that avoids potential obstacles.

The primary robot's workspace is relatively large (horizontal plena region) and the secondary robot must descend to the bottom of the containment vessel. Therefore a long tether 
will be required to yield the freedom required by the robotic system. This could generate space problems as the tether itself must be effectively stored.

(b) Recommended Tether Management

The recommended tether management design utilizes a mechanism nicknamed "the bullet". The bullet rides in a hollow rail mounted to the roof of each plena and carries the tether components. It is restricted to move only within the rail which guides it as it pulls the robotic system back during retrieval.

(c) Tether System Description

The primary tether is stored on two large spools located outside the plena at ground level. One spool contains the wires and hoses required by the sensors, motors, and vacuum system. The second spool contains the retrieval cable used to pull the entire system out in case of failure. As the primary robot enters and moves about the plena region the tether components are simultaneously distributed from the spools.

The tether follows the deployment platform down to the bottom of the access shaft where it enters the rail system. The rail is simply a tube with a slot cut through the bottom to allow the tether components outlet to the primary robot. The rail is mounted to the ceiling of each horizontal plena region and is divided into two sections that each extend half way around the plena region. This is done to reduce the total length of tether required.

The various tether components are pulled through the rail by the bullet mechanism (see Figure 4.8). They each connect into the back of the bullet where their contents are routed through channels to exit ports located on the bottom of the bullet. They are then delivered to the primary robot through hoses of fixed length. Bearings were designed to support the tether components inside the rail and to reduce the frictional effects of the tether components moving through the rail. These bearings are simply collars that contact the rail through ball bearings mounted on their edges (see Figure 4.9).

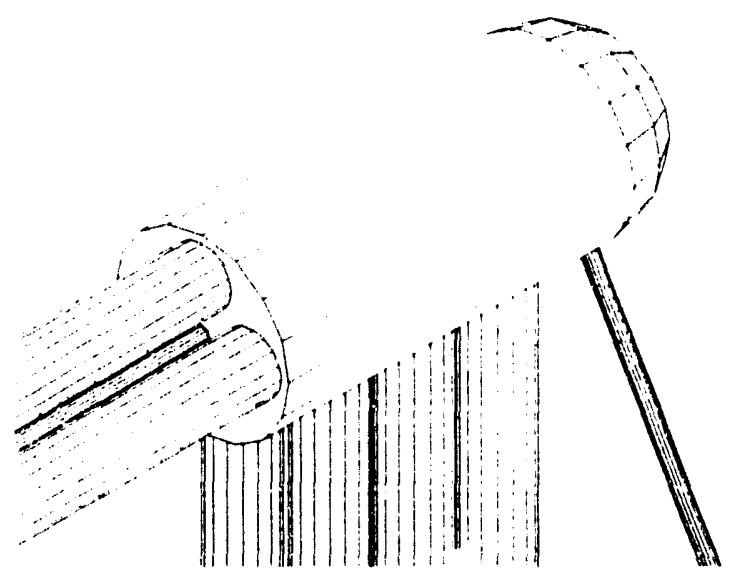

Figure 4.8: Bullet of Tether Mechanism

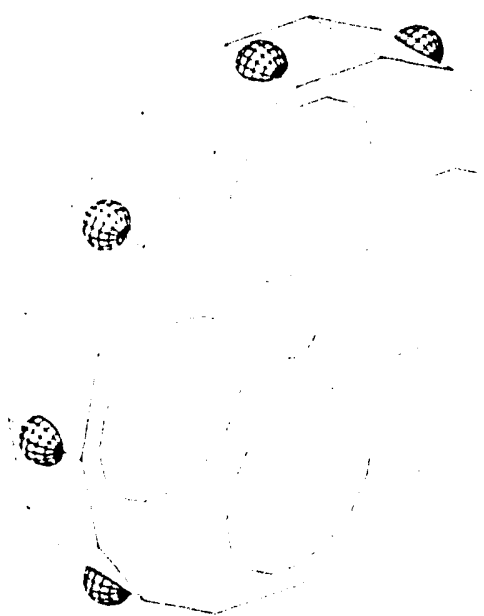

Figure 4.9: Tether Bearing Collars 


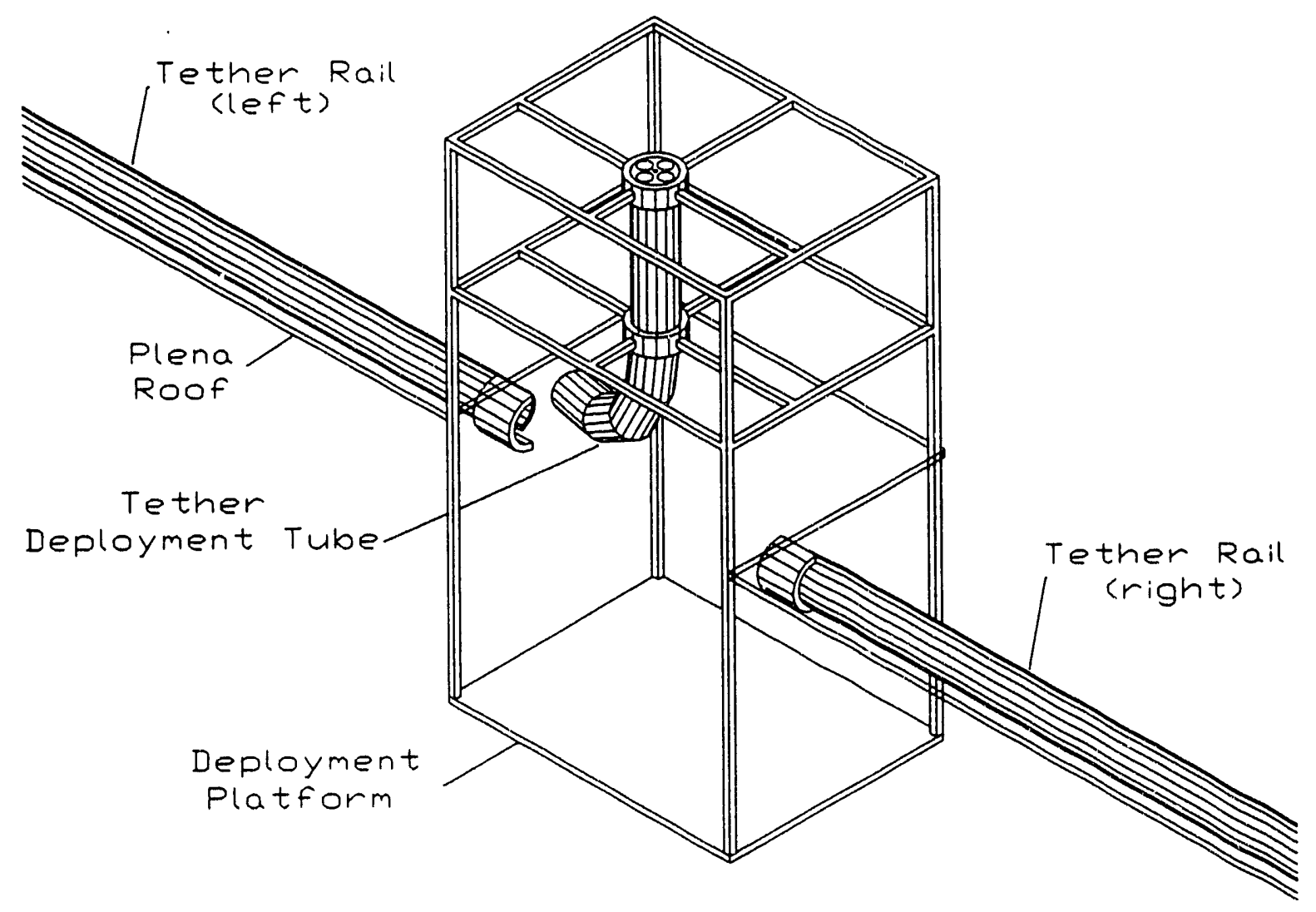

Figure 4.10: Plena Robot Deployment

The tether components enter the rail through a curved tube mounted on the deployment platform that rotates to allow entry into either rail (see Figure 4.10). The tube also stores the bearings and bullet mechanism before deployment. The bearings are attached to each other to insure even distribution along the rail.

The primary plena robot pulls the bullet through the rail using a cable attached to the robot and the bullet. This fixed length cable also restricts the robot's movement in case system failure causes a loss of control. The bullet is ratcheted so that it only moves forward through the rail during the plena inspection. The ratchet is released in one of two ways. In the case of normal operations the ratchet may be released through an external mechanical switch operated by the primary robot manipulator arm. This switch is located on the bullet and is used when the robot is ready to return to the deployment platform. In the case of system failure, the ratchet is released by a small collar rigidly fixed to the retrieval cable. The collar is positioned such that the ratchet is released only when the primary robot has been withdrawn close enough to the rail to allow unobstructed retrieval.

The retrieval cable actually passes through the primary plena robot and continues uninterrupted to the secondary plena robot. This insures that if a system failure occurs after the secondary robot has been deployed, both robots will be properly retrieved. 
A secondary tether system links the primary and secondary plena robots. This tether is stored in a spool located on the primary plena robot and supplies a vacuum intake, sensor requirements, and compressed air to the secondary robot.

To demonstrate the functionality of the retrieval system consider the extreme case of system failure while the secondary robot is fully deployed (underneath the containment vessel). The main retrieval spool (located at ground level) begins collecting cable which will eventually return the secondary robot to its home position on the primary robot. Since the ratchet has not yet been released the bullet remains stationary as the primary robot is drawn toward the rail. When the cable collar disengages the ratchet the primary robot is under the rail and can be safely withdrawn to the deployment platform.

\subsubsection{Plena Robot Operational Scenario}

After the primary deployment platform has been lowered to the access hatch of the hot or cold plena the tube holding the tether bearings and the bullet is moved into place and the primary robot leaves the platform. The bullet and tether are pulled into the rail as the robot leaves the platform. The primary robot performs the horizontal plena inspection. It then positions itself between two of the plena support beams and aligns with the docking posts to begin the vertical inspection. The secondary robot is deployed into the vertical region and begins its inspection as it descends to the bottom. Upon reaching the bottom, the vacuum extensions are reisased and the robot moves across the lower horizontal region. When it reaches the other side, the extensions are closed and the robot is withdrawn.

The primary robot moves between the next two support beams and the secondary deployment process is repeated. When the system finishes this phase of the inspection it will have deployed the secondary robot a total of nine times and will be positioned on the opposite side of the horizontal plena. The bullet ratchet is then manually released and the robot returns to the primary deployment platform. The tether tube is repositioned and the second half of the plena region is inspected in the same fashion as the first.

\subsubsection{Plena Plant Impact}

The plena inspection system was designed to minimize changes to the existing plant design. As a result, only two additions are required.

First, the rail for the tether management must be installed on the ceiling of both the hot and cold plena regions. Since there are two rails for each plena region a total of four must be installed.

Second, the removable docking posts must be installed at each of the vertical plena deployment locations between the plena support beams. This yields a total of thirty six posts for each plena region. 


\subsection{Reactor Vessel Inspection Robot}

\subsubsection{Design Alternatives}

The Reactor Vessel Inspection Robot (RVIR) design provides a mobile platform to inspect the void between the reactor vessel (RV) and the containment vessel (CV). To complete its task, the RVIR must operate in an argon atmosphere at temperatures up to 400 degrees fahrenheit and at radiation levels up to $500 \mathrm{R} / \mathrm{Hr}$. Additional limitations include small void access ports (3.75 x 14.5 inches), sensitive surface conditions (due to the emissivity coating), and vehicle failsafe recovery capability. The basic vehicle design is a sealed casing which contains the sensor and locomotion packages. The use of a single body design reduces the number of potential shielding and cooling systems required. The overall design is therefore reduced to determining the vehicle shape and its method of locomotion.

The following design options were reviewed for possible use for the RVIR: a pipe crawler (existing systerns), pneumatic walker, sensor package suspended from a rail system, and a plant specific crawler. Existing pipe crawler systems were deleted early due to the modification needed to meet the size, payload and environmental constraints. The pneumatic walker was too complex (environmental protection would be extensive) and potentially damaging to the $\mathrm{RV}$ and $\mathrm{CV}$ emissivity coatings. The rail system provided simple navigation possibilities, but required modifications to the RV and CV void area and did not allow for inspection beneath the RV. The final option was to design a vehicle specifically for the plant conditions which allows maximizing inspection goals while minimizing plant impact. This approach is recommended.

\subsubsection{System}

The RVIR is a semi-autonomous vehicle which provides a mobile platform for the sensor package as well as environmental protection for all components (sensors and drive system). The vehicle is designed to carry one fiber optic bundle lens, a panning system, halogen spotlights, two ultrasonic test probes, and expansion volume for additional equipment. Shielding and cooling capabilities are allowed for, but will be added only as needed for specific items. Following is a detailed description of the RVIR's design.

The drive system will consist of two electromagnets to hold the RVIR to the CV wall and two electric motors coupled to the wheels for mobility. The power and control signals for both the electromagnets and drive motors will be externally supplied from the control area. The drive motors will each power a wheel on opposite sides of the RVIR which allows steering by varying the drive motors speed and direction. The electromagnets are separated from the main vehicle body to minimize possible interference from the electromagnetic fields (to current and future components) and to minimize heat transfer from the electromagnetic coils. If coil temperature becomes severe, a vortex tube cooling system may be added specifically for coil cooling.

The RVIR consists of a main body which houses the sensor package and operating systems with two secondary bodies which house the electromagnets. The main body is sealed from the environment for ease of decontamination and to simplify conling system design. All control lines enter the RVIR at the tether cable junction. This junction serves two purposes: first 
to provide an anchor point for a loss of power, manual recovery and to provide a sealed interface for the control cables. The tether is a single bundle which will carry power cables for the halogen lights and electromagnets, high pressure argon for the vortex cooling system and the motion actuators (camera lens panning system and ultrasonic transducers) and a wire cable for reinforcement.

The inspection access port interface system consists of a tether retrieval system, RVIR guide plates and an argon lock. The tether retrieval system will recover the RVIR (in both a manual and automatic mode) and store the tether. The RVIR guide plates consist of four curved surfaces which can be extended into the RV/CV void to guide the RVIR into and out of the inspection access port. The RVIR guide plates also provide a means of directing the RVIR to the CV surface for magnetic coupling. The argon lock will provide a seal to prevent a loss of argon from the void area. The inspection access port interface system will be shielded to allow maintenance personnel safe access while the access port is opened.

\subsubsection{Operational Scenario}

Following plant shutdown and subsequent grace periods, plant personnel will install the inspection access port interface system over an inspection access port. The access port will be opened and the access port plug stored within the interface system. The guide plates will be lowered into the void and expanded. The RVIR will be lowered by the tether recovery system and pressed against the CV inner wall by the guide plates. Once the RVIR is in position, the electromagnets will be energized. The RVIR may now be driven similar to a tracked vehicle along its pre-programmed inspection route. The tether recovery system will deploy and recover the tether so that no excess slack exists. The camera lens system will operate continuously to visually inspect the reactor and containment vessel surfaces. The vehicle will stop and extend an ultrasonic testing sensor at all planned test points. Upon completion of the inspection sequence, the RVIR will return to the access port and secure the electromagnets. The vehicle will be returned to the storage position by the tether recovery system. The access port may be sealed and the inspection access port interface system removed.

\subsubsection{Plant Impact}

The proposed RVIR design or its alternatives place only three requirements on the ALMR design. First, the inspection access port dimensions must stay the same at $3.75 \times 14.5$ inches. Second, a source of three phase power for the electromagnets and single phase power for the halogen lights must be available. Third, a source of high pressure argon is necessary to supply the vortex cooling system and the argon driven actuating motors. 


\section{0. $\quad$ Articulated Transporter/Manipulator System (ATMS) Development}

\subsection{Evaluation of Prototype Hardware}

The first working prototype ATMS segment based on a parallel actuation scheme was completed in 1991. This segment has two coupled degrees of freedom, one revolute and one slider. A test stand was developed so that the segment's performance could be evaluated under load. Observation during testing lead to recommendations for improvements in segment design. Fabrication also produced some suggestions for modifications. The primary work in 1992 has been in performing design iterations that included the noted improvements and modifications. A brief summary of the observations is given below. Most points are not major, but addressing them will improve the performance of the ATMS.

As noted in the ASME paper (Ridgeway), joint torque proved to be satisfactory. The test segment was controllable under load. The segment could be driven out of control by specifying excessive gains, but a gain exists that results in a controlled mechanism under all tested loads.

The overall weight of the test segment (including all four actuators and both slides) is shown in Table 5.1. The estimated segment weight, along with the maximum segment extension of 42 inches, gives a weight per unit length of approximately $5.6 \mathrm{lbs} / \mathrm{in}$. This figure is significantly higher than the goal of $4 \mathrm{lbs} / \mathrm{in}$. The estimated maximum horizontal jump would be approximately 10 feet, based on joint torque of 40,000 in-lbs. This is two feet shorter than desired. Note that the joint torque deliverable in the horizontal configuration exceeds the 40,000 in-lbs estimate due to the kinematic advantage of the parallel actuating mechanism.

\begin{tabular}{||l|c|c||}
\hline \multicolumn{1}{|c|}{ Part } & $\begin{array}{l}\text { Weight } \\
\text { each, lb }\end{array}$ & $\begin{array}{l}\text { Weight } \\
\text { total, lb }\end{array}$ \\
\hline Body & 39 & 39 \\
\hline Cylinder (LDT integral) & 30 & 120 \\
\hline Slide Assembly & 30 & 60 \\
\hline Ring (est) & 10 & 10 \\
\hline $\begin{array}{l}\text { Misc (encoder, hose, } \\
\text { etc) }\end{array}$ & 6 & 6 \\
\hline Total & & 235 \\
\hline
\end{tabular}

Table 5.1 1991 Test Segment Weight 
Observation of the test segment lead to the conclusion that the slide has a relatively flexible mode when excited in the direction normal to the plane of the parallel actuation. The torsional stiffness of the assembly is also subject to some question. This stiffness does not come into play unless the ATMS is navigating in the horizontal plane and the vertical plane at the same time.

The manufacturing processes used in constructing the first prototype created some problems with the structure. Specifically, the welding process caused significant warping of the body and lead to reworking the bearing mounts for the cylinders. This lead to a quick rework of the slide so that assembly was effected with shoulder bolts. This joining is partially responsible for the flexible mode the slide exhibits. It should also be noted that the recirculating ball bearing slides used required two rails and two sets of bearing blocks in order to provide five full constraints. This allowed deflections between rails to affect slide stiffness, particularity in torsion.

\subsection{Design Improvements}

These observations were considered during the design iterations performed in 1992. Two main goals developed from the observations. One is weight reduction and the other is increased slide stiffness. These are obvious, but necessary goals.

With both goals in mind, material selection was reevaluated. The 1991 segment is primarily aluminum. There are fiber reinforced plastics that pose significantly better stiffness to weight ratios than aluminum. The initial concern with these types of materials is environmental effects. A second concern is manufacturability.

Environmental effects on composites can be looked at in several categories. Thermal, chemical, and radiation effects are three generally accepted categories. The thermal environment of the ATMS is expected to range from 0 to 100 degrees $\mathrm{C}$. The chemical environment is relatively unknown, but most composites are more chemically resistant then aluminum. The radiation environment is also unknown, and is of the most concern. Under general operating conditions, exposure is expected to be minimal. However, the ATMS is supposed to handle upset conditions, and in these cases, radiation exposure is expected.

The literature was surveyed to investigate radiation damage to fiber reinforced polymers. It was found that glass does not make a good reinforcing phase due to boron impurities (Clough). Carbon is a favorable reinforcing phase, with respect to its radiation hardness. For reasonable temperature ranges, a carbon/epoxy composite retained or increased its mechanical properties when exposed to $1 \times 10^{10}$ rads (Milkovich). This exposure level is on the order of exposure that is lethal to most hardened electronic hardware. Carbon fiber also has a very good stiffness to weight ratio. Aluminum's stiffness to weight ratio is approximately $1 \times 10^{8}$ in and carbon/epoxy's is approximately $2 \times 10^{8}$ in (Askeland).

Manufacturing a composite body for the ATMS poses some difficult problems. These are primarily associated with mechanical fasteners and dimensional tolerances. Machining is possible, but the composite is isotropic by nature and machining can give rise to large stress concentrations that induce interlaminar failure. Volumetric changes of the matrix during 
processing can give rise to dimensional changes. With these limitations in mind, a manufacturing process was devised that minimizes dimensional changes and allows holes for mechanical fasteners to be molded into the part. The process is based on the wet layup method, utilizing either a vinyl ester resin (a modified epoxy resin) or an epoxy resin. It could be adapted to a preimpregnated composite if needed. One attractive feature of the process is that it uses a mold that can be used more than once. This allows identical parts to be made inexpensively. The primary cost is for the mold and can be spread out over several parts. The material and labor in each part is significantly less than that involved with a conventionally manufactured aluminum part. This does limit design modification, so care must be taken in designing the initial mold.

\subsection{Segment Design}

Layout

Figure 5.1 illustrates a sectional view of the ATMS 1992 design revision. The slide configuration is shown, along with actuator mounting details.

Body

The body has been changed from an internal to an external structure. This was done to increase torsional rigidity, increase internal component protection, and allow redesign of the slide assembly. The material chosen is a fiber reinforced plastic. Initial prototyping is of fiberglass/vinyl ester. This was done to develop the manufacturing process. Graphite fiber (much more expensive than fiberglass) replaces the glass in subsequent versions. The mounting holes for the slide bearing blocks, the hydraulic manifolds, the actuators, and the proposed wheels are molded into the body. The body is a 16 sided tube. Figure 5.2 illustrates the body. The molded-in holes have random $E$ glass chopped mat placed in the laminate to improve elastic response to stress concentrations.

Slide

The primary change is a change in recirculating ball bearing slide type. A smaller slide that can take loads in all five constraint directions was chosen. Four of these steel slides replace four steel slides that acted in two pairs in the 1991 segment. The slide bearings are mounted on a graphite fiber reinforced plastic structure, as illustrated in figure 5.3. This structure is manufactured using the same methodologies developed for the body. The hydraulic fluid path is integrated into the slide design.

Ring/Cross

This part only existed conceptually in the 1991 segment. The 1991 segment was attached to a loading beam and a test stand, not to another segment. Substantial work has been done in designing a rigid connection that does not interfere with the slides or bodies it is attached to. Figure 5.4 illustrates the ring design for the ATMS revision. It is constructed primarily of graphite fiber reinforced plastic.

Actuators

The actuators of the 1992 segments are 2 in. bore 11 in. stroke servo-hydraulic actuators without integral linear displacement transducers (LDT's). Linear displacement is measured via a LDT mounted between the body and slide. 


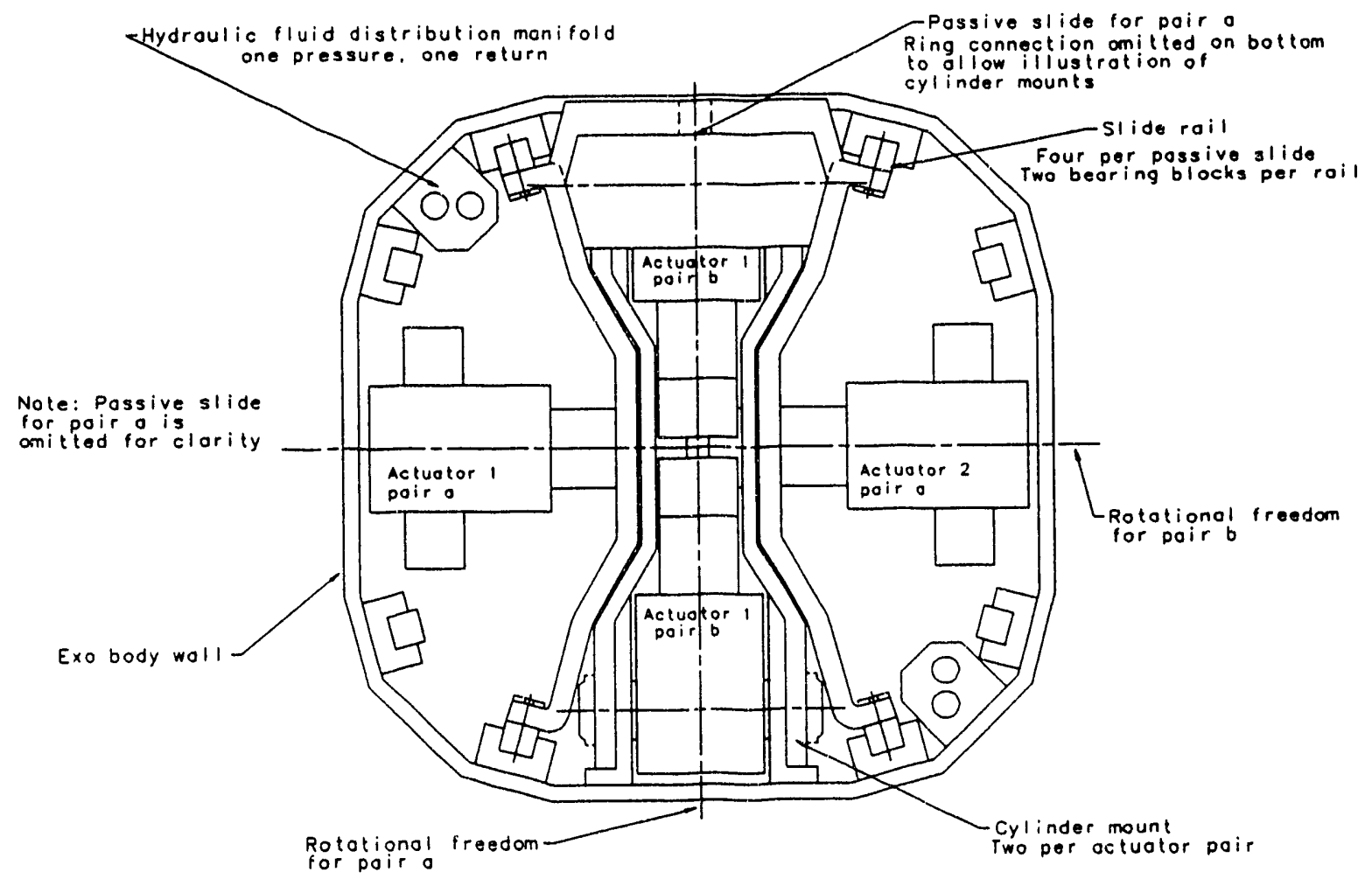

Figure 5.1: Segment cross section. 
54

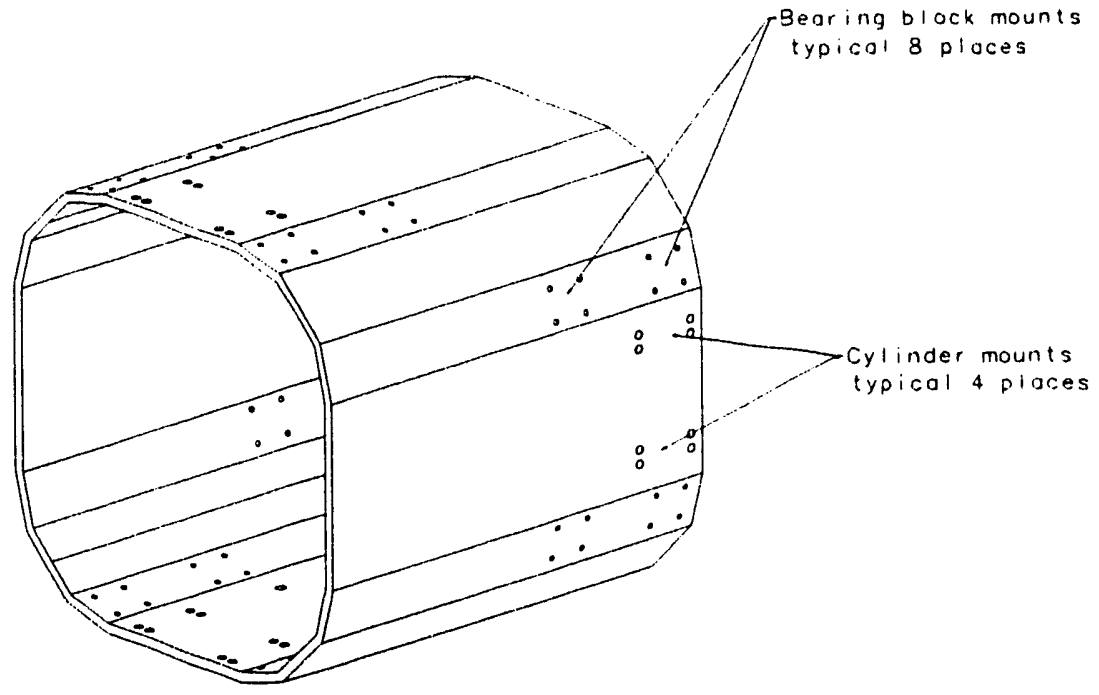

Figure 5.2: $\quad$ Exc Body for 1992 ATM.

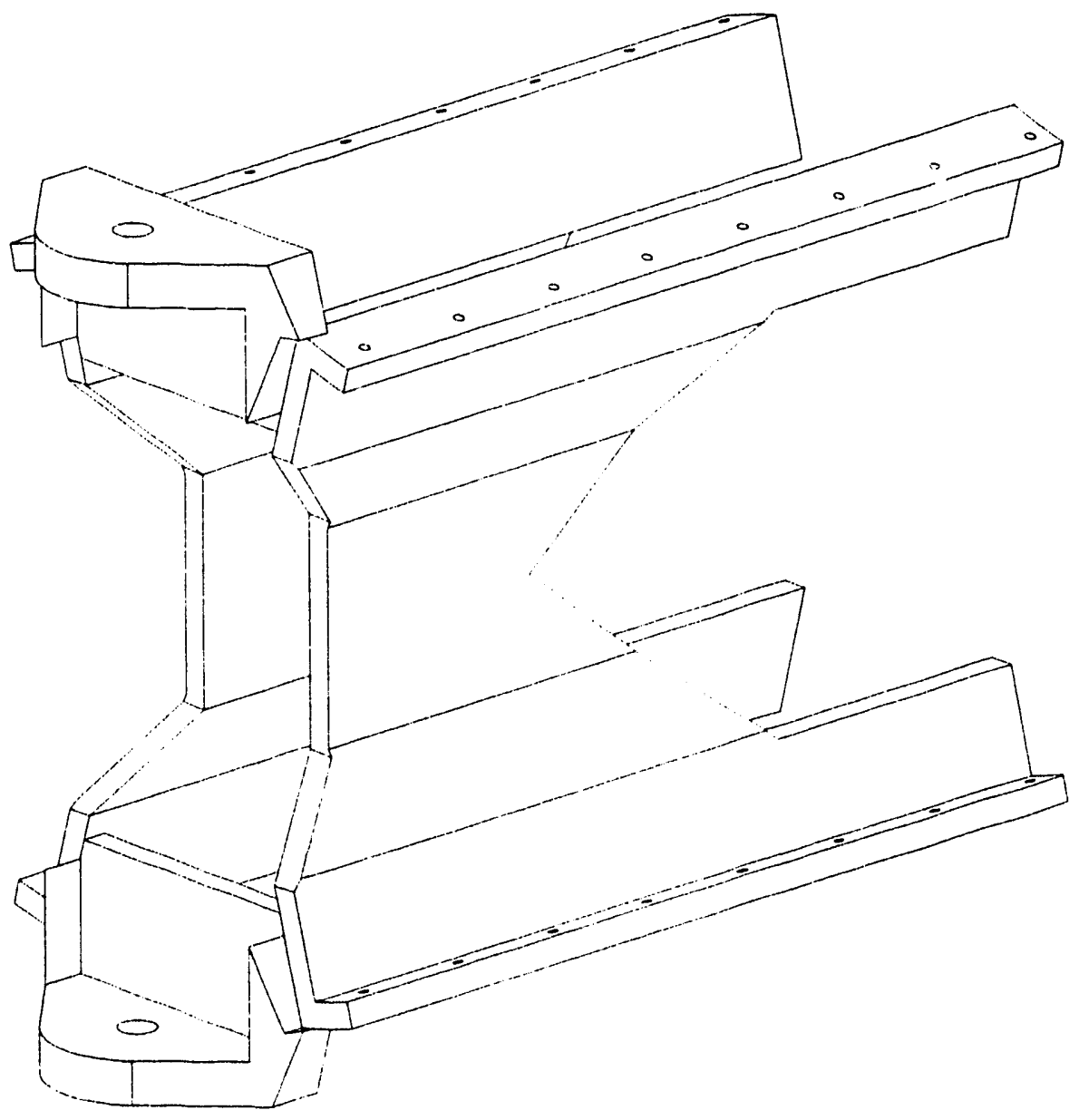

Figure 5.3: Slide structure. 


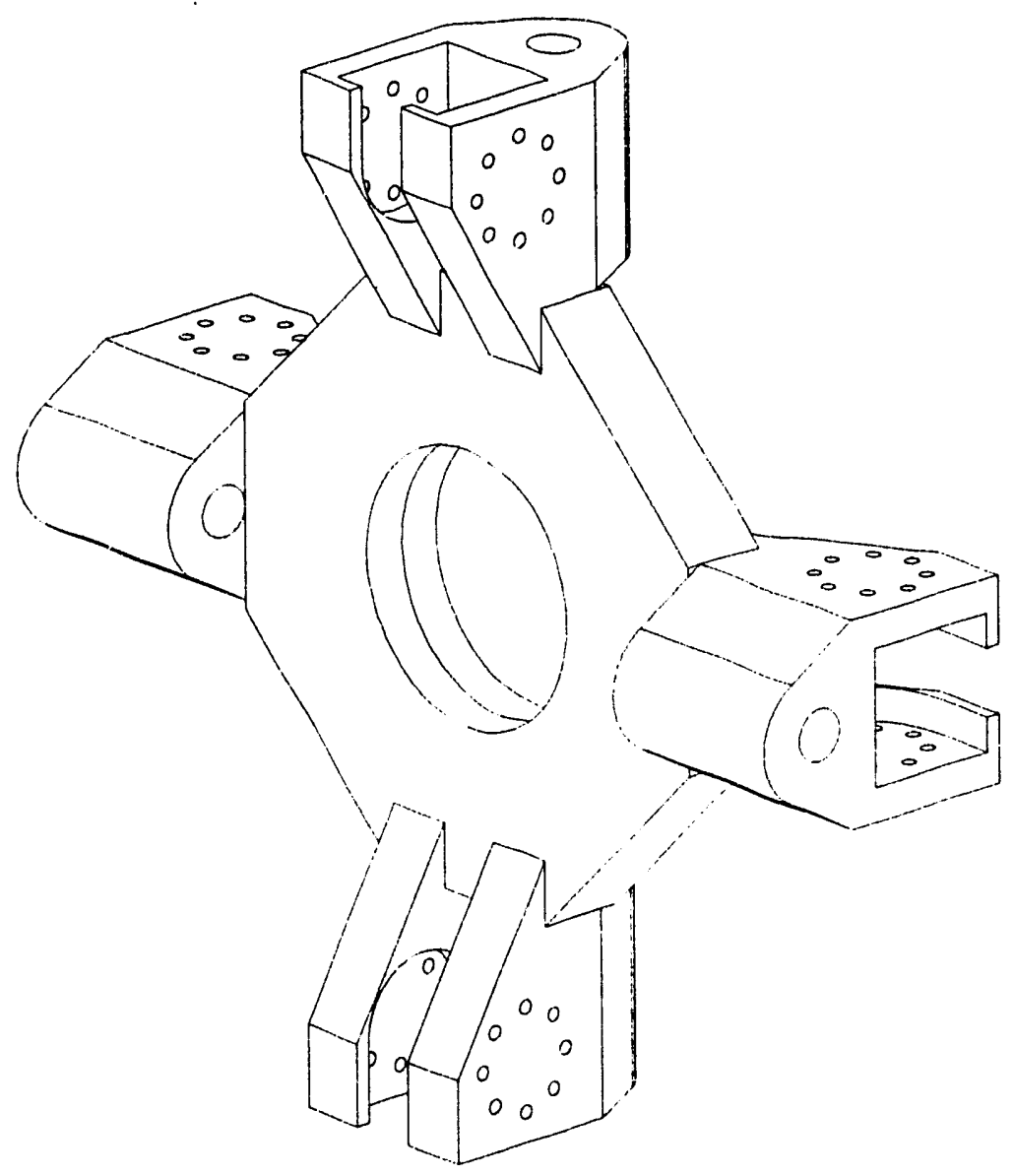

Figure 5.4: Ring/Cross. 


\subsection{Expected Performance}

Joint torque performance is expected to be slightly better for the 1992 segment than for the 1991 segment because the rod is smaller, allowing a larger pull force to be generated. The maximum segment length is approximately 44 in. This leads to a weight per unit length of 4.3 $\mathrm{lbs} / \mathrm{in}$. This allows a horizontal jump (based on 40,000 in-lbs joint torque) of 11.4 feet.

\begin{tabular}{||l|c|c||}
\hline \multicolumn{1}{|c|}{ Part } & $\begin{array}{l}\text { Weight } \\
\text { each, lb }\end{array}$ & $\begin{array}{l}\text { Weight } \\
\text { total, lb }\end{array}$ \\
\hline Body & 24 & 24 \\
\hline Cylinder (LDT integral) & 25 & 100 \\
\hline Slide Assembly & 25 & 50 \\
\hline Ring (est) & 10 & 10 \\
\hline $\begin{array}{l}\text { Misc (encoder, hose, } \\
\text { etc) }\end{array}$ & 6 & 6 \\
\hline Total & & 190 \\
\hline
\end{tabular}

Table 5.2 1992 Test Segment Weight

\subsection{Computer Software and Hardware for the System}

This section describes the computer software and the hardware utilized to control the Articulated Transporter/ Manipulator System (ATMS). The configuration of the computer hardware is presented first followed by a discussion of the software control system. The configuration of the computer hardware is shown in Figure 5.5. The central computer controlling the ATMS was a Force computer running the OS/9 real-time operating system. The Force computer consisted of a central processing unit and several input and output (I/O) boards. The $1 / O$ boards were utilized for transmitting and receiving information to and from the environment. Two other computers were linked to the Force computer through ethernet connections. A Silicon Graphics computer graphically displayed the ATMS components and animated motion. Path planning tasks were also performed on the Silicon Graphics computer. Movement commands were transferred to the Force computer through the ethernet connection using the Helix software. A Macintosh computer was utilized as a user interface console and included data graphing capabilities.

Input boards and various sensors were utilized to acquire information from the environment. Sensors utilized for the ATMS included linear displacement sensors, absolute rotary encoders, and ultrasonic transducers. Linear displacement transducers provided cylinder extension lengths and body length. Absolute rotary encoders were used to obtain body angles. Incorporation of ultrasonic transducers will provide information about objects located in front 


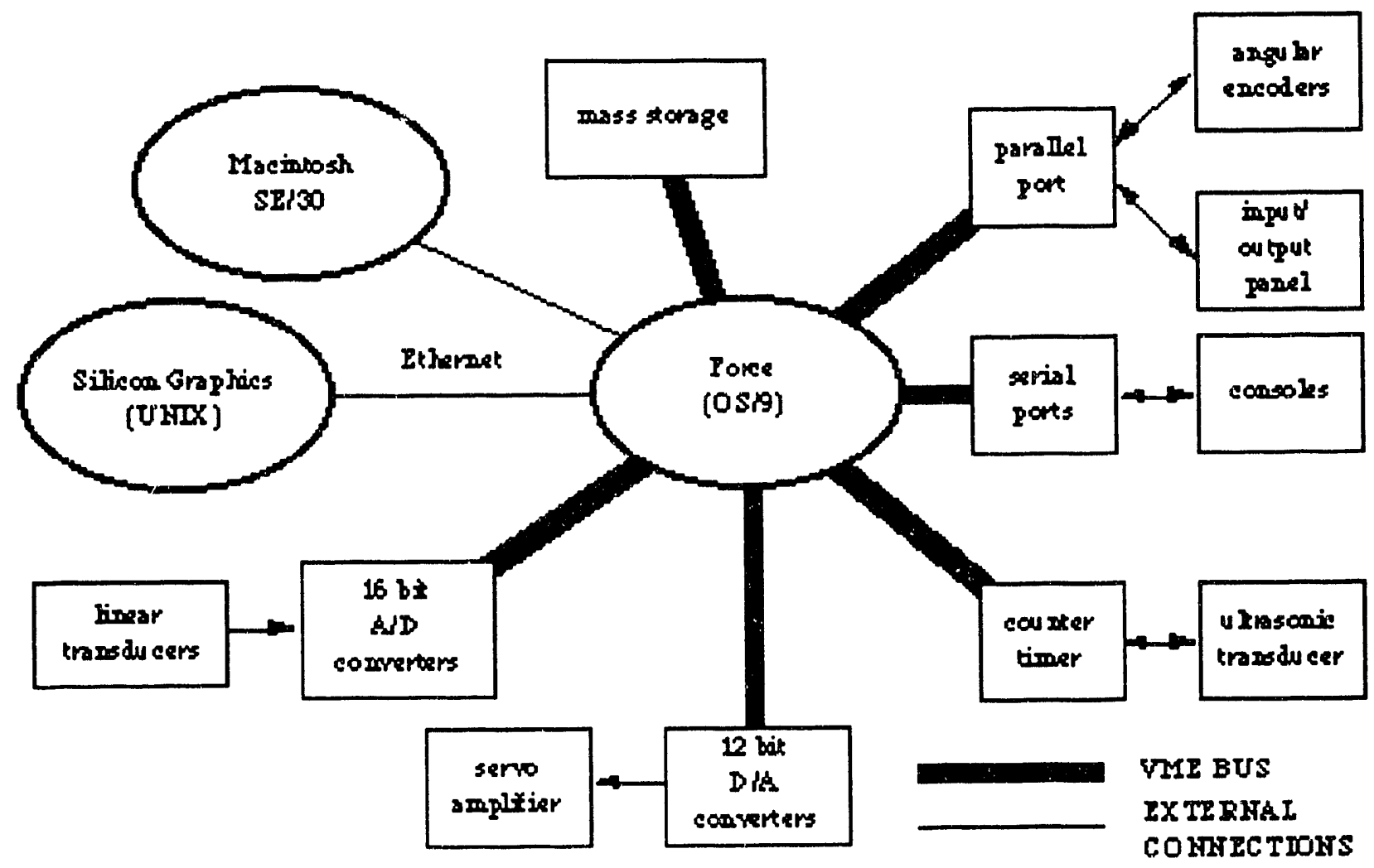

Figure 5.5: Computer Hardware Configuration

of the ATMS. Output boards were utilized to transfer information from the computer to actuation devices. The primary actuation devices used for the ATMS were hydraulic cylinders. The input and output boards used to accomplish these tasks included analog to digital (A/D) converters, digital to analog (D/A) converters, a parallel board, and a counter/timer board. Other hardware were utilized to convert and deliver computer control information to various cornponents in the system. For example, servo-amplifiers were utilized to convert analog voltage signals to a current signal for the servo-valves. Motion of a servo-valve spool opened one side of a hydraulic cylinder to hydraulic pressure. The piston in the hydraulic cylinder moved accordingly.

The operating environment is shown graphically in the Figure 5.6. The operating environment was divided into the work environment, an operating system, an operating language, debugging facilities, and path planning. The operating system included a scheduler, a watchdog, input modules, and output modules. Input and output modules quantified environmental conditions and provided an interface between the computer system and the work environment. The scheduler systematically activated various system components and will be discussed after the operating language is presented. Tne watchdog component provided a safety feature and was responsible for removing hydraulic power to the ATMS system if the execution of the scheduler process was delayed or halted. 


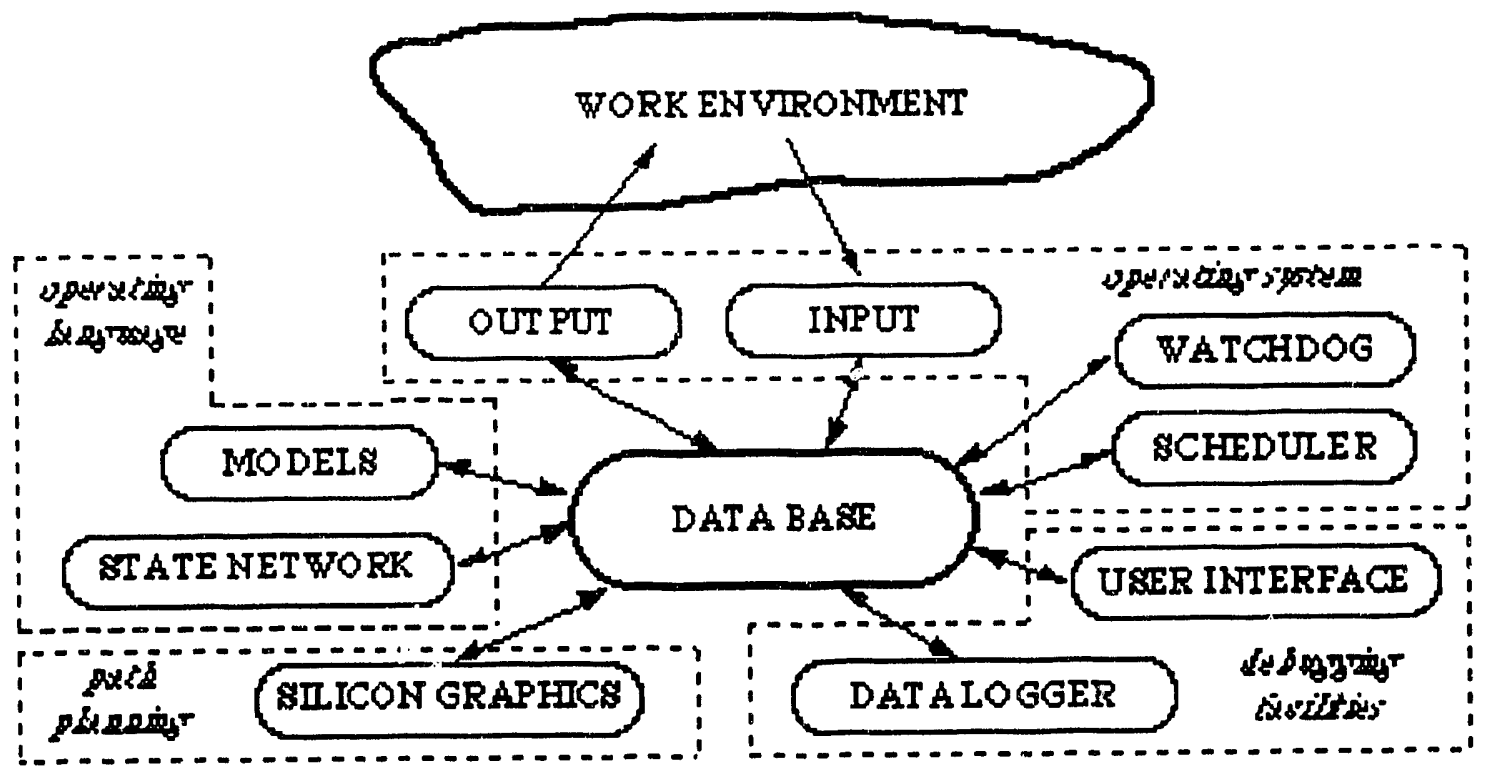

Figure 5.6: Operating Environment

Intelligent operation of the ATMS required the ability to sense the environment, make intelligent decisions, and output information to actuation devices. The data base represented a structure which provided asynchronous data exchange among different software components. This provided a method of data exchange between $\mathrm{I} / \mathrm{O}$ driver software and the operating language. This was accomplished by resurving a section of computer memory for global information storage. Input drivers acquired sensor information from the environment and stored the results in the data base. Output drivers, using results from input drivers, calculated and sent information to actuation devices. Both input and output driver software utilized sections of the data base memory to store information.

The operating language was used to program the various modes of ATMS operation. During development, it was required to operate the ATMS test bed in many different operational modes. Some examples of different modes were open-loop control, closed-loop control, and Silicon Graphics control of body length and angle. The operating language provided the flexibility to alter the operational mode on line. The operating language contained two components: models and a state network. Models characterized events that occurred in the environment by mapping sensor data to binary results. While input drivers mapped infinitely variable environmental quantities to finite numerical results, the data sets were too large to be handled efficiently. For example, a model was used to determine if the length of the ATMS body was close to the desired position setpoint. The binary result from this model was used to determine completion of a sub task. The other component of the operating language was the state network. As the name implies, the state network was a network of individual states. Each state completely defined the desired status (or state) of the robot. Links between the individual states provided a method of changing states. For example, assume that two states are in the state network. Both states specify closed-ioop position control on the boudy length and body angle. Body length and angle setpoints are established at their respective home locations. The 
second state specifies that the Silicon Graphics computer will be able to alter the body length and angle setpoints. The link between the two states is a simple binary flag. If the flag evaluates true, the second state is activated. The link from the second state to the first tests the same flag but determines when the flag evaluates to the false condition. If the flag is set to false, the Silicon Graphics state is deactivated and the first state is activated. At present, 33 states are defined in the state network and encompass open-loop control at a hydraulic cylinder level to closed-loop control on the ATMS segment level.

The state network is programmed using a spread sheet program on the Macintosh computer. The state network is downloaded to the Force computer over the ethernet connection. A program on the Force computer examines the state network and generates the $\mathrm{C}$ code for each state. Alterations to one state in the state network are tracked by comparing the new state network with an old copy of the state network. In this manner, changes to one state will not require recompilation of all other state code.

The scheduler systematically activates various components at a $100 \mathrm{~Hz}$. rate. After input drivers acquired sensor information, models were activated to quantify the sensor data. The state links were then examined to determine if a new state should be activated. After these components had completed execution, the output drivers were activated to transfer information to actuation devices. The data logger was then activated to record pertinent data for later analysis.

The user interface provided a window into the system. The user interface was a command driven program that allowed the user to type commands to alter or examine parameters in the data base. A data logger program could be activated to record 20 seconds of real-time data in a circular queue. The data could be down loaded to a graphical plotting routine on a Macintosh computer. In this manner, tests on the ATMS test bed could be performed and analyzed.

\subsection{References}

Askeland, Donald R. The Science and Engineering of Materials, PWS Publishers, 1984, pp 531.

Clough, Roger L., Gillen, Kenneth T., and Dole, M., International Encyclopedia of Composites, VCH Publishers, 1991, vol. 5 pp 14.

Milkovich, S. M., Herakovich, C. T., and Sykes, G. F., "Space Radiation Effects on the Thermo-Mechanical Behavior of Graphite-epoxy Composites", Environmental Effects on Composites, vol. 3, 1988, pp 141.

Ridgeway, S., Crane, C., Adsit, P., and Harrell, R., "The Mechanical Design of a Parallel Actuated Joint for an Articulated Mobile Robot", ASME Mechanisms Conference, vol. 45, September 1992, pp 591. 

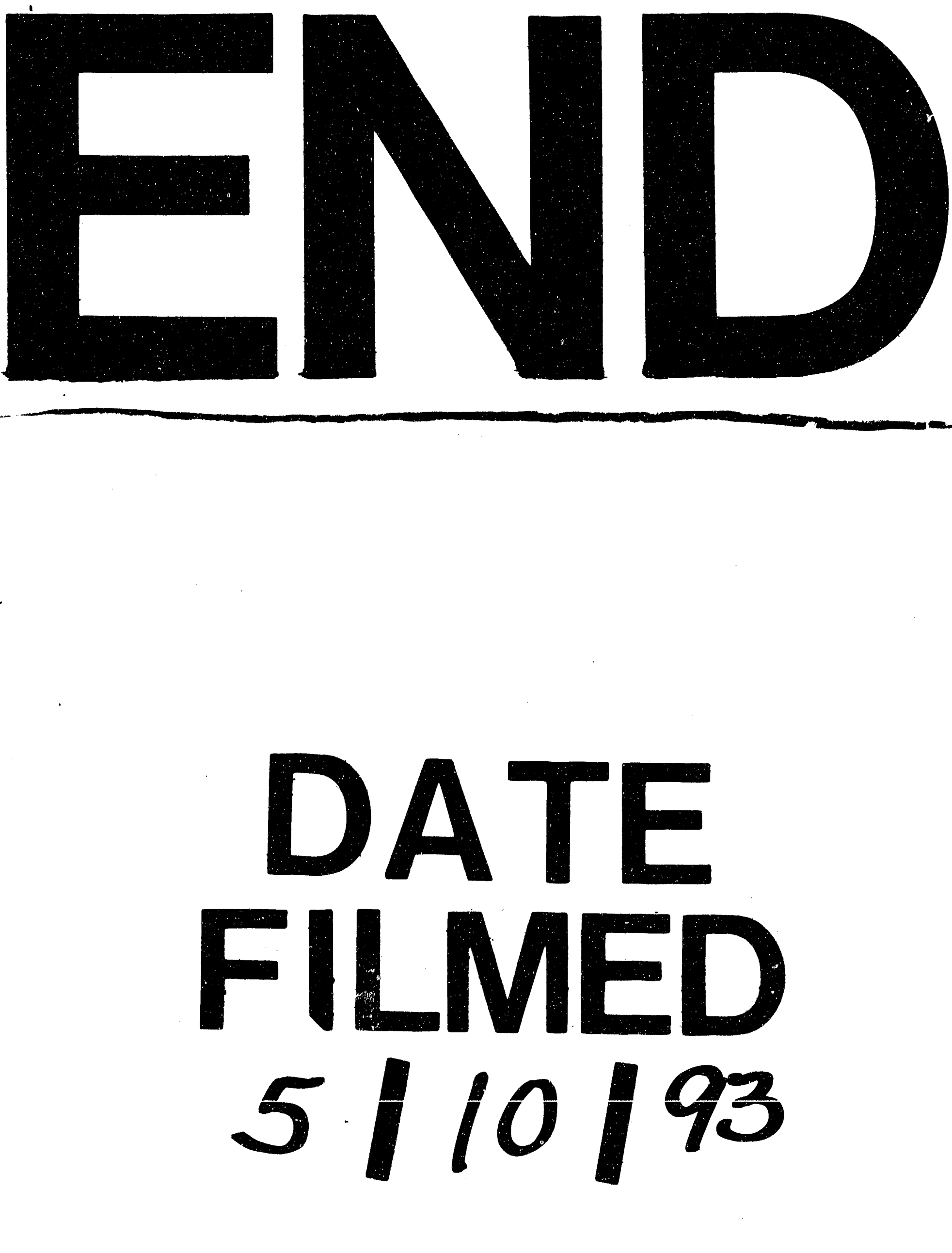
